\title{
Influencing Retirement Intentions of Older Workers - Approaches to Retain Existing Employees Considering Retirement
}

\author{
By \\ Annette Keough, B.Comm. \\ A thesis submitted to the Faculty of Graduate Studies and Research in partial fulfillment \\ of the requirements for the degree of \\ Master of Management Studies
}

Sprott School of Business

Carleton University

Ottawa, Ontario

December 19, 2008

Copyright $\mathbb{C}$ 


$\begin{array}{ll}\begin{array}{l}\text { Library and } \\ \text { Archives Canada }\end{array} & \begin{array}{l}\text { Bibliothèque et } \\ \text { Archives Canada }\end{array} \\ \begin{array}{l}\text { Published Heritage } \\ \text { Branch }\end{array} & \begin{array}{l}\text { Direction du } \\ \text { Patrimoine de l'édition }\end{array} \\ \begin{array}{l}\text { 395 Wellington Street } \\ \text { Ottawa ON K1A 0N4 } \\ \text { Canada }\end{array} & \begin{array}{l}\text { 395, rue Wellington } \\ \text { Ottawa ON K1A 0N4 } \\ \text { Canada }\end{array}\end{array}$

Your file Votre référence ISBN: 978-0-494-47542-3

Ourfile Notre référence

ISBN: 978-0-494-47542-3

NOTICE:

The author has granted a nonexclusive license allowing Library and Archives Canada to reproduce, publish, archive, preserve, conserve, communicate to the public by telecommunication or on the Internet, loan, distribute and sell theses worldwide, for commercial or noncommercial purposes, in microform, paper, electronic and/or any other formats.

The author retains copyright ownership and moral rights in this thesis. Neither the thesis nor substantial extracts from it may be printed or otherwise reproduced without the author's permission.
AVIS:

L'auteur a accordé une licence non exclusive permettant à la Bibliothèque et Archives Canada de reproduire, publier, archiver, sauvegarder, conserver, transmettre au public par télécommunication ou par l'Internet, prêter, distribuer et vendre des thèses partout dans le monde, à des fins commerciales ou autres, sur support microforme, papier, électronique et/ou autres formats.

L'auteur conserve la propriété du droit d'auteur et des droits moraux qui protège cette thèse. $\mathrm{Ni}$ la thèse ni des extraits substantiels de celle-ci ne doivent être imprimés ou autrement reproduits sans son autorisation.
In compliance with the Canadian Privacy Act some supporting forms may have been removed from this thesis.

While these forms may be included in the document page count, their removal does not represent any loss of content from the thesis.
Conformément à la loi canadienne sur la protection de la vie privée, quelques formulaires secondaires ont été enlevés de cette thèse.

Bien que ces formulaires aient inclus dans la pagination, il n'y aura aucun contenu manquant.

\section{Canada}




\section{Abstract}

Increased labour market participation of older workers is viewed as a strategy to avoid anticipated labour shortages. Given the entrenched culture of early retirement in Canada, approaches to delay retirement of older workers will be required. Research in the area of retirement of older workers has focused on the impact of broad macroeconomic forces and individual demographic variables on retirement decisions; however, the role of the employer has not been extensively researched.

This case study research in the Federal Public Service explored how organizations can increase the proportion of engaged older workers who choose to remain with the organization until or after retirement age. Findings suggest that a wide range of work-related factors affect retirement considerations, either encouraging individuals to consider retirement or to consider delaying their retirement plans. The research identified several factors that have not received much attention to date in the literature. 


\section{Acknowledgements}

Many people supported me during the research process and I am thankful for their contribution to this final product.

First, my family, who provided never-ending support and encouragement to me through this entire process - it was great to hear you shout "Congratulations."

Thanks to my colleagues at Deloitte who demonstrated commitment to and support for my ongoing learning - your support kept me going through it all.

A special thanks to my friends who provided support in many ways - your thoughtfulness, advice and coaching kept me going on the right path.

Many thanks to my thesis supervisor, Dr. Linda Duxbury - I have learned from both the patience you have shown in letting this research process unfold as well as the challenges you set to push my thinking.

Finally, thank you to the members of the Examining Board for providing important lessons about the academic research process. 


\section{Table of Contents}

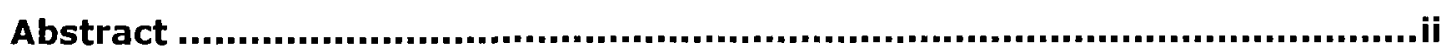

Acknowledgements .................................................................................ii

Table of Contents ................................................................................... iv

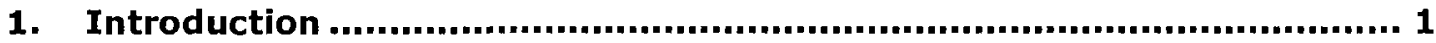

2. Literature Review .......................................................................... 5

2.1 Conceptions and Definitions of Retirement..........................................

2.2 Demographic Trends in the Canadian Population .............................. 13

2.3 Impact of Demographic Trends on the Labour Market .......................... 16

2.4 Potential Extension of Working Life of Older Workers ............................ 19

2.5 Frameworks of Variables Related to Early Retirement Decisions ................ 23

2.6 Organization Factors and the Impact on Retirement Decisions .................40

2.7 Limitations of the Current Literature Related to Organization Factors ...........53

3. Method ........................................................................................55

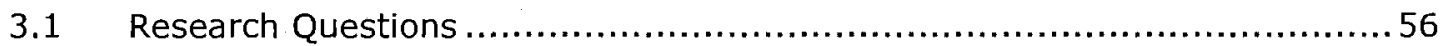

3.2 Selecting Cases: Target Population and Sample Selection...................... 58

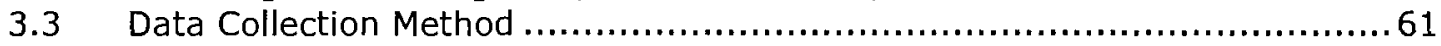

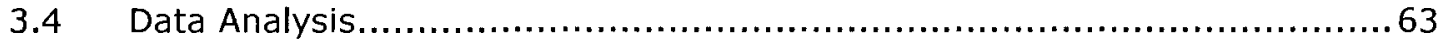

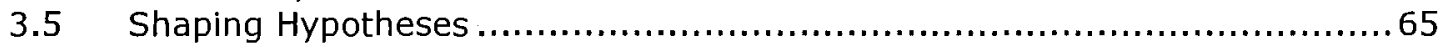

3.6 Linking Emergent Theory with Existing Literature .............................. 66

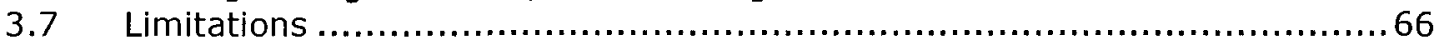

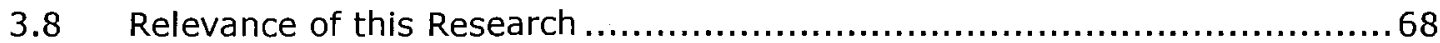

4. Results .....................................................................................70

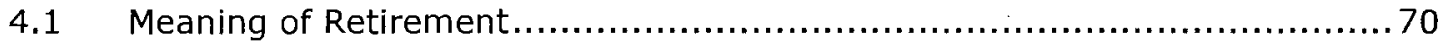

4.2 Factors Considered in Setting Retirement Plans................................. 75

4.3 Employer Actions and the Impact on Retirement Plans ........................ 78

5. Discussion ....................................................................................120

5.1 Retirement Plans of Early Exiters, Early Retirees and Full Pensioners ........ 120

5.2 Summary of Factors Which Impact Retirement Considerations ............... 128

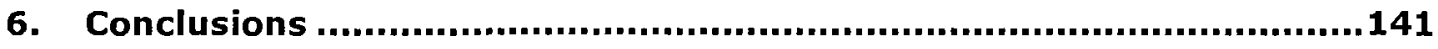

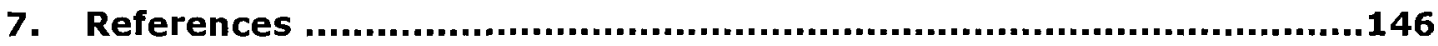

Appendix A - Email to Solicit Study Participants ................................. 151

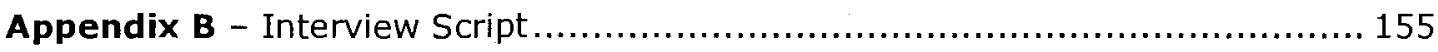

Appendix C - Data Tables Summarizing Key Themes from Interviews By Classification of Employees Whose Retirement Decisions were Impacted by Employer Action/Inaction ..................................................................... 159

Appendix D - Data Tables Summarizing Key Themes from Interviews - By Retirement Plans. 


\section{Introduction}

Through the 1960 s and 1970 s, the baby boomer cohort created tremendous growth in the work force, providing a rich pool of talent for employers. The same wave of baby boomers will push forward again in the coming decade, this time towards retirement, taking with them vast knowledge and expertise. Cohorts following the baby boom generation are simply not large enough to fill all of the gaps in labour supply, creating fierce competition for talent in the marketplace in the near future.

Researchers and analysts are pointing to increased labour market participation by older workers as a key approach to averting potential labour shortages. A significant challenge will be to overcome an entrenched culture of early retirement in Canada. The median retirement age in Canada has declined since the 1970s, and in 2002, it stood at 61 (Bowlby, 2007). For many industries, particularly those in the public sector, the median retirement age can be two to three years lower (Statistics Canada, 2004).

The concept of retirement is changing to reflect a new pattern of life-cycle activity. The retirement component of the traditional life-cycle increasingly includes labour force activity - labour force participation of seniors has increased (Giles and Pyper, 2002; Marshall and Ferrao, 2007) and many older workers choose to work part-time following an initial retirement (Schellenberg, Turcotte, and Ram, 2005). These trends indicate that opportunities exist to influence labour market participation of older workers. Stakeholders, including governments, employers, and individuals, must act to find creative ways to capitalize on the talents of the baby boomers and to continue to engage them in the workforce. 
Research in the area of retirement of older workers has focused on understanding the impact of broad macroeconomic forces as well as individual demographic variables on retirement decisions. To date, little focus has been placed on understanding the incentives required to keep individuals in the workforce, either by delaying their retirement for a number of years or by working part-time. In particular, the role of the employer in setting appropriate policies and programs to retain older workers has not been extensively researched. Some empirical evidence in the literature points to flexible working arrangements and salary increases as a means to keep older workers in the workplace. Many barriers to older workers remaining in the workplace have also been identified including age discrimination, absence of learning training, and early retirement packages. A limitation of the current literature is the absence of a single comprehensive framework of factors under the control of organizations that impact retirement decisions.

The purpose of this research is to further explore and understand how policies and programs under the control of organizations impact retirement decisions of older workers.

Specifically, this research seeks answers to the following question:

- How can organizations increase the proportion of engaged older workers who choose to remain with the organization until or after retirement age?

Using a qualitative research method, this research study will address these issues in a Federal Public Service (FPS) context. The decision to focus on this sector of the economy is supported by data showing that the FPS will be one of the first to experience the effects of baby boomer retirements given that it has a low median retirement age and its workforce is, on average, older than the Canadian workforce 
at large (Policy Research Initiative, 2005). Research will be guided by theoretical frameworks previously identified in the literature related to older workers and early retirement, including frameworks by Feldman (1994) and the OECD (2005). These models provide a starting point for our understanding of organization factors affecting early retirement decisions.

This document presents a review of related literature, a summary of the research method used to investigate the research topic, followed by the results of the research and concluding with discussion and conclusions. The literature review begins with an overview of concepts and definitions related to older workers and retirement. This is followed by a summary of the demographics trends in the Canadian population which have pushed the topic of retirement and retention of older workers to the forefront. Recent trends in labour market participation rates and modeling of scenarios of future participation rates are examined with the view of understanding the potential impact on the labour supply if older workers choose to stay in the workforce. Following the discussion of these labour market trends, the focus of the literature review turns to frameworks of variables related to older workers' decisions to remain in the workforce or retire early. Relevant frameworks developed by Feldman (1994) and OECD (2005) are reviewed to convey the wide range of factors under the control of the government, employers and individuals which affect retirement decisions. Given the stated focus of this thesis, further attention is given to reviewing the literature related to factors under the control of organizations which encourage individuals to either stay in the workforce or retire early.

An overview of the method for this thesis follows the literature review. The section provides an overview of how a case study research strategy has been applied to 
explore and understand how factors under the control of employers impact individual decisions about retirement. The key steps of the method, modeled after Eisenhardt's (1989) approach to building theory from case study research, are discussed to provide the reader with an overview of the approach to selecting cases, collecting data, and conducting analysis. Approaches used to identify concepts, constructs and potential relationships between variables which are grounded in the case study data are described. The section concludes with the potential limitations of the method and relevance of the research.

Section 4 of this thesis presents the results of the research using descriptive narratives, data tables and quotes from interviews with study participants. Section 5 contains a discussion of the results leading to the presentation of conclusions in Section 6 . 


\section{Literature Review}

This section begins with an overview of the literature relating to retirement concepts and definitions which set the context for discussions throughout this document. Key statistics and trends related to Canadian demographics and labour market participation rates are explored to understand the magnitude of the issue being faced by Canadian employers as many older workers reach retirement age and confront decisions about whether to remain in the workplace. This section presents the results of several analyses which suggest that the impact of pending labour shortages can be mitigated or softened by extending the labour market participation of older workers. The focus of the literature review then shifts to examining frameworks that summarize factors which influence individual decisions to retire or remain in the workforce. Given the intended focus for this thesis, particular focus is given to the role of organization factors and the impact on retention of older workers.

\subsection{Conceptions and Definitions of Retirement}

\subsubsection{A Changing Conception of Retirement}

There are many conceptions of retirement, ranging from 'guillotine retirement' (Reday-Mulvey, 2006) to living the 'Freedom 55' dream. The retirement plans and realities of an individual working in 1930 is likely very different than that of an individual today. The Institute for Research on Public Policy (2007) contends that "retirement is a social construct in constant evolution."

In a discussion on retirement of previous generations of workers, Reday-Mulvey (2006) made the following observations. In the past, people retired when they grew old and were no longer viewed as useful or productive. A French term "la retraite couperet" or "guillotine retirement" was a fitting description of the abrupt or 
overnight end to a long working life, typically at a fixed age. With a much shorter life expectancy than experienced today, workers were blessed to have a few short years of rest before the end of their life.

Today, increasing life expectancy has had a dramatic effect on the current characterization of retirement (Policy Research Initiative, 2005; Reday-Mulvey, 2006). Canadians today retire younger and in far better health than their counterparts over 70 years ago. In 2002, life expectancy at age 65 was 82.2 years for a Canadian male and 85.6 years for a Canadian female (Policy Research Initiative, 2005). Based on Statistics Canada LifePaths analysis, the Policy Research Initiative (2005) found that in 2000 the average Canadian male aged 50 could expect to spend many more years of their remaining life out of the labour market (approximately 20) than in it (approximately 12). In 1930, the same individual aged 50 would expect to work for another 15 years, with approximately eight years out of the labour market in the remaining years of their life.

Reday-Mulvey (2006) notes that the age of retirement is becoming increasingly disassociated from the age at which people become old. Citing research in 2001 by the Conseil Economique et Sociel, Reday-Mulvey (2006) notes that the onset of old age, defined as 'the time when the population starts suffering from real incapacities', has increased from around 60 years for men and 65 for women in 1930 to 71 years for men and 77 for women in the early 1990s. The research suggests that this represents an increase in the onset of old age by a rate of one and a half months per decade. Assuming this rate holds true, by 2040 the threshold for old age will have reached 82 years. Canadian statistics suggest that the expectancy of years in good health (also known as health-adjusted life expectancy) for people at age 65 was 12.7 years for men and 14.4 for women (Statistics Canada, 2001). 
The current characterization of retirement is affected by more than a change in life expectancy. Reday-Mulvey (2006) notes that individuals retiring today have, for the most part, enjoyed longer periods of education and training, and much more flexible work patterns than their parents' generation. Underlying this different work experience is a changing work life-cycle, one that traditionally included horizontal (or sequential) periods of training, work and retirement. The realities of modern society now have resulted in a vertical arrangement of these activities, with continuous training often as a standard feature of the workplace, exits from the workplace for parents who choose to raise children, and retired people taking on part-time professional work (Reday-Mulvey, 2006). Figure 1 below depicts the evolution of work-life or age-based distribution of activities.

Figure 1: Evolution of life-cycle or age-based distribution of activities

\section{Age-based distribution of activities}

Vertical distribution of activities

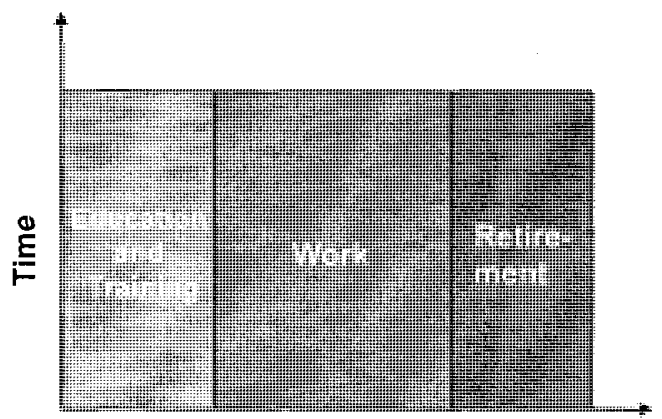

Age
Horizontal distribution of activities

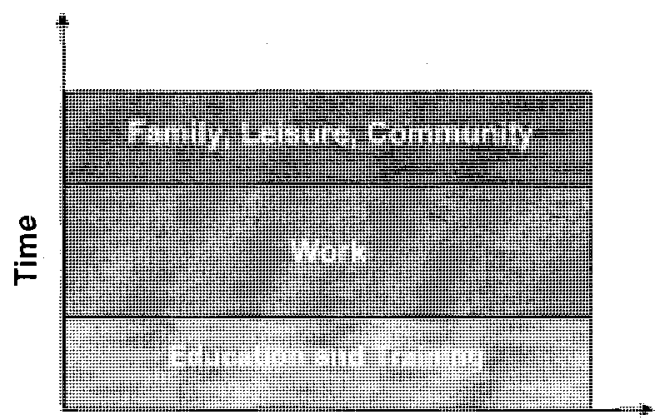

Age

Source: Reday-Mulvey, 2006, p. 22 
Reday-Mulvey (2006) contends that under this new age-based distribution of activities, periods of education, work and retirement are no longer compartmentalized into discrete periods of time. Lifelong learning is an important element of this new life-cycle. With respect to work, trends include a decline in the proportion of lifetime dedicated to work due to increased life expectancy and lowered effective retirement age (Reday-Mulvey, 2006). As well, there is a growing tendency to organize work in new ways through the use of more flexible work patterns (parttime employment, sabbaticals, and gradual retirements). There is an ongoing emphasis on family, leisure and community which may manifest in individual choices to combine work with caring of elderly parents, or employment breaks dedicated to leisure.

Most notable in Reday-Mulvey's depiction of the evolution of age-based distribution of activities is the absence of the word retirement under the depiction of the horizontal distribution of activities, another indicator that the concept of retirement is changing and evolving with societal changes. Reday-Mulvey (2006) argues that people retiring today have experienced a different life-cycle pattern, one which is diverse and flexible. This same life-cycle is likely to continue in later life years, allowing people to manage different priorities which can include family, work, leisure, and voluntary commitments, among others.

An implication of the new life-cycle that Reday-Mulvey (2006) describes is that the concept of retirement is becoming much more complex, and the traditional transition from work-to-retirement may not be the reality or the desire of older workers that are currently approaching retirement. 


\subsubsection{Definitions and Measurement Approaches of Retirement in the}

\section{Literature}

As the concept and nature of retirement changes, researchers are attempting to define and measure retirement in a way that reflects its complex nature. Deschenes and Stone (2006) noted that there are few explicit definitions of the concept of the "transition to retirement." Some researchers including Feldman (1994), use definitions that assist in marking the beginning of the transition to retirement, incorporating both objective and subjective elements in the definition. Feldman (1994) suggests that retirement is the exit from an organizational position or career path of considerable duration, taken by individuals after middle age, and taken with the intention of reduced psychological commitment to work thereafter. The definition recognizes that retirement does not necessarily mean withdrawal from the labour market and that an individual may choose to work part-time, in temporary employment or become self-employed.

In a recent publication on retention of older workers, Statistics Canada (2004) provided an outline of the approach used to define retirement in the General Social Survey; a summary follows. The General Social Survey analysis related to retirement is based on a subjective definition of retirement - self-identification of individual's 'main activity' during the last 12 months as "retired". Statistics Canada's definition of retirees in the General Social Survey also includes individuals who respond "yes" to "Have you ever retired?" Reflecting great variability in transitions to retirement, the General Social Survey further probes with additional questions relating to eligibility for a pension, receipt of an early retirement package, retirement from a job or significant reduction in work time because of health or the ability to live on savings and investments. 
Given the complex nature of retirement, there are critiques of current measurement approaches. Stone and Nouroz (2004) noted that existing indicators of retirement have only one or two variables related to labour market activity, such as the drop in number of hours worked, the end of a job held over many years. This critique applies to definitions such as those used by Feldman (2004) and Statistics Canada (2004) noted above. Stone and Nouroz (2004) concluded that a larger number of aspects needed to be considered within a single indicator. Gauthier and Asselin (2007) note that "cross-sectional statistics do not explain significant aspects of the retirement process".

As researchers continue to study the phenomenon of retirement, alternative research methods are providing opportunities to better understand and describe more complex aspects of the definition of retirement. Gauthier and Asselin (2007) posit that longitudinal studies of the transition towards retirement will provide greater insight into this transition, and point to a highly innovative project by Stone and Nouroz (2007), which was based on abundant detail on activities of individuals initiating a transition to retirement in the late 1990s. The project examined patterns of work-to-retirement transition among Canadian public-sector employees as part of a longitudinal study of trajectories to retirement ${ }^{1}$.

Longitudinal studies such as the one conducted by Stone and Nouroz (2007) demonstrate that alternative approaches that capture more complex aspects of the transition-to-retirement provides new insights to inform future research and policy development in the area of transition to retirement. Given the unique nature of this

\footnotetext{
${ }^{1}$ Deschenes and Stone (2004) define the concept of trajectory with reference to the transition to retirement to include a sequence of movements among a set of positions, or conditions, through which a person passes, either voluntarily or involuntarily, before reaching retirement.
} 
study and its contribution to measurement of the concept of retirement, additional details on the study and its results are provided below.

Stone and Nouroz (2007) examined properties of trajectories to retirement, such as the length of the transition, events that increase vulnerability to reductions of retirement income, instability, flexibility and the propensity to rejoin the workforce. Using a longitudinal approach, Stone and Nouroz (2007) examined the trend that public-sector employees retire at an earlier age, on average, than those in the private sector. However, in examining the work-to-retirement transition of both public and private sector workers, Stone and Nouroz (2007) found that public sector workers that began their transition to retirement in 1996-97 were more likely to still be in the labor market in 2001 than private sector employees. In their discussion, the authors noted that this finding was contrary to the well-known trend that publicsector employees retire at an earlier age, on average, than those in the private sector. The significant difference can be explained by the fact that the two findings are based on substantially different measures of retirement. The longitudinal study by Stone and Nouroz (2007) allowed an examination of whether individuals who started a transition to retirement subsequently returned to the workforce. Other studies of retirement based on Statistics Canada Labour Force Survey track individuals who have left the labor market, with "retired" as the reason. This crosssectional approach cannot detect, however, that individuals may soon return to the labour market. Stone and Nouroz (2007) demonstrated the limitations of crosssectional studies in understanding the complex nature of retirement, and illustrated that a longitudinal approach is necessary to understand the complete work-toretirement transition that older workers choose at the end of their working career. 


\subsubsection{Definitions of Other Terms Related to Retirement}

Accepting that an individual's path to retirement may actually involve several stages and that retirement is no longer a clearly defined state, gives rise to the need for additional terms to describe interim phases. Feldman (1994) notes that employment taken on after full-time employment ends and permanent retirement begins is known as bridge employment. Bridge employment can be a part-time job, self-employment, or even temporary employment. Honig \& Hanoch referred to the desire for reduced labour force participation in terms of fewer hours or responsibilities as partial retirement (cited in Weckerle and Shultz, 1999, p. 317). Early retirement is characterized by Kieren (2001) as retirement before the age of 60 . Kieran (2001, p. 8) notes that "60 was chosen because it probably meets normal expectations of 'early retirement', and is the minimum age at which Canada/Quebec Pension Plan benefits (other than for disability) are payable". Individuals that retire under the age of 60 are referred to as early retirees (Kieren, 2001).

Several other terms are used throughout this document and the related definitions follow. Marshall and Ferrao (2007) identify older workers as workers between the ages of 55 to 64; many older workers in Canada belong to the baby-boom generation, defined as individuals born between roughly 1946 and 1965 . Seniors are defined as individuals age 65 and over (Duchesne, 2002).

The literature review in this section has the following implications for research. It indicates that research to inform policy decisions in response to demographic trends will be more valuable if concepts related to the transition to retirement are well defined and measured, reflecting retirement as a process and not an event, as well as acknowledging its objective and subjective nature. The next section of the literature review further explores the demographic trends which are causing policy- 
makers to turn their attention to the topic of retirement and labour force participation of older workers.

\subsection{Demographic Trends in the Canadian Population}

This section provides a summary of key demographic trends observed in the Canadian population, drawing from Statistics Canada data and analysis from the 2006 Census, with a particular emphasis on the trends that will impact the labour market.

\subsubsection{Portrait of the Canadian Population Based on the 2006 Census}

A new portrait of the Canadian population was recently released by Statistics Canada based on the 2006 Census, one that shows progressive aging of our country's population. The median age of Canadians has been steadily rising since 1966 , reaching 39.5 years in 2006 (Statistics Canada, 2007b). The United Nations Secretariat predicts the median age in Canada will reach 44.8 by the year 2030 (OECD, 2005). Population aging is attributed to two main factors - declining fertility rates and increasing life expectancy (Statistics Canada, 2007b).

Current fertility rates, measured by the average number of live births per woman, are at approximately 1.54 in Canada (Statistics Canada, 2005). Espenshade, Guzman and Westoff (2003) note that in North America approximately 2.1 children per woman are required to keep the population stable; as a society we are not producing enough children to replace the population. According to Statistics Canada population projections, net immigration may become the only source of population growth by about 2030 (Statistics Canada, 2005). 
Longevity is increasing at a rate of 2.4 years per decade, such that life expectancy at the age of 65 in 2002 was approximately 82 for males and nearly 86 for females (OECD, 2005). The 2006 Census revealed that seniors, aged 65 and older, represent nearly $14 \%$ of the Canadian population and population projections anticipate that this proportion could double in the next 25 years (Statistics Canada, 2007b). OECD (2005) projections indicate that the old-age dependency ratio, the ratio of persons aged 65 and over to the working-age population, will rise to $45 \%$ in 2050 , more than doubling from 2004 level of $20 \%$. In 2050 , there will be only 2.3 individuals of working age for every person over the age of 65 , posing serious challenges for socioeconomic policy-making related to public expenditures and labour markets (OECD, 2005).

A recurring theme in Statistics Canada's analysis of the 2006 Census is the impact of the baby-boomers on our population aging. Baby-boomers are individuals born between 1946 and 1965, a 20 year period of above average number of births (Marshall and Ferrao, 2007). This generation represented nearly one in three Canadians in 2006 (Statistics Canada, 2007b). Because of this cohort's size, it has a significant impact on Canada's overall demographic trends, so much so that Statistics Canada conducted specific analysis of the 2006 Census data with the baby boom cohort of the Canadian population as the key reference point. The following figure was excerpted from Statistics Canada (2007b) and a brief description of each of these cohorts follows. 


\section{Figure 2: Cohorts in the Canada Population}

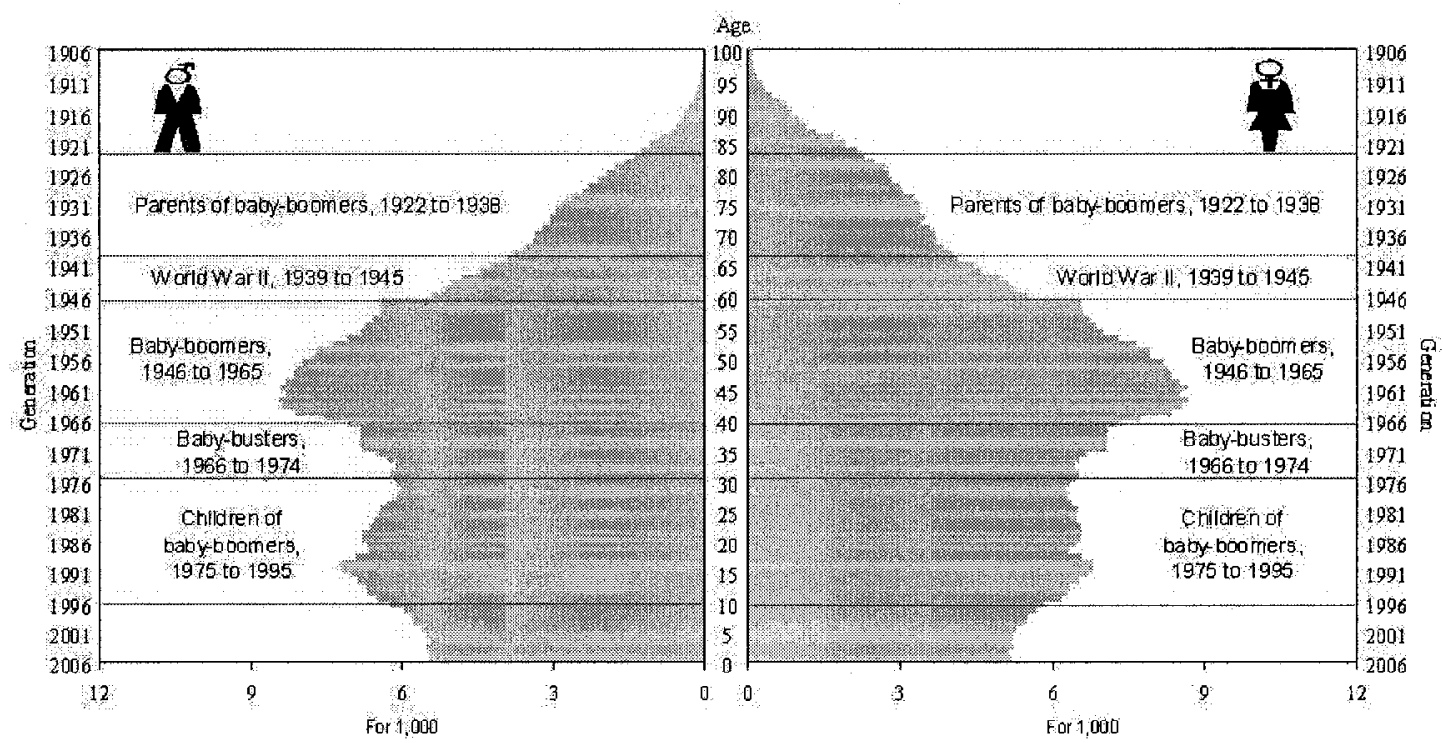

Source: Portrait of the Canadian Population, Statistics Canada, 2007b, p. 12

In relation to the baby-boomer generation, there are two older cohorts in the current Canadian population - Parents of Baby-Boomers and Second World War (Statistics Canada, 2007b). Born between 1922 and 1938, the parents of baby-boomers represent less than $10 \%$ of the Canadian population in 2006 . The Second World War cohort includes individuals born in the six-year period between 1939 and 1945 . This small cohort represents $6.4 \%$ of the population (Statistics Canada, 2007b).

Statistics Canada (2007b) identified two cohorts in the Canadian population younger than the baby-boomers - Baby-Busters (also known as Gen X) and Children of BabyBoomers (also known as "Echo Boomers"). The period of 1966 to 1974 marked the birth of the Baby-Busters generation, a time of rapid decline in the fertility rates of the previous two decades (Statistics Canada, 2007b). Representing $12.4 \%$ of the population in 2006, many individuals of the Gen X generation are children of the 
Second World War cohort. Over one in four Canadians in 2006 form part of the Children of Baby-Boomers cohort. This cohort is recognized as being the echo from the baby-boomer generation. Born of baby-boomer parents between 1975 and 1995, this cohort represents $27.5 \%$ of the Canadian population (Statistics Canada, 2007b).

Statistics Canada (2007b) has made several observations and projections related to demographic changes with the aging of the baby-boomer generation. First, the number of people aged 55 to 64 reached a record high in 2006, representing $17 \%$ of the working population, or 3.7 million people. The first baby-boomers, those born in the mid to late 1940 s are now reaching the $55+$ age range. The proportion of workers aged 55 to 64 will continue to grow, potentially reaching $20 \%$ of the working population in 2011. Given the smaller relative size of the Echo generation, Statistics Canada (2007) suggests that in about 10 years, Canada may have more people at the age where they can leave the labour force than people at the age where they can begin working.

\subsection{Impact of Demographic Trends on the Labour Market}

This section presents the results of analyses that examine the impact of the abovenoted demographic trends on the Canadian labour market. Organizations including Statistics Canada, the Policy Research Initiative and the OECD have investigated the impact of our aging population on overall labour supply, as well as considering how susceptible various industries within the Canadian economy might be to one of the most important demographic trends - the pending retirement of baby-boomers. This section provides a sense of the magnitude of the challenge faced by Canadians and illustrates the sense of urgency that is building in both academic circles and popular media to find solutions to avert a labour shortage crisis. 
Growth in the working age population over the next fifty years will pale in comparison to the first half of the $20^{\text {th }}$ century (OECD, 2005). OECD projections indicate a slowing of growth in the labour force, with less than a $5 \%$ increase over the next five decades, in sharp contrast to the $200 \%$ growth that the labour force experienced during the previous fifty years from 1950 to $2000^{2}$ (OECD, 2005).

Canadian employers will begin to feel the effects of the fall in labour force participation in the coming years, putting additional pressure on an already tight labour market (Bowlby, 2007). By the mid 2010s, Statistics Canada (2007) predicts the profile of the working-age population will be such that there may be more people at the age where they can leave the labour force ( 55 to 64 ) than people at the age where they can begin working (15 to 24). Recent analysis by the Policy Research Initiative (2005) suggests that total labour supply per capita (defined as total hours worked per year divided by total population) will peak in 2010 , coinciding with a mass exodus of baby boomers from the workplace.

The OECD (2005) contends that future labour market challenges in Canada will be exacerbated by the fact that individuals are exiting the labour market, on average, before the age of 65 . Kieren (2001) reports that although 65 remains the most common age to retire, the proportion of retirees who wait to retire at this age is decreasing. Only $12 \%$ of recent retirees between 1997 and 2000 retired at the age of 65 , compared to $19 \%$ between 1987 and 1990 . While some Canadians retire in their early 50 s and others in their late 70 , the ages of 65,60 and 55 were the most popular ages at which Canadians retired from their last job (Kieran, 2001).

\footnotetext{
2 This estimate assumes that labour force participation rates remain constant over the next five decades.
} 
Schellenberg (2005) has suggested that there is now an entrenched culture of early retirement in Canada. Kieren (2001) notes that 60 meets normal expectations of 'early retirement'. Schellenberg (2005) found that two-thirds of near-retirees would prefer to leave the paid labour force before they reach the age of 60 (that is, retire early), however, a much smaller proportion plan to leave the labour force before that time. The average age of retirement in 2006 in Canada was 61.5 , up slightly from a low of 60.9 in 1998 (Marshall and Ferrao, 2007).

Statistics Canada (2004) suggests that the public sector will be particularly vulnerable to labour shortages in the future, given that the three largest public sector industries - public administration, education, and healthcare and social assistance - experience some of the lowest median retirement ages, ranging from 57.3 to 60.2 . The near-retirement rate is the percentage of workers within a sector who are within 10 years of the median retirement age (Statistics Canada, 2004). In 2002 , nearly $40 \%$ of workers were within 10 years of the median retirement age of 57.3 in the education sector. Similarly, in public administration, nearly one-third of workers were nearing the median retirement age of 58.2. For workers in health care and social services, the near-retirement rate is about one-quarter, with a median retirement age of 60.2 .

The federal public service is particularly vulnerable to loss of knowledge and expertise associated with retirement of baby boomers. Because employees in this sector of the public service are generally older than the overall Canadian work force, the exodus of baby boomers has already begun (Policy Research Initiative, 2005). Analysis by the Policy Research Initiative (2005) suggests that overall retirements in the federal public service will peak in 2013 , when 5,600 permanent employees are expected to retire. 
Labour market challenges will not be short-lived, with most analysts pointing to the 2030s as a time of stabilization or leveling off of labour supply (Statistics Canada, 2005; Policy Research Initiative, 2005). Significant changes will be required to ensure that the forecasted slowdown in labour force growth does not undermine Canada's ability to sustain past advances in living standards (OECD, 2005).

\subsection{Potential Extension of Working Life of Older Workers}

Evidence that some older workers are willing to continue in the workplace beyond traditional retirement ages (Policy Research Initiative, 2005; Schellenberg, Turcotte and Ram, 2005) has inspired further investigation into the impact of extensions to labour market participation on the overall labour supply. This section presents the results of two simulations of extending the participation (delaying retirement) of older workers in the workforce, as well as examining the recent trends of labour force participation for workers aged 50 to 64 in Canada. It attempts to help the reader understand the evidence related to the following question "What increase in the labour supply could be achieved if older workers remained in the workforce beyond the point when they are eligible to retire?"

\subsubsection{Models to Predict the Impact of Increasing Labour Market Participation}

Two recent analyses, independently conducted by the OECD (2005) and Statistics Canada (cited in Policy Research Initiative, 2005, p. 23-24), have examined the potential impact extension of labour market participation by older workers could have on labour supply in the future. These studies demonstrate that delaying 
retirement can have a significant impact on labour supply, dampening the potential negative effect on GDP growth and living standards.

The OECD (2005) analysis contemplated two scenarios based on several underlying assumptions $^{3}$. The first assumed that prevailing participation rates for workers over the age of 50 in Canada in 2000 remain unchanged over the period to 2050, while the second scenario contemplated gradual adjustment to the highest participation rates observed among OECD countries in 2000 for workers over the age of 50 . This modeling exercise, which assumes a gradual increase in participation rates for workers over the age of 50 to maximum OECD 2000 levels by 2030, shows that the labour force in 2050 would include approximately 20 million workers, an extra 3 million workers compared to the constant scenario (OECD, 2005). The OECD concedes that "while it is perhaps unlikely that participation rates in Canada reach the highest level present in OECD, ... there is scope in the Canadian context to improve the labour market outcomes of older workers and better optimize labour supply especially for this group."

A simulation was conducted by Statistics Canada (LifePaths) ${ }^{4}$ to determine the impact on labour supply of a two year extension of working life for Canadians, using assumptions developed by the Interdepartmental Working Group on Population Aging and Life-Course Flexibility (Policy Research Initiative, 2005). This simulation indicated that the total labour supply per capita under this scenario would push the peak of labour supply out a few years to 2015 . The results also showed that with a

\footnotetext{
${ }^{3}$ For additional details on the assumptions for these two scenarios, the reader is encouraged to refer to the source document.

${ }^{4}$ LifePaths is a dynamic longitudinal microsimulation model of individuals and families created by Statistics Canada.
} 
two-year working life extension, the labour supply relative to the population would be about equal in 2025 to what it is today (Policy Research Initiative, 2005).

While these models predict a positive impact on overall labour supply when working lives of older workers are extended, the question remains whether these workers are willing to remain in the workplace beyond traditional retirement ages. The remainder of this section examines evidence around recent increases in labour market participation rates and presents key aspects of the debate on whether increased participation rates can actually be achieved. Later sections of this review will explore this debate further by exploring why people would choose to continue working or to retire early.

\subsubsection{Trends in Labour Force Participation Rates for Older Workers}

While some analysts are projecting into the future to understand the potential impact of increasing labour market participation of older workers, other analysts are closely examining recent evidence that shows an upward trend in actual labour force participation rates. Examining the changes in participation rates over the past 30 years, from 1976 to 2007, Marshall and Ferrao (2007) noted that the overall participation for male and female workers aged 55 to $64 \mathrm{grew}$ from $53 \%$ to $59 \%$. For men, the 2007 rate of $67 \%$ is actually below 1976 levels (76\%), and is now on the rise having dropped to a low of $58 \%$ in 1995 . For women, participation rates have been steadily increasing from the 1976 level of $32 \%$ and in 2007,to $53 \%$ in 2007 .

In 2007 , the majority of workers in their late 50 s are still working, with $76 \%$ of men aged 55 to 59 still attached to the labour force, and $62 \%$ of women (Marshall and Ferrao, 2007). As previously observed with males aged 55 to 64 , there has been a recent upward trend for men aged 55 to 59 , rising from a 1998 low of $71 \%$. For 
women in this age group, the rate has risen from $38 \%$ in 1976 to current levels of $62 \%$ (Marshall and Ferrao, 2007).

OECD (2005) contends that participation rates of Canadian men and women start to fall substantially between the ages of 55 and 60 , with the most significant decline between the ages of 59 and 60 , a drop of almost 11 points for both men and women. While there is a smaller proportion of people aged 60 to 64 participating in the labour force than at ages 55 to 59, Marshall and Ferrao (2007) note that there have been recent increases for both men and women. For men aged 60 to 64 , the participation rate increased from $43 \%$ in 1995 to $53 \%$ in 2006 and reached an all time high of $37 \%$ for women in 2006.

There is debate in the literature whether participation rates will continue to rise. Marshall and Ferrao (2007) suggest that the upward trend of participation rates for both men and women is likely to continue for two reasons. First, participation rates for early baby-boom women have been found to be consistently higher than for preboom cohort. This suggests that the women of the early baby-boom cohort will have higher participation rates than their predecessors as they approach retirement years. The authors also contend that participation rates in the future will be boosted by the fact that individuals aged 55 to 64 in 2006 were more likely than their predecessors to have university degrees. Increasing levels of educational attainment have been found to increase the likelihood of employment (Marshall and Ferrao, 2007).

While noting the positive improvements in older worker participation rates, the OECD (2005) is cautious and notes that "there is little evidence to suggest that such an increase is an indication of a longer term trend." In particular, the OECD notes that 
older workers continue to face significant employment barriers and that it is difficult to predict participation rates for individuals aged 50 and above.

While advocating the concept of increasing the labour force participation of older workers, Morissette, Schellenberg and Silver (2004) note that not all older workers are willing, or able, to continue working beyond traditional retirement ages. Based on surveys of recent retirees, the authors concluded that the potential labour supply increase does not represent all older workers, given that many retire for health reasons or are simply not interested in working longer. The study by Morissette, Schellenberg and Silver (2004) showed that if presented with different working conditions, only one-third of recent retirees would have continued working.

While there is debate on whether labour participation rates can be increased to a level to substantially offset pending labour supply shortages, there is consensus on the need for a broad-based approach with action on the part of all stakeholders (OECD, 2005; Policy Research Initiative, 2005). The following section first presents an overview of frameworks of factors related to early retirement decisions of older workers, followed by perspectives on gaps in existing research in relation to these factors.

\subsection{Frameworks of Variables Related to Early Retirement Decisions}

This section begins by outlining two broad schools of thought with respect to early retirement decisions, following which two frameworks are presented to provide an overview of the wide range of variables that influence older worker's decisions to remain in the workforce or retire early. A comparison of the frameworks is conducted 
to identify the common factors, as well as any unique factors identified by the authors of these frameworks.

There are two broad schools of thought in relation to the question of why individuals retire from the labour market before statutory retirement age (Jepsen, 2002). One perspective is that retirement decisions are viewed as an individual choice based on a trade-off between income and leisure. Jepsen (2002) concludes that this view is the "basic assumption in most 'Anglo-Saxon' based research." Jepsen (2002) notes that research has been conducted internationally by several researchers with the conclusion that age of the individual, individual health, and level of retirement benefits are important influences on the retirement decision. For a comprehensive list of international researchers in this area, see Jepsen (2002, p. 29).

Another perspective, and the one supported by Jepsen (2002), is that retirement decisions are the result of a complex interaction between a number of influences including the social security system, the operation of the labour market, the state and the individual. In summarizing the research in this area, Jepsen (2002) disputes that individual choice theory can explain many retirement trends observed in Europe and that more complex factors are at play. The author references many studies that support this viewpoint and interested readers can refer to Jepsen (2002, p.34-35).

Inherent in both theories outlined above are a wide range of factors that influence an individual's decision to retire early or to remain in the workforce. Feldman (1994) and the OECD (2005) both provide frameworks in relation to this decision, although from slightly differing perspectives. Feldman (1994) reviewed the factors in the organizational sciences literature and developed a set of factors influencing early retirement and bridge employment decisions. Feldman also developed a decision- 
tree framework for understanding the early retirement process. Similarly, the OECD (2005) documented employment barriers for older workers, including shortcomings on the part of the state, employers, unions and individuals. Both Feldman (1994) and the OECD (2005) concluded that there are a wide range of factors under the influence of governments, employers, unions and individuals that influence retirement decisions, and that these factors work in concert to affect decisions made by older workers (Feldman, 1994; OECD, 2005). While these frameworks do not focus directly on approaches to delay retirement of older workers, they look at the same issue from a different viewpoint - factors that influence early retirement or barriers to employment for older workers. As such, these frameworks will be used to inform this study. A summary of both frameworks follows.

\subsubsection{Factors Influencing the Decision to Retire Early by Feldman (1994)}

Feldman (1994) reviewed the organizational sciences literature and identified four levels of factors - individual-level, opportunity structures, organizational-level, and environmental-level - that may influence the decision to retire early. Table 1 provides examples of each type of variable as defined by Feldman (1994), as well as similar variables from other researchers. These factors reflect the complexity of multiple stakeholders (governments, employers and individuals) and their role in influencing individual retirement decision-making. Details on each of these types of variables are discussed below. 
Table 1. Factors Influencing the Decision to Retire Early

\begin{tabular}{|c|c|c|}
\hline $\begin{array}{l}\text { Type of Variable } \\
\text { (Feldman, 1994) }\end{array}$ & $\begin{array}{l}\text { Examples } \\
\text { (Feldman, 1994) }\end{array}$ & Similar Variables in the Literature \\
\hline Individual-level & $\begin{array}{l}\text { Demographic - gender, race, and } \\
\text { marital status } \\
\text { Health status - major physical } \\
\text { illnesses, functional impairment, and } \\
\text { psychosomatic illnesses } \\
\text { Work-history patterns - years of } \\
\text { service, number of exits and entries } \\
\text { from the workforce, and number of } \\
\text { layoffs experienced during a career } \\
\text { Attitudes towards work - self- } \\
\text { identity, company identification, } \\
\text { professional identification } \\
\text { Attitudes towards retirement - } \\
\text { certainty about plans, significance of } \\
\text { loss }\end{array}$ & $\begin{array}{l}\text { - Biographical variables including age, } \\
\text { gender, income, length of time since } \\
\text { retirement, traditional job search } \\
\text { constraints (health, inadequate } \\
\text { transportation), older worker job } \\
\text { search constraints (Adams and Rau, } \\
\text { 2004) } \\
\text { Job-seeking self-efficacy; Motive } \\
\text { including work ethic and retirement } \\
\text { negativity; Social variables including } \\
\text { job seeking social support (Adams and } \\
\text { Rau, 2004) } \\
\text { Health at retirement and probability of } \\
\text { returning to paid employment } \\
\text { (Schellenberg, Turcotte and Ram, } \\
\text { 2006) } \\
\text { Education and early retirement (Kieren, } \\
\text { 2001) }\end{array}$ \\
\hline $\begin{array}{l}\text { Opportunity } \\
\text { structures in } \\
\text { career paths (job- } \\
\text { and career- } \\
\text { related) }\end{array}$ & $\begin{array}{l}\text { - Age-related performance decrements } \\
\text { associated with a career path - } \\
\text { physical, intellectual, social } \\
\text { Discrimination against older workers } \\
\text {-"voluntariness" of the retirement, } \\
\text { opportunities for part-time } \\
\text { employment or self-employment } \\
\text { outside the current organization } \\
\text { Type of industry - manufacturing vs. } \\
\text { service, large vs. small firms, } \\
\text { industry growth vs. decline, } \\
\text { unionization } \\
\text { Primary versus secondary labor- } \\
\text { market career paths } \\
\end{array}$ & $\begin{array}{l}\text { - Voluntariness of retirement (Weckerle } \\
\text { and Shultz, 1999) } \\
\text { Type of job separation (voluntary or } \\
\text { involuntary) and subsequent job status } \\
\text { (Pyper and Giles, 2002), } \\
\text { Job strain and retirement (Turcotte and } \\
\text { Schellenberg, 2005) } \\
\text { Occupation and retirement, industry } \\
\text { and retirement (Statistics Canada, } \\
\text { 2004) }\end{array}$ \\
\hline Organization-level & $\begin{array}{l}\text { - Financial rewards (in terms of wages } \\
\text { and pensions) } \\
\text { Organizational early retirement } \\
\text { counseling programs } \\
\text { Organization's flexibility in managing } \\
\text { older workers in terms of scheduling } \\
\text { and work assignments }\end{array}$ & $\begin{array}{l}\text { - Voluntariness of retirement, flexibility, } \\
\text { pre-retirement planning, anticipated } \\
\text { financial reward and decisions of early } \\
\text { retirement or bridge employment } \\
\text { (Weckerle and Shultz, 1999) } \\
\text { Organizational incentives and retention } \\
\text { of older workers (Morissette, } \\
\text { Schellenberg and Silver, 2004) } \\
\text { - Employment barriers for older workers } \\
\text { influenced by employers and unions } \\
\text { (OECD, 2005) } \\
\text { Flexibility as a tool to prevent baby } \\
\text { boomers from retiring (Christensen and } \\
\text { Pitt-Catsouphes, 2005) } \\
\text { Incidence of training of older workers } \\
\text { (Peters, 2004) }\end{array}$ \\
\hline $\begin{array}{l}\text { Environmental- } \\
\text { level factors }\end{array}$ & $\begin{array}{l}\text { Uncertainty about macroeconomic } \\
\text { trends } \\
\text { Social Security - changes in national } \\
\text { policy on Social Security eligibility and } \\
\text { taxation } \\
\text { Economic growth and inflation - } \\
\text { Macroeconomic changes in growth } \\
\text { rates and inflation rates } \\
\text { Government programs to assist older } \\
\text { workers - Introduction or phasing out } \\
\text { of government programs to assist the } \\
\text { elderly in finding jobs }\end{array}$ & $\begin{array}{l}\text { Work incentives and disincentives for } \\
\text { older people in public pension and social } \\
\text { security schemes (OECD, 2005) } \\
\text { Institutional incentives for later } \\
\text { retirement (Policy Research Initiative, } \\
2005 \text { ) } \\
\text { Employment measures by the state to } \\
\text { increase the participation of workers } \\
\text { beyond } 60 \text { (Reday-Mulvey, 2005) }\end{array}$ \\
\hline
\end{tabular}


A significant body of research exists to explain the influence of individual-level factors on retirement decision-making. Key variables included in this grouping include demographic variables such as age, gender, health status, and work history patterns. Many of the analyses completed by Statistics Canada using rich data sets on demographic variables from longitudinal studies such as the Labour Force Survey and the General Social Survey would fall in this category. Other examples of research that focus on individual factors include work ethic and retirement negativity (Adams and Rau, 2004), health at retirement and probability of returning to paid employment (Schellenberg, Turcotte and Ram, 2006), and education and early retirement (Kieren, 2001).

The second category - opportunity structures in career path - refer to job- and career-related factors that can offer differential opportunities for older workers to continue in their regular pre-retirement jobs and/or to find satisfactory bridge employment (Feldman, 1994). Examples of variables examined in this body of research include unionization of the industry, discrimination against older workers (i.e. voluntariness of retirement), as well as the physical, intellectual, and social demands of the job which may impact age-related performance. Some examples of research in this category include type of job separation (voluntary or involuntary) and subsequent job status (Pyper and Giles, 2002), job strain and retirement (Turcotte and Schellenberg, 2005), occupation and retirement, industry and retirement (Statistics Canada, 2004).

Factors under the control of organizations which relate to how they manage employees fall in the third category defined by Feldman (1994) which he labeled organization factors. Financial rewards (wages and pensions), early retirement counseling programs, and flexibility in managing older workers in terms of 
scheduling and work assignments are included within this grouping. Some examples of researchers contributing to this domain of research include Weckerle and Shultz (1999) with a study of organizational variables affecting bridge employment decisions, as well as Morissette, Schellenberg and Silver (2004) who examined organizational incentives and retention of older workers.

The last category of variables is macroeconomic and external environmental variables such as taxation policies, changes in inflation rates, and government programs to assist older workers with job-searching. Organizations such as the Policy Research Initiative and the OECD actively research and provide recommendations on how potential policy changes related to taxation, social security programs and government programs are likely to influence retirement decisions. Both research bodies issued reports in 2005 dealing with policies to encourage workers to remain in the workforce, and to provide for greater choice by older workers in their transition to retirement. Another good example of research in this area is a synthesis by Reday-Mulvey (2005) of employment measures taken by various European countries to increase the participation of workers beyond age 60 .

In addition to the identification of four levels of factors influencing the decision to retire early, Feldman (2004) also put forth a decision-tree framework for understanding the early retirement process, reproduced below. 


\section{Figure 3: A Decision-Tree Framework for Understanding the Early} Retirement Process

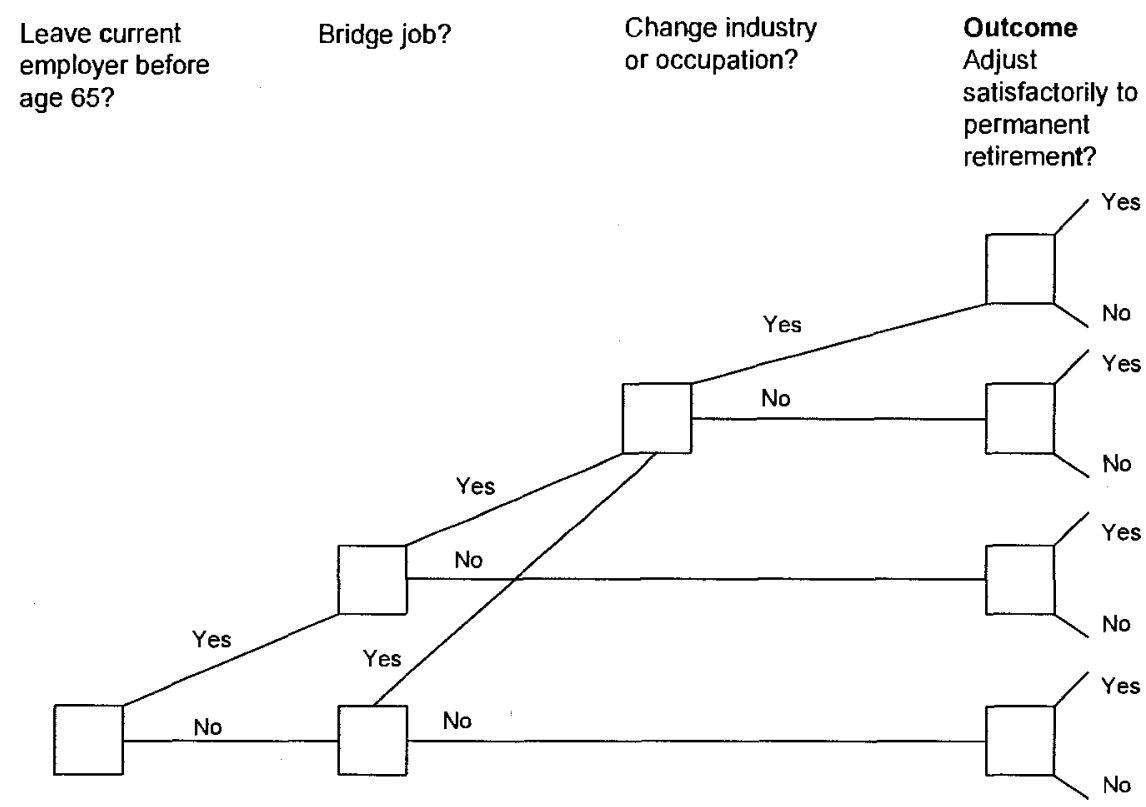

Source: Feldman, 1994, p.289

The framework includes a series of interconnected questions that older workers are hypothesized to use in making a decision to retire early. The set of factors previously discussed are hypothesized to influence individual decisions. Included in the decisiontree framework are three decisions: the decision to leave the current employer; the decision whether to accept bridge employment; and the decision whether to accept bridge employment in the same industry or occupation (Feldman, 1994).

The first decision individuals make, according to Feldman's framework, is "whether they leave their current employers before they are eligible for maximum Social Security or pension benefits." Given Feldman's research focus, this is a critical decision point which individuals choose either to retire early or remain in their jobs until normal retirement age. 
The second decision point in Feldman's decision-making tree occurs when individuals leave their current employer (whether early retirement or not). At this point, these individuals must decide whether to take on bridge employment. Bridge employment is employment taken on after full-time employment ends and permanent retirement begins (Feldman, 1994).

The final decision in this framework for individuals who accept bridge employment is whether it is in the same industry or company as their last full-time job. Feldman (1994) notes that while bridge jobs are typically viewed as being part-time work in the same industry or company as the last full-time job, bridge jobs can also involve a change in occupation and industry. Feldman (1994) emphasizes that while the decisions in this decision tree framework may appear to be independent and sequential, they could also be interdependent and simultaneous.

The outcome of interest in this model is adjustment to retirement, noted by Feldman (1994) as the outcome most frequently studied in the retirement-decision literature. Adjustment to retirement generally includes three elements: psychological wellbeing, physiological well-being, and financial well-being. Feldman (1994) treats adjustment to retirement as a dichotomous variable (either satisfactory or unsatisfactory adjustment).

Werkerle and Shultz (1999) examined a narrow subset of the organizational and individual variables identified by Feldman (1994) to determine their influence on older workers' decisions related to early retirement, continuing work, bridge employment in the same job or bridge employment in a different job. This study did not look at adjustment to retirement. Support was found for three of four organization factors identified by Feldman (1994) including perceived voluntariness 
of retirement, job flexibility and anticipated financial reward. The research by Werkerle and Shultz (1999) suggests that Feldman's work serves as a useful foundation for further research and refinement of our understanding of early retirement and bridge employment decisions.

\subsubsection{Factors Identified as Employment Barriers for Older Workers by OECD (2005)}

A 2005 OECD report on ageing and employment policies notes that there are significant barriers and disincentives to working longer for older workers. Consistent with Jepsen (2002), the OECD (2005) notes that several stakeholders - the state, individuals, as well as unions and employers - have influenced the current situation which includes many deterrents to extension of working life. The following figure documents the employment barriers for older workers as identified by the OECD. A brief overview of the role of each of these stakeholders is given below. A more indepth discussion of the model is presented later in this section. 


\section{Figure 4: Employment Barriers for Older Workers}

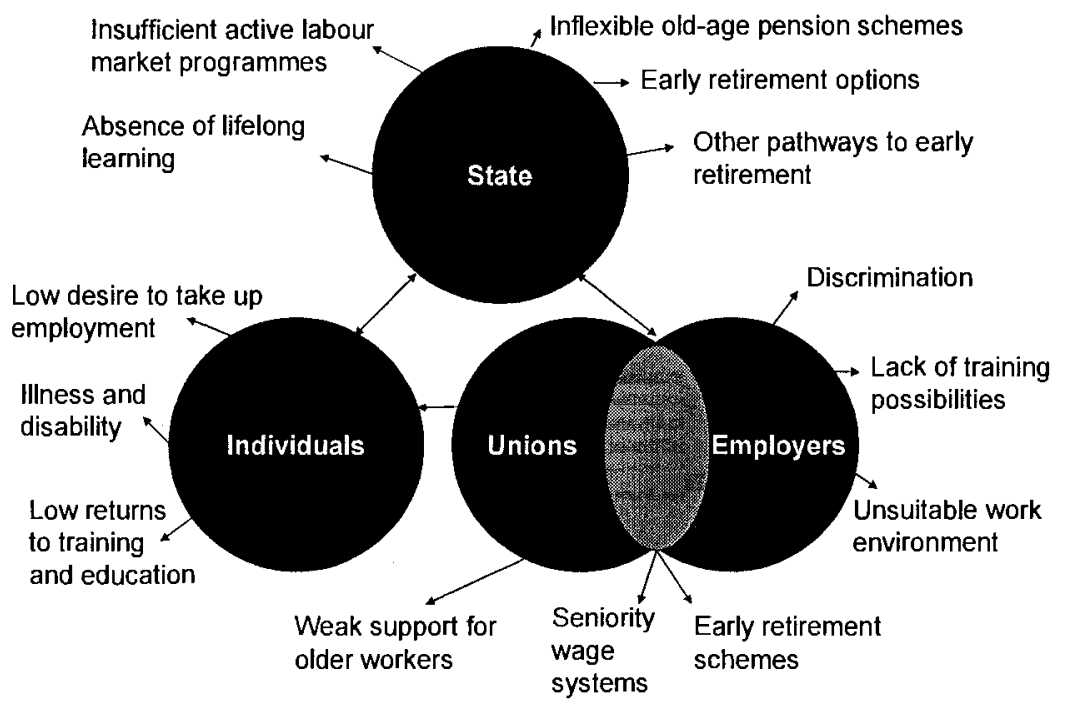

Source: OECD Framework, reproduced in Policy Research Initiative, 2005, p. 26

This framework put forth by the OECD suggests that the state has a significant role to play in creating a legislative framework and programs to encourage increased labour market participation by older workers. A key policy recommendation by the OECD (2005) was to create supply-side incentives to mobilize increasing numbers of older workers. An example of such a program given by the OECD was changes to the retirement system to increase flexibility of combining pensions with work income. The OECD (2005) also called upon governments to put in place programs that encourage labour market participation of older workers, with a focus on lifelong learning and increasing employability of this segment of the workforce.

To provide supports on the demand-side, the OECD (2005) notes that unions and employers must tackle some of the stereotypes that exist about older workers. The 
OECD (2005) suggests that discriminatory attitudes toward older workers may influence employer practices related to hiring and training of these workers. Jepsen (2002) provides a good summary of the debate on employers' attitudes towards older workers, suggesting that while some researchers have outlined costs associated with aging workforces, others have disputed these claims or provided methods for addressing potential challenges. Given prevailing attitudes and conflicting research, it may be easier for employers to offer early retirement than to recognize and capitalize on the benefits that this segment of the workforce presents.

Finally, the OECD (Policy, Research Initiative, 2005) suggests that there are employment barriers at the individual level. They note that some older individuals may remain out of the workforce due to illness or disability, while others may not be investing in the training and education required to maintain skill levels. The OECD also reports that some individuals may have a low desire to participate in the workforce, either because they are financially capable of staying out or that the barriers noted above are real for them, effectively keeping them from participating in the workforce despite their desire.

This framework clearly illustrates the importance of all stakeholders working together to address employment barriers for older workers. From the perspective of employers, there is an opportunity to further research policies and programs that affect the work environment of older workers which may currently be acting as barriers to continued employment. 


\subsubsection{Comparison of Frameworks of Factors Influencing Older Worker's Retirement Decisions}

The frameworks developed by Feldman (1994) and OECD (2005) both recognize that a number of stakeholders potentially influence the decision of older workers to remain in the workforce or retire early. This implies that research in this area needs to consider a wide range of factors when examining the possibility of extending the working lives of older workers. These frameworks are designed from differing perspectives and while there are many parallels in terms of constructs of interest, there are also many points of divergence (i.e. concepts specific to each framework). The figure below illustrates the parallels between the models (i.e. broad categories and specific factors), as well as areas of divergence. 


\section{Figure 5: Comparison of Frameworks by Feldman (1994) and OECD} (2005)

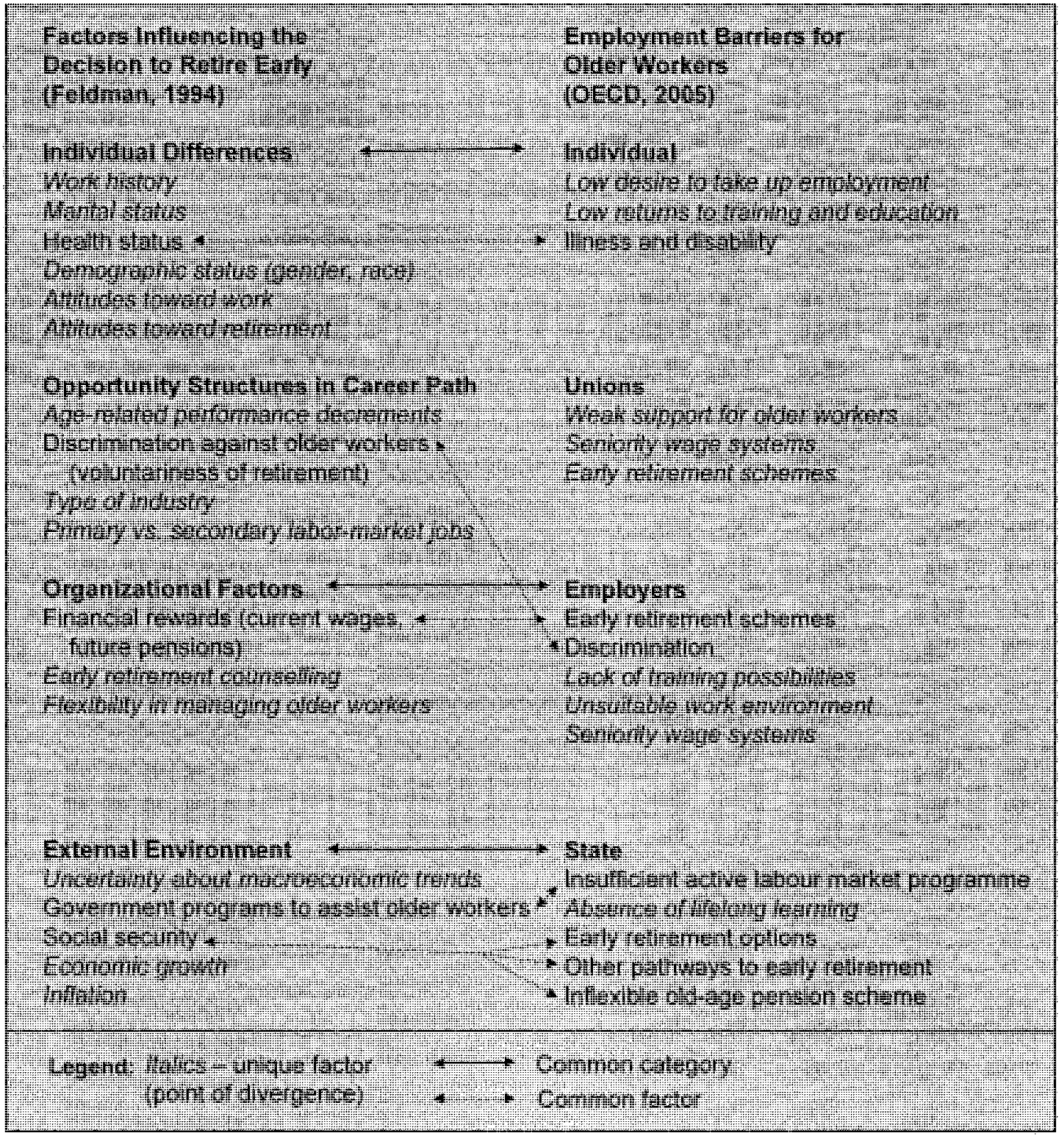

A common category of factors identified by both Feldman (1994) and the OECD

(2005) pertains to the individual. Within this category, a common factor is individual

health, noted as health status by Feldman and as illness and disability by the OECD.

Other factors identified by the two authors in their respective frameworks appear to

be relatively unique. Feldman (1994) presents a much more extensive list of factors 
relating to individual differences, with a significant focus on demographic factors (marital status, gender and race). Both OECD and Feldman include factors related to individual attitudes towards employment that have some similarity. Feldman's factors tend to be stated more broadly (e.g. attitudes towards work considers selfidentify, company identification and professional identification), while those in the OECD framework are more specifically defined (e.g. low desire to take up employment).

Feldman (1994) identifies a grouping of factors influencing the decision to retire early which appear to be quite unique in comparison to the OECD framework of employment barriers for older workers. The concepts within this category of factors by Feldman are based in labour economics and suggest that an individual's career path may offer differential opportunities for continued work in regular (preretirement) jobs or for satisfactory bridge employment. There is very little commonality between factors identified by Feldman in this category and any of the barriers noted by the OECD. The topic of discrimination is noted by Feldman in relation to opportunity structures in career paths, and also by the OECD as a barrier under the control of employers. At a conceptual level, these appear to be common; however, Feldman (1994) places emphasis on discrimination in the context of a specific job or career as opposed to the OECD's general view of discrimination of older workers. In general, the concepts that underlie the category of opportunity structures in career path are a point of divergence between the Feldman and OECD frameworks.

The comparison of the OECD (2005) and Feldman (1994) frameworks yields another key point of divergence related to how significant the role of unions is portrayed by these two authors. The OECD framework explicitly identified unions as a key 
stakeholder in relation to employment barriers for older workers. Unionization is noted as one component of the "type of industry" factor identified by Feldman in relation to opportunity structures in career paths. It might also be suggested that unions also have a role in determining some of the practice related to wages, pensions and other human resources practices noted in Feldman's framework as organization factors. The comparison of these two frameworks suggests that the impact of unions on individual decisions to retire early or remain in the workplace is much more explicitly stated in the OECD framework.

Feldman (1994) puts forth organization factors which parallel some of the barriers presented by employers and unions in the OECD (2005) framework. "Financial rewards (current wages, future pensions)" identified as a factor by Feldman is similar to "early retirement schemes" noted by the OECD as an employment barrier for older workers. Feldman specifically identifies early retirement counseling and flexibility in managing older workers as organization factors and the OECD (2005) goes further to add other factors including lack of training possibilities and seniority wage systems. Feldman (1994) identifies "flexibility in managing older workers" as an organizational factor which appears to touch on the same topic as "unsuitable work environment" in the OECD framework.

External environmental factors from Feldman (1994) are fairly similar to the barriers suggested by OECD to be under the influence of the state. Social security programs referenced by Feldman (1994) would encompass pension schemes, early retirement options, and other pathways to retirement as outlined by OECD. In addition, there is also a parallel between Feldman's factor "government programs to assist older workers" and the following OECD barriers - "insufficient active labour market programme" and "absence of lifelong learning". 
One final point of divergence identified in the comparison of the Feldman (1994) and the OECD (2005) framework is that the OECD places significant emphasis on the importance of lifelong learning in contrast to a much less prominent identification as a factor by Feldman. The OECD notes that barriers related to learning exist and are perpetuated by individuals, employers and the state. Learning is noted by Feldman as a potential government program to assist older workers; however, learning is not referenced as a construct in any other categories of factors influencing decisions to retire early.

In summary, these frameworks provide important context for this study given that they articulate a wide range of factors that must be considered in encouraging and enabling older workers to delay early retirement. The comparison of these two frameworks from the literature suggests that there is significant opportunity to clarify and confirm the role that various stakeholders can play in encouraging longer working lives for Canadians.

\subsubsection{The Role of Employers in Individual Retirement Decisions}

The review of the existing frameworks and models suggests that there are a wide range of factors that influence an individual's decision to either retire early or remain in the workforce. In Canada, an Expert Panel on Older Workers was recently convened to examine several topics including the broader issue of population ageing and the role of older workers in society. The panel selected this focus because "there is much we do not know about barriers to participation, factors affecting the decision to retire, and appropriate roles for the government and private sector" (Institute for Research on Public Policy, 2007, p. 2). 
A question to be answered in framing the focus for this thesis is "where are the gaps in existing knowledge with respect to the categories of factors identified in these frameworks?". In his review, Feldman (1994) noted that much of the research on early retirement and bridge employment has focused on individual- and environmental-level variables and that greater attention was required on organizational and opportunity structure factors that influence early retirement and bridge employment decisions. Feldman (1994) theorized that individual-level and environmental-level variables have the greatest impact on individual decisions to exit career-long positions, while opportunity structures and organization factors have the greatest impact on decisions about bridge employment.

The research objective for this thesis is to understand how organizations can increase the proportion of older, engaged workers who choose to remain with the organization until or after retirement age. This research focus was selected for several reasons. First, given the vast array of variables that influence early retirement decisions, it is beyond the scope of this thesis to investigate factors under the control of individuals, employers, unions and governments. In addition, there is a clear gap in existing knowledge related to organizational variables (Feldman, 1994; Institute for Research on Public Policy, 2007). Finally, the results of the proposed research will be of benefit to employers facing talent shortages to help guide their decisions around potential approaches to retain existing workers to help avert the labour shortages discussed earlier.

The specific organization factors to be explored in more detail have been identified through the frameworks put forth by Feldman (1994) and OECD (Policy Research Initiative, 2005). The list of factors to be reviewed includes organization factors that encourage retention of older workers - financial rewards (current wages and future 
pensions) and flexibility in managing older workers. The literature will also be reviewed to understand organization factors that encourage early retirement, including early retirement counseling programs, discrimination, lack of training, and early retirement schemes.

Given increasing interest in this topic over the past decade since Feldman's initial review, some research attention is being focused on the potential impact of organizational policies on retirement decisions, although there are still calls in Canada to better understand this issue. Recently, Statistics Canada published a book entitled New Frontiers of Research on Retirement and noted that there continues to be opportunities for additional research into how the workplace environment affects various aspects of the transition to retirement, especially the preparatory stages (Statistics Canada, 2006). Focusing attention on the importance of this research to understand older workers in the workplace, Conroy, Lamontagne, Stone and Maloney (2006) noted that "new data, theory and research are urgently needed to help Canadian institutions confront the implications of the up-coming wave of baby boomer retirements, especially as regards the workplace and labour-market environments in which older workers find themselves."

The remainder of this section will explore the literature related to organizational-level variables in more detail as context for focused thesis research in this area.

\subsection{Organization Factors and the Impact on Retirement Decisions}

Jepsen (2002) notes that retirement decisions are a result of the interaction between the social security system, the operation of the labour market, the state and the individual. Early retirement is a well entrenched desire for many Canadians (Schellenberg, 2005) and in the past, many older workers had their wishes granted 
with generous retirement packages from employers making significant workforce adjustments (Kieren, 2001). Early retirement provisions built into public and private pension plans by governments and employers have effectively discouraged late retirement and reduced the labour supply of older workers. These approaches may have been appropriate and necessary in times of surplus labour supply, however, the Policy Research Initiative (2005) notes that in some cases, these practices have become barriers to adjustment and flexibility in a time of tightening of supply.

The issue of retaining older workers has not received much attention to date by employers in Canada. A study commissioned by the Alliance of Sector Councils in 2003 found that "little has been done in Canada related to attracting, retaining and maintaining older workers" (cited in Policy Research Initiative, 2005, p.30). Even more discouraging are findings that employers do not view older workers as a critical component of strategies to avert labour shortages. The Alliance of Sector Council study suggested that employers would look toward retention of older workers only after exhausting other strategies such as competing hard for new recruits in the existing labour force, and growing the labour force through groups such as immigrants and First Nations peoples (Policy Research Initiative, 2005).

Research attention has only recently turned to answering questions related to the role of the employer in retaining older workers in the workplace. Flexible work options and financial incentives are one of the most frequently referenced incentives in the literature to either retain older workers contemplating retirement, or to attract them back into the workplace (Werkerle \& Schultz, 1999; Morissette, Schellenberg, and Silver, 2004; Christensen and Pitt-Catsouphes, 2005). Other research, including work by the Policy Research Initiative (2005) and OECD (2005), has identified barriers that must be removed by employers if they are to fully engage this growing 
segment of the workforce. A challenge is put forth to employers to approach the issue of retention of older workers in the context of a broader age management program which includes incentives that employees are seeking, as well as removing barriers to continuing labour force participation. The ultimate goal for employers is to extend the working lives of older workers and keep them engaged in the workplace, continuing to be motivated and energized by their job and organization.

Within this context, the remainder of this section will explore perspectives from the literature related to factors under the control of organizations that influence decisions of older workers related to retirement. Based on the review of relevant frameworks by Feldman (1994) and OECD (2005), the discussion that follows will first provide an overview of the factors that are believed to encourage older workers to remain in the workforce, followed by factors that encourage workers to retire early.

\subsubsection{Organization Factors that Encourage Retention of Older Workers}

Organization factors that may encourage retention of older workers include financial rewards (current wages and future pensions) and flexibility in managing older workers.

\subsubsection{Financial Incentives}

Financial incentives have been found to be a factor in decisions around work and retirement for older workers. Statistics Canada research has shown that over one in five recent retirees reported that salary increases might have influenced them to continue working (Morissette, Schellenberg and Ram, 2004). Salary increases alone, however, do not necessarily appear to be sufficient motivation to retain older workers, as $15 \%$ of recent retirees reported that a combination of flexible working 
arrangements and salary increases would have kept them in the workplace (Morissette, Schellenberg and Ram, 2004). Other research has indicated that financial considerations are also the number one reason that retirees returned to paid employment. Schellenberg, Turcotte and Ram (2005), for example, report that nearly $40 \%$ of recent retirees indicated that financial issues caused them to return to work. Those that retired involuntarily were more likely than voluntary retirees to report this as the motivation to return to work (Schellenberg, Turcotte and Ram, 2005).

Researchers have also examined the issue of financial preparations for retirement of older workers. Jepsen (2002) reports that one of the characteristics of individuals who prefer to stay on the labour market is that they 'have family dependents and cannot afford to retire.' Recent Canadian research concluded that about one-third of near-retirees may not be saving enough for retirement (Statistics Canada, 2001 and Schellenberg, 2004). Statistics Canada (2001) found that of families where the highest income earner was an employed individual aged 45 to 64 , one-third may not have saved enough to replace two-thirds of their earnings, or to generate an income in retirement that is likely to be above the LICO (Low Income Cutoff) ${ }^{5}$.

A subsequent study using different analytical approaches by Schellenberg (2004) provided similar findings to the above-noted 2001 Statistics Canada study. Schellenberg's 1994 study examined the perceptions of adequacy of financial preparation for retirement of individuals aged $45-64$, and examined the experiences of older Canadians that have already withdrawn from the labour force. Analysis of the data from the 2002 General Social Survey found that "just under one-third of

\footnotetext{
${ }^{5}$ Low income cutoffs are income thresholds below which families will devote a larger share of income to the necessities of food, shelter and clothing than an average family would (Statistics Canada, 2006).
} 
non-retired Canadians aged 45 to $59(30.6 \%)$ does not feel that he/she is adequately preparing financially for retirement. Similarly, over one-third (38.0\%) believes that his/her retirement income will either be barely adequate, inadequate, or very inadequate to maintain his/her standard of living once he/she has left the labour force." (Schellenberg, 2004, p. 8-9). The study also examined retrospective information from recent-retirees, defined as individuals who retired in the years 1992 to 2002. Approximately $34 \%$ of recent-retirees in the General Social Survey reported that they are financially worse off now compared with the year prior to their retirement (Schellenberg, 2004).

Schellenberg (2004) notes that concerns about the adequacy of financial preparations for retirement or retirement income are most prevalent among nearretirees in their late forties; those that are widowed, separated or divorced; immigrants who arrived in Canada since 1980; and individuals with poor or fair selfassessed health. A correlation was found between the perceived adequacy of retirement preparations and several financial characteristics of near-retirees, including those that do not have pension coverage, who do not own their home, who have lower personal and household incomes, and fewer weeks of employment during the year.

In summary, the literature related to financial incentives would suggest that there is a group of older workers whose motivation to remain in the workforce is that their employment provides them with a necessary stream of income support. The research also suggests that while increased salary may contribute to retention of older workers, this incentive may have to be combined with other offers, such as flexible work arrangements, to keep these older workers in the workplace. 


\subsubsection{Flexible Work Arrangements and Part-time Work}

Flexible arrangements, particularly flexible hours and telecommuting, are becoming more common in Canada. A recent Conference Board report found that the majority of employers surveyed offer flexible hours, telecommuting, compressed workweek, and voluntary reduction of working hours to employees. Nearly $30 \%$ of employers also reported offering phased retirement as a form of flexible work arrangement (Conference Board of Canada, 2006).

Recent retirees appear to be pursuing continued employment, often on a part-time basis. A study of recent retirees (those that retired between 1992 to 2002) by Schellenberg, Turcotte and Ram (2005) included the following findings in relation to paid work engaged in by retirees. Just over one-fifth of individuals reported having done paid work, at any job or business. While almost all men had worked at full-time jobs prior to retirement, over one-third took on part-time employment postretirement. For women, approximately $86 \%$ had been employed full-time prior to retirement, and over half switched to part-time when they returned to work.

Feldman (1994) hypothesized that employees in organizations that offer flexible policies for handling workers were more likely to retire early from full-time jobs and to accept bridge employment in the same job or occupation. This means that employers effectively retain the employee and their knowledge, at least on a parttime basis.

Subsequent research by Werkerle and Shultz (1999), Christensen and PittCatsouphes (2005) and Morissette, Schellenberg, and Silver (2004) supports Feldman's hypothesis, indicating that greater work flexibility could result in changes to retirement decisions, either preventing individuals from retiring or retaining them 
on a reduced work schedule. Based on recent research in the United States, Christensen and Pitt-Catsouphes (2005) reported that baby boomers expect or want to continue working and that more flexibility would prevent them from retiring. Work flexibility can mean a range of things including scheduling of work hours, amount of time worked, as well as career flexibility with multiple points of entry, exit and reentry (Christensen and Pitt-Catsouphes, 2005). In a large study of Canadians who retired between 1992 and 2002, nearly $30 \%$ of respondents noted they would have continued working on a part-time basis, either reducing their work schedule or increasing their vacation leave, assuming no effect on their pension (Morissette, Schellenberg, and Silver, 2004). Finally, Werkerle and Shultz (1999) reported that workers considering early retirement had more ability to reduce their work hours than other workers who were either considering continuing work, accepting bridge employment in the same job or bridge employment in a different job. A suggestion is made by Werkerle and Shultz (1999) that this finding may demonstrate that a positive view of the flexibility of the work environment influences an older worker's consideration for early retirement.

While there appears to be a desire on the part of many older workers to continue working under flexible arrangements, there are still many challenges for employers to implement such programs. The federal government recently made legislative changes to allow for phased retirement, effectively allowing members of defined benefit registered pension plans to draw benefits from their pension while still accruing additional benefits (Watson Wyatt, 2008). While employers with federallyregulated pension plans can proceed under these new phased retirement provisions, members of pension plans subject to provincial regulations must wait for provincial pension standards legislation (Watson Wyatt, 2008). Research by Morissette, Schellenberg, and Silver (2004) suggests that a critical component of the incentive 
for older workers to stay is that there will be no impact on their pension earnings. As a result, workers covered by some registered pension plans may face challenges setting flexible work arrangements with their current employer, and may have to retire from a career job and begin working with another employer to achieve a reduced schedule.

\subsubsection{Organization Factors that Encourage Early Retirement}

Organization factors that have been linked to the decision to retire early include early retirement schemes, early retirement counseling programs, discrimination, lack of training, and seniority wage systems. This section of the literature review provides a summary of the key findings related to this topic as it can be assumed that the reduction of any of these factors may encourage people to remain in the workforce longer.

\subsubsection{Early Retirement Schemes}

Strong financial incentives to retire early are presented in the design of many Registered Pension Plans, particularly defined-benefit plans, offered by Canadian employers (Policy Research Initiative, 2005). In Canada, more than $40 \%$ of Canadian salaried workers are covered by Registered Pension Plans ${ }^{6}$. The vast majority of these plans are defined benefit pensions, with a particular concentration of coverage for individuals employed in the broad public sector (Policy Research Initiative, 2005). The OECD (2005) observed that defined benefit plans offer strong financial incentives to retire early and often before the age of 60 . This assertion is consistent with the retirement trends observed for public administration and education, where the observed retirement ages are in the range of 57 to 58 (Statistics Canada, 2004).

\footnotetext{
${ }^{6}$ Registered pension plans are plans established by either employers or unions to provide retirement income to employees. These plans are registered with the Canada Revenue Agency for tax purposes and, in most cases, also with the federal or a provincial pension regulatory authority (Statistics Canada, 2007c).
} 
The OECD presents several suggestions to reduce the barriers to work inherent in the design of Registered Pension Plans, thereby allowing older workers to continue to work for the same employer while receiving a pension. OECD (2005) suggests unions and employers should consider providing possibilities for phased retirement under the plans. The federal government has removed a fundamental barrier to phased retirement - income tax rules that prohibit accrual and receipt of benefits from the same defined-benefit registered pension plan (Watson Wyatt, 2008). Governments and employers must now make additional changes to pension plan regulations to allow opportunities for phased retirement to be fully explored.

\subsubsection{Early Retirement Counseling Programs}

Feldman (1994) noted that there is very little empirical research that documents the link between various types of corporate pre-retirement programs and ultimate retirement decisions. Feldman (1994) hypothesized that employees who receive preretirement counseling are more likely to retire early. His rationale is that comprehensive preparation for retirement reduces an employee's ambivalence about the decision, and gives them an opportunity to prepare. Werkerle and Shultz (1999) made a similar observation following a review of literature suggesting that planning for retirement could reduce the uncertainty towards retirement decisions. Werkerle and Shultz (1999) examined the impact of pre-retirement planning on decisions to retire early, accept bridge employment, or continue working; however, support was not found for Feldman's (1994) hypothesis. 


\subsubsection{Discrimination}

In Canada, the Canadian Human Rights Act and provincial human rights codes protect older workers from being discriminated against in the workplace because of their age (Human Resources Development Canada, 2002). Protection against age discrimination depends on legislation which differs by province. Some provinces provide protection from age discrimination only to the age of 65 , while others have effectively banned mandatory retirement (Kerr, Ibbott and Beaujot, 2004).

While protection is offered by legislation in some jurisdictions, there is still room for progress in terms of attitudes towards older workers and their capabilities and contributions in the workplace.

Research around discrimination of older workers highlights that while employers perceive both positive and negative aspects of older employers (The Urban Institute, 2007; Jepsen, 2002), it appears that overall there is negative stereotyping of older workers (Jepsen, 2002). Schetagne (2001) suggests that employers hold a stereotypical and somewhat ambivalent view of older employers, recognizing their capacity for work and their outlook on employment, while thinking that older workers are lacking in flexibility and adaptability. Jepsen (2002) reviewed the literature related to employers' attitudes towards older workers and suggests that while employers' attitudes towards older workers are said to have changed, written evidence is scarce. Jepsen $(2002$, p. 38) summarizes the work of many researchers in this area with the following list of types of costs to the employer for holding on to their ageing workforce:

- Older workers are less productive than younger workers because of health and less up-to-date skills.

- Wages increase with age/seniority. 
- Costs linked to lower ability to adapt or learn new skills.

- Shorter expected stay because of upcoming retirement, thus making it less interesting to invest in their skills.

- Imbalance in age pyramid of work force, thereby decreasing the motivation of the younger workers.

On the other hand, Jepsen (2002) reviewed several studies which suggested that these stereotypes can be disputed or addressed with appropriate approaches. For example, Jepsen (2002) notes a body of research has called into question whether productivity really does decrease with age. Similarly, Jepsen (2002) suggests that the scientific evidence related to training and adaptability for older workers is that it is a question of using the right training method rather than learning difficulties. A recent Expert Round Table on Older Workers by the Institute for Research on Public Policy concurred with this observation and noted that programs need to be adapted to suit the audience and their preferred learning style (Institute for Research on Public Policy, 2007).

In summary, the research suggests that stereotypes of older workers can be a barrier for many older workers who wish to continue in the workplace. Employers who wish to retain older workers need, therefore, to encourage positive views of older workers and make decisions with respect to training and other human resources practices without regard for age.

\subsubsection{Absence of Training and Learning}

While the barriers to employment for older workers identified by OECD (2005) are often specific to individual stakeholders, absence of training and learning is noted as 
a barrier created by many stakeholders including the state, employers and individuals.

Employability levels of older workers are affected by levels of investment in training and learning, and there is evidence to suggest that this investment decreases as workers age. Statistics Canada (2004) reported that fewer older workers (55 to 64) than younger workers (25 to 34 ) engage in formal job-related training, measured by participation rates. Statistics Canada (2004) suggests that the underlying theory of higher participation rates for younger workers is that there are significant benefits and returns for the expansion of skills for younger workers, while the benefits of training older workers are perhaps less obvious. Jepsen (2002) notes that there are several arguments that dispel the notion that training older workers is not worthwhile because they will soon retire. The main argument, she contends, is that older workers are more loyal, with a much lower probability of leaving current employment within five years than younger workers. As such, investment in this group is more likely to pay dividends to the organization.

There are a number of authors who note that both increased training investments and shifts in attitudes and perceptions regarding training for older workers will be required to build and maintain employability levels of older workers in Canada in the future (Morissette, Schellenberg and Silver, 2004; OECD, 2005; Policy Research Initiative, 2005). There are some indications that job-related training for older workers may increase in the future given that there have been recent increases in participation rates in training reported by older workers aged 55 to 64 (i.e. Peters (2004) notes that training in this group increased by over $50 \%$ from 1997 to 2002). Factors that may be motivating this change include the idea that employers are recognizing that training older workers is a necessity and older workers themselves 
are participating in training to prepare themselves for employment during their "retirement years." Training was found to be related to education levels in the 2004 Statistics Canada study. Workers with university credentials were more likely to participate in formal, job-related training than those with secondary education or less (Peters, 2004). Given that the baby boom generation has generally higher levels of education than previous generations, a greater proportion of older workers may be involved in job-related training in the future.

\subsubsection{Seniority Wage Systems}

The OECD (2005) suggested that seniority wage systems are a barrier to employment for older workers. In a discussion on the dynamics between mandatory retirement and workplace practices, OECD (2005) noted that seniority wage systems are the result of an implicit contract between the employer and the employee such that wages depend on age or length of service, rather than an individual worker's performance. Jepsen (2002) suggests that wage increases with age/seniority combined with perceptions of other costs (lower productivity, lower adaptability, poor return on training investments) result in decisions to substitute younger workers for older workers. Proponents of mandatory retirement suggest that the period when wages exceed the marginal productivity of older workers can be capped or limited by such a mechanism (Lazear, 1979). As a result, the concept of seniority wage systems is very much tied to topics of mandatory retirement and age discrimination previously discussed. 


\subsection{Limitations of the Current Literature Related to Organization Factors}

There are several limitations of the current literature related to organization factors that influence early retirement decisions. First, there has been limited theoretical and empirical research attention placed on organization factors that influence early retirement decisions. Second, there are differing perspectives as to the role of these factors in early retirement and bridge employment decisions. For example, while Feldman (1994) theorized that organization factors impact decisions to accept bridge employment, Stone and Nouroz (2006) provide a contrary perspective. They propose that the speed at which individuals move through transitory stages towards retirement is influenced by corporate policies and working environment in a very limited way. More important, Stone and Nouroz (2006) theorize, is the individual's actions in response to behaviour changes made by others in their social network, as well as their ability to cope with major intrusive life events and their consequences.

A third limitation is that while some frameworks of organization factors exist, there is little commonality between the specific factors within these frameworks. The primary reason for this divergence appears to be that the issue is being examined from different perspectives. Much of the literature related to organization factors noted above, with the exception of research related to financial incentives and flexible work arrangements, is written based on research and analysis independent of the perspective of the key decision-maker - the individual approaching retirement,. For example, there are calls by OECD (2005) and Policy Research Initiative (2005) to increase training for older workers given that lack of training is a barrier to continued employment. The research does not tend to focus on answering the following question - "To what extent would the provision of training to older workers actually impact their decision to retire or to remain engaged in the workplace?" Similarly, Jepsen (2002) summarizes the literature related to age discrimination by employers, 
much of which focuses on the employer's perspective (perceived costs associated with older workers). There is a need to expand the current research to explore perspectives from individuals who are approaching retirement to better understand the factors that influence their individual decisions. New research from this perspective can be used to begin to develop a single comprehensive framework of factors under the control of organizations that impact individual decisions related to retirement. 


\section{Method}

The research strategy to be used for this thesis work is a case study. Yin (2003, p.13) defines a case study as "an empirical inquiry that investigates a contemporary phenomenon within its real-life context, especially when the boundaries between phenomenon and context are not clearly evident."

A case study research method has been selected for several reasons. The focus of this research is to explore and understand how factors under the control of organizations impact individual decisions about retirement. Yin (2003) notes that case studies are a preferred strategy when "how" or "why" questions are being posed.

Yin (2003) also emphasizes that the case study method is useful when contextual conditions may be highly pertinent to the phenomenon under study. In this thesis, an individual's decision to retire early or remain in the workplace will be examined. Existing frameworks of factors that influence early retirement decisions noted in the literature review highlight that there are a wide range of factors under the control of many stakeholders including governments, employers, unions and individuals. Therefore, it is important to understand the role of employers in influencing individual retirement decisions within this broader context.

Finally, a case study method is suitable for use when there is a need to generate theory (Eisenhardt, 1989). Given that one of the limitations of the current research in this area is the absence of a comprehensive framework of the factors under the control of organizations that impact early retirement decisions, the case study 
method will allow for the generation of potential theories to explain the role of organization factors and influences on individual retirement decisions.

Eisenhardt (1989) describes the process of building theory from case study research, building on previous work in qualitative methods by Miles and Huberman, Yin, and Glaser \& Strauss. The end result is a roadmap for executing case study research to develop new theories. The roadmap developed by Eisenhardt (1989) will be used to guide the steps and activities to carry out the research for this thesis. While the headings of this section do not correspond directly to the steps defined by Eisenhardt (1989), the planned activities are based on her roadmap.

The remainder of the method section will describe how the guidelines set out in the roadmap by Eisenhardt (1989) have been applied to this research, covering the research questions, selection of cases, collection and analysis of data, and shaping of the hypothesis. The section concludes with a discussion of the limitations of the selected method and relevance of this research.

\subsection{Research Questions}

Eisenhardt (1989) suggests that the first step in getting started in building theory from case study research is to define the research question because without this focus, it is easy to get overwhelmed by the volume of data. Given that the nature of the research is exploratory, the research questions are set to establish a focus for the research, recognizing that there may be refinements to this focus during the data collection period. 
While theory-building research is ideally intended to be established with no theory in mind, Eisenhardt (1989) suggests that investigators can refer to extant literature at the initial stage of research. The literature review in the previous section suggests that there are a group of factors under the control of organizations, primarily the existence or absence of policies and programs related to employment and workplace conditions, which influence an individual's decision about early retirement. The literature review demonstrated that while some frameworks exist that have begun to delineate potential variables, no single comprehensive model of organization factors influencing early retirement decisions exists.

The following question will form the basis of inquiry for this research:

- How can organizations increase the proportion of engaged older workers who chose to remain with the organization until or after retirement age?

The literature review suggests that there are two ways that organizations could potentially achieve this goal - by decreasing the likelihood that individuals will retire early and by increasing the likelihood that people will stay longer. This thesis explores both of these ideas and aims to discover the overlap between the two. The results of the research can be used to identify potential organizational policies or programs to increase the age at which older workers choose to retire and leave the organization.

At the outset of this research, the intent was to use a modified version of Feldman's 1994 definition of retirement which would incorporate the concept of being in receipt of a full pension (without penalties). During the data collection process, it became evident that the most common reference point for eligibility to retire for study participants was retirement at or after age 60 with two or more years of pensionable service, or at 55 with 30 or more years of pensionable service. According to the 
Public Service Superannuation Act pension plan overview, a pension paid to an employee meeting the above-noted conditions will not be reduced in any way ${ }^{7}$. The maximum years of pensionable service is 35 years. Therefore, the revised definition is stated as "the exit from an organizational position or career path of considerable duration, taken by individuals who are eligible for a pension without penalties, with the intention of reduced psychological commitment to work thereafter."

For ease of reference in this thesis, study participants who plan to retire with the maximum years of pensionable services ( 35 years) will be referred to as "full pensioners." Study participants who intend to retire at or after age 60 with two or more years of pensionable service, or at 55 with 30 or more years of pensionable service will be referred to as "early retirees." Finally, those individuals who indicated that they intend to retire before meeting the eligibility criteria for a pension without penalties are referred to as "early exiters."

\subsection{Selecting Cases: Target Population and Sample Selection}

Given that the research focus for this thesis work is how individual retirement decisions are impacted by organization factors, the unit of analysis is the individual. The sampling approach for identifying cases in qualitative research involves theoretical sampling, with the goal of choosing cases that will replicate or extend the emergent theory (Eisenhardt, 1989). Also known as purposeful sampling, the approach involves selecting cases strategically and purposefully based on the purpose of the study (Patton, 2002).

The literature review in the previous section suggests that while organizations across all sectors of Canadian industry will be facing some degree of labour market

\footnotetext{
${ }^{7}$ Refer to htup/ www tbs-sct.ge.calpubs pol/hrpubs/Pensions/yppl c.aspt Toc497204654 for details on the pension plan which is governed by the Public Service Superannuation Act.
} 
shortages, the federal public service appears to be a good target for several reasons. First, Stone and Nouroz (2006) put forth a case that expansion of the existing body of knowledge about work-to-retirement transitions should focus on the public sector, primarily because it is "perhaps the venue of the most advanced planning concerning gradual retirement in Canada" (Stone and Nouroz, p. 291). In addition, this sector of the economy will be one of the first to experience the effects of baby boomer retirements given that it has a low median retirement age and its workforce is, on average, older than the Canadian workforce (Policy Research Initiative, 2005). For these two reasons, the federal public service was selected as the broad target population for this research.

Research by Statistics Canada on the federal public service provides additional insight as to how this broad population can be narrowed further to provide greater direction for the theoretical sampling for this thesis. In 2006, just over 100,000 workers, representing $58 \%$ of the Core (federal) Public Administration (CPA) ${ }^{8}$, were classified as knowledge-based workers (Statistics Canada, 2007a). In the CPA context, knowledge-based occupational categories have been identified as scientific and professional; computer systems; program and administrative; executive; and administrative and foreign service (Statistics Canada, 2007a). The literature review has suggested that highly educated workers (knowledge-workers) are more likely to retire early than those with less formal education. Given this data, a highly relevant target population for this thesis is knowledge workers within the Core (federal) Public Administration.

\footnotetext{
${ }^{8}$ The Core (federal) Public Administration (CPA) refers to the federal government employees excluding the Royal Canadian Mounted Police, the Canadian Forces and separate agencies such as the Canada Revenue Agency. In 2006, the total number of employees within the CPA was 178,000 (Statistics Canada, 2007a).
} 
Specifically this research focuses on workers within the Core Public Administration knowledge-based occupational categories who are approaching retirement and are actively contemplating decisions related to the nature and timing of their retirement transition.

The approach to identify individuals to participate in this research study began with the identification of Citizenship and Immigration Canada (CIC) as a federal government department with an interest in and a focus on making policy changes to retain workers who are nearing retirement. CIC agreed to distribute information related to this research study to a subset of their employee complement, specifically all employees within their Executive cadre as well as all middle managers who have supervisory responsibilities. The selection of these two groups was made for practical reasons, as it was not possible to directly target communications about the study to all employees within CIC that would fall into the knowledge worker classification. CIC maintains and uses email distribution lists for regular communication with the executive and middle manager cadres, thereby facilitating the distribution of messages about the study to this narrower target audience.

An email was distributed by an executive of the Human Resources Department to all executives and middle managers within CIC in late May 2008, providing an overview of the study, the profile of desired participants, as well as instructions how to contact the researcher to express an interest in participating in the study. This email communication is included in Appendix A.

The sample size used in qualitative inquiries depends on a range of considerations, including the purpose of the inquiry, requirements for credibility, along with practical considerations of available time and resources (Patton, 2002). In addition to 
pragmatic concerns related to time dedicated to data collection efforts, Eisenhardt (1989) suggests that theoretical saturation should guide decisions around when to stop adding cases. Researchers have reached the point of theoretical saturation when the incremental learnings from addition of cases is minimal because no new phenomena are being observed (Glaser and Strauss, 1967). The target sample size for this thesis was set at 25 . Nineteen individuals volunteered to participate in the study in response to the email distribution made at CIC. A decision was made not to seek additional volunteers given that the final interviews were not resulting in new learnings and followed along the same themes as previous interviews.

The table below summarizes basic demographic about the research study participants, including gender and current retirement plans of study participants.

Table 2. Current Retirement Plans of Study Participants by Gender

\begin{tabular}{|c|c|c|c|}
\hline Current Retirement Plans & Male & Female & $\begin{array}{c}\text { Count } \\
\text { (Percentage) }\end{array}$ \\
\hline $\begin{array}{l}\text { Early Exiter - } \\
\text { Exit public service before meeting } \\
\text { the minimum requirements for } \\
\text { retirement. }\end{array}$ & 0 & 3 & $3(16 \%)$ \\
\hline $\begin{array}{l}\text { Early Retirees - } \\
\text { Retirement at or after age } 60 \text { with } \\
\text { two or more years of pensionable } \\
\text { service, or at } 55 \text { with } 30 \text { or more } \\
\text { years of pensionable service. }\end{array}$ & 4 & 6 & $10(53 \%)$ \\
\hline $\begin{array}{l}\text { Full Pensioners - } \\
\text { Retirement with maximum years of } \\
\text { pensionable service }\end{array}$ & 3 & 3 & $6(32 \%)$ \\
\hline count (Percentage) & $7(37 \%)$ & $12(63 \%)$ & $19(100 \%)$ \\
\hline
\end{tabular}

\subsection{Data Collection Method}

Qualitative data was collected through interviews with each individual participating in this research. Qualitative research interviews tend to be flexible, with an interest in seeking rich, detailed information and understanding the interviewee's point of view 
(Bryman and Bell, 2003). A semi-structured interview guide was used to direct the line of questioning for the interviews, and the use of this guide allowed for flexibility to adjust the emphasis of questions if a particular topic or issue raised by the interviewee is of particular relevance. The interview guide was tested with two individuals before the research began and this testing did not result in any significant changes to the questionnaire, but provided an opportunity for the researcher to anticipate where additional probing or clarification might be required during the interviews with study participants.

The majority of interviews were tape recorded with the permission of participants and subsequently transcribed. Detailed notes were taken in some cases where the interviewee did not want the interview recorded or if ambient noise interfered with the quality of the tape recording.

Eisenhardt (1989) notes that the freedom to adjust data collection instruments or case samples is a key feature of theory-building case research. A key criteria suggested by Eisenhardt (1989) in deciding whether to alter data collection is whether the change would provide for better grounding for the theory or to provide new theoretical insight. Questions for this research study were designed to understand each case (in as much detail as possible), while allowing for opportunities to probe specific areas of interest that emerge. In many cases, additional follow-up questions were used to probe and further understand the responses study participants gave.

The interview guide was designed to explore participant's conception/idea of "retirement" and current retirement intentions. These questions were asked at the beginning of the interview to provide context for the remainder of the discussion. In 
keeping with the focus of this research, participants were asked questions to understand how organizations can influence their retirement decisions, either encouraging them to remain in the workplace or to retire early. The interview guide used in this research study is included in Appendix B.

\subsection{Data Analysis}

In keeping with Eisenhardt (1989), the approach to data analysis included overlap of data analysis with data collection. This feature of the method for this research allows for flexibility in the data collection approach, either adjusting the interview guide or adding additional samples to further explore particular phenomena that have not been fully explained by the initial sample of cases.

Several techniques were used to support the parallel activities of data collection and analysis. Following each interview, notes to summarize striking observations or impressions from the interviews were recorded. Other methods of analysis suggested by Eisenhardt (1989) to build theory from case study research - within-case and cross-case analysis - were used. Within-case analysis was used to gain a deep understanding of each case and patterns within each case. A key supporting technique for this analysis includes summary write-ups reflecting the responses to the primary lines of inquiry based on the interview transcripts and notes. Key themes that were emerging from each interview along each of major questions on the interview guide were also extracted during the data collection period. In addition, at the end of each interview, interview transcripts were reviewed to confirm that the essence of the concepts that were being conveyed by the study participant had been accurately reflected. Summary phrases which captured this essence were recorded to begin to build the foundation for the final coding scheme. At the end of all 
interviews, the summary phrases related to each question were reviewed to identify common themes which were set as codes. These codes were entered in SPSS as a permanent record of the overall themes that emerged from the study as well as the themes from the interview with each individual study participant.

Cross-case analysis focused on identifying similarities across cases and examining subsets of the broader sample to identify themes or patterns that might be unique to specific categories of employees. For this aspect of the analysis, the study participants were segmented along two separate dimensions - by their retirement plans (eligibility for pension based on age and years of service) and the type of employer action that had caused consideration of retirement.

The cross-case analysis helped to identify concepts or constructs that are grounded in the data. The analysis was based on profiles of subsets of study participants which were contained frequency counts of the themes that emerged from the interview guide questions. Comparison of these profiles allowed for the identification of themes and trends that were particularly prominent or unique to a specific subset or segment of the overall study participants (e.g. individuals who planned to retire with 35 years of service or more versus those that planned to exit the public service before meeting the minimum requirements for pension eligibility without penalty).

Sections 4 and 5 present the results and discuss the findings of the study and include data tables which are based on the coding scheme to summarize and display the data for the reader's review. The data in the table is ordered by frequency count, beginning with the most frequently referenced concept or topic. Responses to each question are organized into several broad themes or categories which have supporting concepts or topics that emerged in the discussions with participants. 
Frequency counts are provided at both the concept/topic level, as well as the theme or category level. Note that the frequency count at the theme or category level is not a summation of the counts at the concept level. If study participants referenced two or more concepts which roll up to a single theme, the count at the theme level will be displayed as one, indicating that the one study participant referenced one or more concepts in relation to that theme.

\subsection{Shaping Hypotheses}

Theory-building case study research can produce results that are concepts, a conceptual framework, propositions or theories (Eisenhardt, 1989). This research has been undertaken with the goal of contributing to body of knowledge related to the factors that influence retirement decisions. The initial concepts, constructs and relationships between variables that result from the data analysis will be documented to serve as a starting point for more focused effort in building related theory.

Eisenhardt (1989) notes that this step of the process of building theory from case studies is highly iterative, using a technique that systematically compares the emergent frame (impressions, tentative themes, concepts, and possibly even relationships between variables) with the case data and testing the consistency between the two. Initial themes and concepts identified in the data analysis stage of the research will be reviewed in the context of case study data with the objective of determining whether there is evidence within each case that is consistent with the evolving theory. Cases that do not fit with the emerging theory will be examined to identify whether the theory can be refined to reflect this evidence. The concept of theoretical saturation discussed in relation to decisions related to increasing sample size also applies when iterating between theory and data. The iteration process between theory and data ends when minimal incremental improvements are being 
made to the theory (Eisenhardt, 1989). The output of this step of the research will be refined concepts, constructs, and potentially relationships between constructs.

\subsection{Linking Emergent Theory with Existing Literature}

The emergent theory from this case study research will be considered within the context of existing literature discussed in Section 1 of this paper. The goal is to identify whether the findings of this study are consistent with, or contrary to, the existing body of knowledge around factors that influence retirement decisions.

Given that there is a limited body of knowledge in this area, it is anticipated that this research will make a contribution to our understanding of the key constructs influencing the decision to retire early as well as the relationships between these constructs. To the extent that the findings are contrary to existing knowledge, further investigation will be required to understand the conflict and whether additional analysis will be required. Eisenhardt (1989) notes that linking results to the literature is crucial in theory-building from case study research, because findings are generated based on a very limited number of cases.

\subsection{Limitations}

There are a number of limitations of the method for this research that should be acknowledged at the outset. This section identifies these challenges and outlines how they have been addressed in this thesis. First, data collected through interviews can be subject to bias on the part of both interviewers and interviewees. Interviewers may seek out and pay attention to responses of interviewees that fit with preconceived ideas related to the research topic. Responses from interviewees may 
be distorted due to personal bias or the emotional state of the interviewee at the time of the interview (Patton, 2002). While it is difficult to eliminate all potential for bias, approaches that will be used in this research to mitigate potential bias include approaching the research from a theory-neutral perspective, and making attempts to make interviewees comfortable with the interview process and the confidentiality of the information shared.

Another potential weakness or limitation of building theory from case studies is that it may result in theory that is overly complex or specific to a relatively narrow phenomenon (Eisenhardt, 1989). Given the rich base of data collected through case study research, it may difficult for researchers to synthesize findings to identify the most important concepts or relationships between variables. In addition, the theory that results from case study research can also be narrow and specific to the phenomenon observed in cases under study. Eisenhardt (1989) suggests that while case study research will result in empirically valid theories, these theories may be modest in that they describe a specific phenomenon. The approach taken in this research (i.e. focus study on a relatively restricted number of concepts which have been identified through the literature review as potentially notable) should minimize concerns with respect to this issue.

A final limitation of this method relates to a common criticism of qualitative research which is that the findings are not generalizable. It is important to recognize that the goal of case study research, or other qualitative research methods, is not designed to produce findings that are representative of a population. The purpose of qualitative research is to generalize to theory rather than to populations (Bryman and Bell, 2003). As such, the findings of this research must be reviewed and judged in the context of the contribution that the emerging theory makes, using 
considerations of whether the theory is parsimonious, testable, and logically coherent (Eisenhardt, 1989). It should be noted that the sample was selected purposefully to develop concepts, constructs or theories that would permit generalizability to a key group of employees - older workers in the federal public sector.

\subsection{Relevance of this Research}

This research will make a contribution to the literature and will also be of interest to practitioners in the field for several reasons.

First, a closer examination of how organizations can influence the retirement decisions of older workers is very timely. Talent management, including retention of older workers, is one of the key issues that many organizations are currently focusing on, given that labour supply will constrict with the pending retirement of baby boomers. This research was designed to identify potential approaches organizations can use to delay the retirement of a large cohort of workers, many of whom occupy key leadership positions in organizations. It is anticipated that the results of this research will provide insights to help shape organizational policies and programs related to the employment of older workers.

This research is also relevant because it explores a topic in a relatively limited body of literature, where existing research contains contradictory theoretical perspectives on the role of organization factors in retirement decisions. While some researchers suggest that organization factors do have a role in early retirement and bridge employment decisions, others have suggested that organizational policies impact an individual's path to retirement in a limited way. This research has been designed to 
specifically explore the role that employers and organizational policies have on early retirement decisions.

Another important contribution of this research is that it will provide additional evidence related to early retirement and bridge employment decisions from the perspective of the key decision-maker - the individual approaching retirement. Much of the literature related to organization factors is written from other perspectives, either the employer's perspective or a broad system-wide perspective (e.g. lack of training for older workers is a barrier to continued employment). Given that the topic has been approached from differing perspectives, there is significant divergence in the factors that have been identified to date, and no single comprehensive framework of organizational variables exists. This research gives individuals a voice to convey what factors they have or are currently considering in making decisions related to early retirement and bridge employment and which factors can be influenced by organizations. 


\section{Results}

This section of the thesis has been organized to present the key findings from the interviews with study participants and to propose a list of factors under the control of employers that can potentially influence the retirement decisions of older workers. Section 4 begins with a summary of the meaning of retirement as expressed by study participants, as well as an overview of the activities that they plan to undertake following their retirement from the public service. The section continues with the presentation of all factors considered by study participants in setting their retirement plans, both personal and work-related. The focus on retirement factors is then followed with presentation of findings and analysis directly related to the focus of this research - the role of employers in influencing retirement plans.

\subsection{Meaning of Retirement}

Participants were asked "What does retirement mean to you?" Responses to this question are shown below in Table 3. The responses suggest that the meaning of retirement is associated with several broad concepts - gaining personal control, time of significant change, and apprehensive anticipation. 
Table 3. Meaning of Retirement - Key Themes

\begin{tabular}{|c|c|c|}
\hline Meaning of Retirement & $\begin{array}{l}\text { Number of } \\
\text { Responses }\end{array}$ & $\begin{array}{c}\text { Percentage of } \\
\text { Cases } \\
(n=19)\end{array}$ \\
\hline Gaining personal control & 16 & $84.2 \%$ \\
\hline Time for personal interests & 10 & $52.6 \%$ \\
\hline Freedom to make choices & 7 & $36.8 \%$ \\
\hline Activities under personal control & 6 & $31.6 \%$ \\
\hline Expand activities outside work & 3 & $15.8 \%$ \\
\hline Remaining busy & 2 & $10.5 \%$ \\
\hline Time of significant change & 14 & $73.7 \%$ \\
\hline New phase of life & 7 & $36.8 \%$ \\
\hline Opportunity and potential & 4 & $21.1 \%$ \\
\hline Positive anticipation & 4 & $21.1 \%$ \\
\hline Career change or shift & 3 & $15.8 \%$ \\
\hline Achievement and reward & 2 & $10.5 \%$ \\
\hline Apprehensive anticipation & 5 & $26.3 \%$ \\
\hline Closer to end of life & 3 & $15.8 \%$ \\
\hline Apprehensive anticipation & 2 & $10.5 \%$ \\
\hline Loss & 1 & $5.3 \%$ \\
\hline
\end{tabular}

Nearly $85 \%$ of participants see retirement as an opportunity to gain personal control of time and activities. As noted by the diversity of responses included in this category, this control is manifested in a number of ways. For some, retirement is about having time for personal interests. For others, retirement is more closely associated with having freedom and control over their activities, a shift from their working life when a significant portion of their time was dedicated to their employer. In some cases, individuals saw retirement as an opportunity to expand activities, and for others, it was a time to remain busy while doing different things.

"To me retirement means not having to work for another employer and having the full 24 hours of my day to do things I am interested in doing. That's it really."

- Female that plans to retire at age 58, two years before eligibility for a full pension 
Another significant theme that emerged from discussions with participants of the study is that retirement is a time of significant change. Nearly three-quarters of participants responded in a way that suggested that retirement would be a significant change for them in a very positive way - a new phase of life, an opportunity, and potentially even a career change or shift.

For most participants, retirement had a very positive association; however, approximately one-quarter of participants noted an apprehension towards retirement. For some, it was an indication that they were closer to the end of their lives and that it was time to focus on things that really mattered for their remaining years. Two individuals recognized that retirement was an important step or milestone but admitted that they were scared or apprehensive about this stage of their lives. For one individual retirement had a connotation of loss, explained as a loss of contacts and status associated with the work environment.

Participants were also asked "What activities do you plan to do when you retire?" The responses to this question fall into four broad categories - leisure, work, community and learning, as summarized in Table 4 below. 
Table 4. Planned Retirement Activities - Key Themes

\begin{tabular}{|c|c|c|}
\hline Planned Retirement Activities & $\begin{array}{l}\text { Number of } \\
\text { Responses }\end{array}$ & $\begin{array}{c}\text { Percentage of } \\
\text { Cases } \\
(n=19)\end{array}$ \\
\hline Leisure & 19 & $100 \%$ \\
\hline Travel and tourism & 14 & $73.7 \%$ \\
\hline Outdoor activities & 10 & $52.6 \%$ \\
\hline Hobbies & 10 & $52.6 \%$ \\
\hline More time on current interests & 9 & $47.4 \%$ \\
\hline Time with friends & 3 & $15.8 \%$ \\
\hline Vacation and rest & 3 & $15.8 \%$ \\
\hline Other leisure & 4 & $21.1 \%$ \\
\hline Work & 15 & $78.9 \%$ \\
\hline Maybe & 6 & $31.6 \%$ \\
\hline Definitely & 4 & $21.1 \%$ \\
\hline Part-time & 6 & $31.6 \%$ \\
\hline Not for money & 3 & $15.9 \%$ \\
\hline Not to any extent & 1 & $5.3 \%$ \\
\hline Related to current work & 4 & $21.1 \%$ \\
\hline Not related to current work & 1 & $5.3 \%$ \\
\hline Community & 10 & $52.6 \%$ \\
\hline Volunteer & 7 & $36.8 \%$ \\
\hline Volunteer - resume prior activity & 3 & $15.9 \%$ \\
\hline Family & 6 & $31,6 \%$ \\
\hline Spending time & 3 & $15.9 \%$ \\
\hline Providing support & 3 & $15.9 \%$ \\
\hline Learning & 6 & $31.6 \%$ \\
\hline
\end{tabular}

All 19 participants in the study intend to occupy at least a portion of their time on leisure activities. The most frequently referenced leisure activities included travel; outdoor activities such as hiking, skiing and sailing; and personal hobbies such as reading, writing and art. Others intend to spend time with friends or devote time to vacation and rest. Just under half of individuals indicated that they will spend more time on current interests, not necessarily starting new ones in their retirement. 
"I would like to do more traveling, spending time in my garden, reading more, things I really have to shoehorn into my life right now."

- Female with plans to retire at age 60 with more than 35 years of service

Nearly four in five participants also cited work as an activity that they plan on doing after retirement. Discussions about their plans for working after retirement often resulted in further clarifications or qualifiers to the amount of time that they planned to work or the type of work that they would be doing, as noted in the table. Six of the 15 individuals expressing an interest in working after retirement indicated that maybe they would work after retirement. Four of the 15 individuals expressed more definite plans, stating they would definitely work. Six individuals indicated that they planned to work part-time while others did not explicitly state their plans. One-fifth suggested that they might work, but not for the money. One individual thought they might work, but not to any great extent. Several thought that their work after retirement would be related to their current work, while one individual indicated that their plan would be to pursue work not related to their current field.

Discussions with study participants indicate that just over half plan to give back to the community during their retirement. Of the ten individuals that indicated a plan to volunteer, three of these individuals reported that they will be resuming previous volunteer activities that they found they no longer had time for. For these individuals, volunteering is seen as an opportunity to contribute and respond to the need in the community.

Almost one in three of the individuals identified activities with family as part of their retirement plans. For $16 \%$ of individuals that will mean spending time with their family and another $16 \%$ of individuals suggested that they would be providing support to their family, in some cases, to aging parents. 
Finally, nearly one-third of individuals reported that they had plans for learning. In several cases, individuals planned to study at the university level, while other indicated that they would take courses related to their hobbies.

In summary, the majority of study participants have a very positive outlook of retirement and look forward to an opportunity to take greater control of their lives and daily activities. While leisure is an important planned activity for the retirement phase of their lives, working and learning will not necessarily cease for many individuals who participated in the study. Many will continue to work, either in paid or volunteer roles and several will study, continuing to expand their knowledge and skills during the later stages of their life.

\subsection{Factors Considered in Setting Retirement Plans}

Study participants were asked the question "What factors did you or will you consider when setting your retirement plan?" Table 5 summarizes the key themes that emerged from the analysis of the responses to this question. At the summary level, the factors noted were financial, life considerations, work-related and health. 
Table 5. Retirement Plan Factors - Key Themes

\begin{tabular}{|c|c|c|}
\hline Retirement Plan Factors & $\begin{array}{l}\text { Number of } \\
\text { Responses }\end{array}$ & $\begin{array}{c}\text { Percentage of } \\
\text { Cases } \\
(n=19)\end{array}$ \\
\hline Financial & 15 & $78.9 \%$ \\
\hline Being financially ready & 14 & $73.7 \%$ \\
\hline Need to earn an acceptable level of pension & 4 & $21.1 \%$ \\
\hline Life Considerations & 14 & $73.7 \%$ \\
\hline Coordinating with partner's retirement plans & 12 & $63.2 \%$ \\
\hline Family considerations & 6 & $31.6 \%$ \\
\hline Other life decisions (moving, learning) & 2 & $10.5 \%$ \\
\hline Work-Related & 12 & $63.2 \%$ \\
\hline Work environment - satisfied & 4 & $21.1 \%$ \\
\hline Work environment - dissatisfied & 4 & $21.1 \%$ \\
\hline Have served and made my contribution & 4 & $21.1 \%$ \\
\hline Finding the right transition to retirement & 4 & $21.1 \%$ \\
\hline Mitigate impact of work on health & 3 & $15.8 \%$ \\
\hline $\begin{array}{l}\text { Open to staying longer and seeking } \\
\text { opportunities }\end{array}$ & 1 & $5.3 \%$ \\
\hline $\begin{array}{l}\text { Other (to be in control of activities, to do other } \\
\text { activities as soon as possible) }\end{array}$ & 2 & $10.5 \%$ \\
\hline Health & 7 & $36.8 \%$ \\
\hline Retire while have health & 4 & $21.1 \%$ \\
\hline Health & 3 & $15.8 \%$ \\
\hline
\end{tabular}

The most common factor noted by study participants was financial, identified by nearly $80 \%$ of individuals. This was often expressed in a broad sense as being financially ready to retire, in terms of having sufficient pension to cover off anticipated expenses during their retirement years. In some cases, responses were more specific in suggesting that it was important for study participants to work until they had an acceptable level of pension, making trade-offs between what pension would be earned by remaining as an employee for an extended period of time. 
Life considerations, related to family and major life decisions, were also noted as being important factors in setting retirement plans for nearly three-quarters of study participants. In this category, the most critical consideration in setting individual retirement plans was coordinating with partner's retirement plans. Two in three individuals reported this as a factor in setting their retirement plan. Most often, individuals were looking to minimize the amount of time that one spouse would be retired and the other would be working. Another life consideration reported as a factor in setting retirement plans was family considerations, including support to aging parents and children. Other major life decisions included in this group were decisions around where to live and whether to pursue continued learning.

The next important category of factors considered in setting retirement plans are workrelated, cited by nearly two-thirds of participants. Level of satisfaction with the work environment was noted as a consideration in setting retirement plans, with four reporting that their current satisfaction with the workplace is a consideration and another four suggesting that dissatisfaction with the work environment is a factor in their mind. Related to both work and health, almost one in five respondents indicated that a factor considered in their retirement plan was to mitigate the impact of work on their health. Another factor that appeared to be considered was whether individuals felt they had made a sufficient contribution as a public servant, with one in five stating that they felt by the time of their planned retirement, they would have served the public for a sufficient time.

"Apart from that what I considered was the rate of the job, the pace that is here, just the actual idiosyncrasies of being a public servant and how that impacts and kind of saying I will continue to give my best for next years, but after that I will have done my share and I will have served Canadians for as long as I can with my best focus."

- Female who plans to retire at age 58 
Another consideration reported by just over $20 \%$ of study participants was to find the right transition to retirement, whether that is opportunities to move gradually into retirement with part-time work or opportunities to continue to keep busy after retirement with personal or volunteer activities.

The final category of factors affecting retirement plans is health. About one-third of participants indicated health as a factor in setting their retirement plan. For some, it is important to retire while they have their health to enjoy retirement. For others, retirement is necessary to mitigate the impact of work stresses on their health.

There is a positive you are going to, and positive of not going through as much stress, worrying about your health as you get older. When you see how much more relaxed you are after 1, 2, 3 weeks off, you come back to work and have a feeling of well-being and you are back at work for 7 days and you say "Oh my god it feels like I have never even had a holiday." So, the work environment can be very stressful, juggling a number of issues and sometimes the type of work you are going can be very negative, if you are always battling for a result and it is difficult to get that result, it can be very draining.

- Female who plans to leave at age 54 with 30 years of service

While individual-related factors such as financial, life considerations and health are important considerations in setting retirement plans, the analysis suggests that workrelated considerations are also considered by a notable proportion of individuals in setting their retirement plans.

\subsection{Employer Actions and the Impact on Retirement Plans}

Participants were asked a series of questions to better understand whether their employer had taken any actions that had either encouraged them to consider retirement or to consider staying beyond their retirement eligibility date. Participants were also asked what their employer could do to get them to stay beyond their current planned retirement date. 
This section of the report provides an overall summary of the themes that emerged from the discussions with study participants on these topics.

\subsubsection{Summary of Themes Related to Employer Actions and Impact on Retirement Plans}

\subsubsection{Actions That Have Caused Individuals to Consider Retirement}

Participants were asked the following questions "What has your employer done that has encouraged you to consider retirement? What has your employer not done that has encouraged you to consider retirement?" An analysis of the responses to these questions demonstrates that participants fit into one of four categories with respect to the role of employer action on retirement considerations, as illustrated in Figure 6 below. A summary of the responses are provided in Table 6.

Figure 6: Type of Employer Actions Causing Retirement Considerations

Q. What has your employer done that has encouraged you to consider retirement? What has your employer not done that has encouraged you to consider retirement?

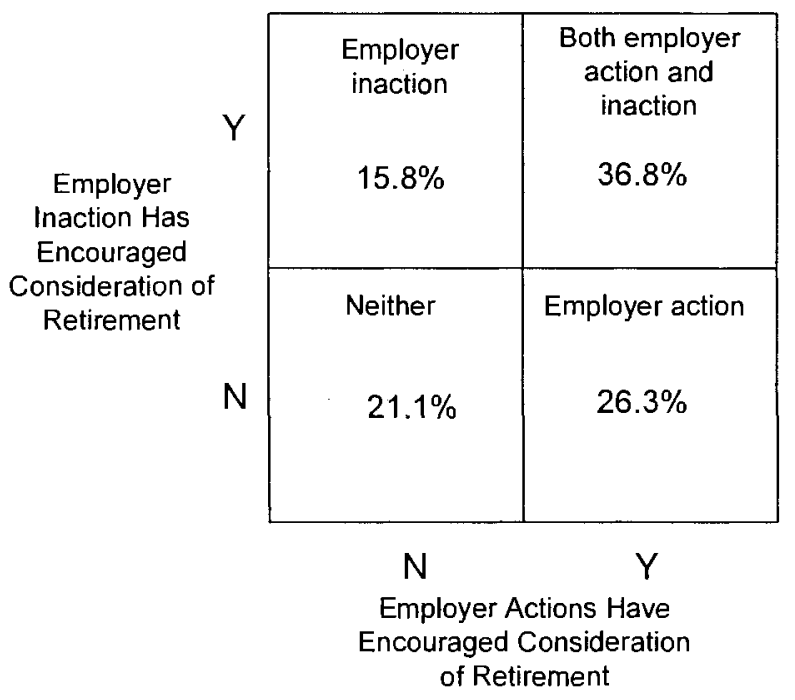


Participants reported that there are forces under the control of their employer which have encouraged them to retire. Nearly two-thirds of participants reported something that their employer has done that has encouraged them to consider retirement, either an action $(26.3 \%)$ or a combination of action and inaction (36.8\%). Just over half reported that there is something that their employer has not done that has encouraged them to consider retirement, either inaction alone $(15.8 \%)$ or inaction in combination with direct actions $(36.8 \%)$. A notable finding is that about $20 \%$ of the individuals participating in the study reported that their employer did not affect their retirement plans.

Finally, while many study participants specifically mentioned during the interviews that while employer action or inaction was causing them to consider retirement, nearly $40 \%$ of individuals specifically mentioned that their employer is not influencing or pushing them to retire (i.e. pushing them out of the workforce).

Three themes emerged in the analysis of direct actions that employers take that encourage individuals to consider retirement - an imbalance between work demands and feeling of accomplishment; the design of benefit programs; and use of policies and practices that cause dissatisfaction. Detailed findings related to these themes are noted in Table 6 below. 
Table 6. Employer Actions That Have Encouraged Retirement - Key Themes

\begin{tabular}{|c|c|c|}
\hline $\begin{array}{l}\text { Employer Actions That Have Encouraged } \\
\text { Retirement }\end{array}$ & $\begin{array}{l}\text { Number of } \\
\text { Responses }\end{array}$ & $\begin{array}{c}\text { Percentage of } \\
\text { Cases } \\
(n=19)\end{array}$ \\
\hline $\begin{array}{l}\text { Direct action that has encouraged me to } \\
\text { consider retirement }\end{array}$ & 12 & $63.2 \%$ \\
\hline $\begin{array}{l}\text { Many work demands, not } \\
\text { enough results or rewards }\end{array}$ & 6 & $31.6 \%$ \\
\hline No sense of progress or accomplishments & 5 & $26.3 \%$ \\
\hline Work is demanding or stressful & 3 & $15.8 \%$ \\
\hline Need to adapt to change & 2 & $10.5 \%$ \\
\hline Pressures external to the department & 1 & $5.3 \%$ \\
\hline $\begin{array}{l}\text { Benefit program design provides incentive to } \\
\text { retire }\end{array}$ & 5 & $26.3 \%$ \\
\hline Provide a benefit package & 4 & $21.1 \%$ \\
\hline Provide pre-retirement training course & 2 & $10.5 \%$ \\
\hline Dissatisfaction with policies and practices & 5 & $26.3 \%$ \\
\hline $\begin{array}{l}\text { Unhappy with style of management or } \\
\text { management practices }\end{array}$ & 4 & $21.1 \%$ \\
\hline Bilingual requirements & 2 & $10.5 \%$ \\
\hline
\end{tabular}

Just over $30 \%$ of participants provided comments that suggested that there were many work demands and stresses but not enough results or rewards to balance out these demands. More specifically, one-quarter of study participants suggested that the absence of progress or accomplishments in their work leads them to consider retirement.

"Nothing seems to change, and we go through all these studies and we had a bunch of them and nothing really seems to change. You get your hopes up and nothing changes. That's a difficult challenge..... it is general feeling of the way things are going that affects my decision. And it a sense rather than a reality. Lots of talk and no sense of progress."

- Female who plans to retire at age 55 with 32 years of service

Others identified several sources of stresses or demands that encouraged them to consider retirement. These included the volume of work, the need to respond to constant change, as well as demands from central agencies. 
Another encouragement to retire identified by one in four respondents is the benefit program offered by the Government of Canada. One in five participants noted that their employer offers a good pension plan which allows people to retire with financial security at a relatively young age. Two participants mentioned that the pre-retirement training course helps people start thinking about retirement.

Finally, about one-quarter of participants suggested that some policies or practices adopted by their employer or managers within the department have encouraged them to consider retirement. Examples of these policies and practices include emphasis on rules which restricts managers' ability to manage, use of consultants, poor communications with staff, and sending near-retirees for French training.

In addition to what their employer has done, participants also identified a number of things that their employer has not done which has encouraged them to consider retirement. Three themes emerged from these discussions and are summarized below in Table 7 - not proactively engaging experienced workers, not using a strategic approach to plan for pending retirements, and not appreciating and respecting experienced workers. 
Table 7. Actions Employer Has Not Taken That Has Encouraged Consideration of Retirement - Key Themes

\begin{tabular}{|l|c|c|}
$\begin{array}{l}\text { Actions Employer Has Not Taken That Has } \\
\text { Encouraged Consideration of Retirement }\end{array}$ & $\begin{array}{c}\text { Number of } \\
\text { Responses }\end{array}$ & $\begin{array}{c}\text { Percentage of } \\
\text { Cases } \\
\text { (n=19) }\end{array}$ \\
$\begin{array}{l}\text { Inaction on the part of my employer has } \\
\text { encouraged me to consider retirement }\end{array}$ & $\mathbf{1 0}$ & $\mathbf{5 2 . 6 \%}$ \\
\hline $\begin{array}{l}\text { Not proactively engaging } \\
\text { experienced workers }\end{array}$ & 8 & $42.1 \%$ \\
\hline $\begin{array}{l}\text { Not engaging me in a discussion } \\
\text { Not understanding or responding to the needs } \\
\text { of older workers }\end{array}$ & 4 & $21.1 \%$ \\
\hline \begin{tabular}{l} 
Not doing things to get people to stay \\
\hline $\begin{array}{l}\text { Not using a strategic approach to plan for } \\
\text { pending retirements }\end{array}$
\end{tabular} & 4 & $21.1 \%$ \\
\hline $\begin{array}{l}\text { Not proactively managing to retain corporate } \\
\text { knowledge }\end{array}$ & 4 & $15.8 \%$ \\
\hline $\begin{array}{l}\text { Not planning for or managing pending } \\
\text { retirements }\end{array}$ & 4 & $21.1 \%$ \\
\hline $\begin{array}{l}\text { Not appreciating and respecting } \\
\text { experienced workers }\end{array}$ & 2 & $21.1 \%$ \\
\hline $\begin{array}{l}\text { Not considering the needs of employees in job } \\
\text { assignments }\end{array}$ & 2 & $10.5 \%$ \\
\hline $\begin{array}{l}\text { Not demonstrating that long-serving employees } \\
\text { are valued }\end{array}$ & 1 & $10.5 \%$ \\
\hline
\end{tabular}

Just over $40 \%$ of participants indicated that they are encouraged to consider retirement

because their employer is not proactively engaging experienced workers. Specifically, one in five individuals would like to be engaged in a discussion about how best to use their talents until they retire, and one in five feel that their employer either does not understand the needs of older workers or is not responding to these needs. Examples of these needs might be to move out of stressful positions, to be promoted, to provide more flexibility in allowing for leaves to give rest and rejuvenation. 
Several participants (one in five) reported being frustrated that their employer is not taking a strategic approach to planning for pending retirements. These participants are discouraged that their employer is not proactively managing the transfer of corporate knowledge from those that are retiring and not planning for pending retirements of older workers. This lack of action is a de-motivator for some individuals and has caused them to think about retiring.

(There is) no evidence that they would like people to stay. One of the things that is happening is that people are leaving and almost immediately the next day, coming back on contracts. What could they do to keep people? Obviously, if they bring them back on contract, it means that they can't afford the loss of capital, knowledge, expertise, corporate memory. They can't afford to lose it but have they done anything to retain it and transfer it? Has anyone ever approached me and asked me to help pass on what little I might have learned in 35 years with CIC? No!

- Male who plans to leave with 35 years of service

Finally, two participants suggested that they are considering retirement because their employer does not appreciate and respect experienced workers. These individuals do not believe that their needs are considered in job assignments and in one case, it appears to them that long-serving employees are not valued.

\subsubsection{Actions That Have Caused Individuals to Consider Staying Beyond Their Retirement Eligibility Date}

Participants were also asked "What has your employer done that has encouraged you to stay beyond your retirement eligibility date?" The results are provided in Table 8 below. Nearly two-thirds of participants indicated that an action by their employer has caused them to consider staying beyond their retirement eligibility date, including providing interesting and rewarding work; demonstrating that they are valued; and designing work programs and benefits with an incentive to stay. Approximately one-third of participants indicated that their employer is not taking any action to encourage them to stay longer, including two 
participants that suggested that their employer has not had any discussions with them about staying longer.

"I haven't heard anything (that my employer has done to get me to stay). Annually executives are asked to fill in their career plans, aspirations and I keep pointing out that I am leaving in a couple of years and I guess the only thing I hear is a decision in terms of monetary, my premium pay, performance pay."

- Male who plans to retire at age 60 with 28 years of service

Two in five participants feel that their desire and interests for work are being met and this had encouraged them to stay beyond their retirement eligibility. Specifically, participants identified enjoyable work; assignments that met their needs and interests; and opportunities to make a difference.

About $30 \%$ of participants indicated that work programs and benefits offered by their employer encourage them to stay in the workplace as well. Examples of programs and benefits identified by participants include the pre-retirement transition program, income averaging program, pension plan, extra vacation time at higher years of service, and alternative work arrangements (compressed work weeks, job sharing, tele-working).

Finally, just over $20 \%$ of participants suggested that they were encouraged to consider staying longer because they felt that their employer demonstrated that they were valued. Examples of actions reported by participants included being asked to stay in jobs for longer than originally assigned or telling employees that they are glad that they have stayed beyond their eligibility date. 
Table 8. Employer Action That Has Encouraged Consideration of Staying Beyond Retirement Eligibility Date - Key Themes

\begin{tabular}{|c|c|c|}
\hline $\begin{array}{l}\text { Employer Action That Has Encouraged } \\
\text { Consideration of Staying Beyond } \\
\text { Retirement Eligibility Date }\end{array}$ & $\begin{array}{l}\text { Number of } \\
\text { Responses }\end{array}$ & $\begin{array}{c}\text { Percentage of } \\
\text { Cases } \\
(n=19)\end{array}$ \\
\hline $\begin{array}{l}\text { Some action that has encouraged me to } \\
\text { consider staying }\end{array}$ & 12 & $63.2 \%$ \\
\hline $\begin{array}{l}\text { Provided interesting and } \\
\text { rewarding work }\end{array}$ & 8 & $42,1 \%$ \\
\hline Provided jobs/assignments that meet my needs & 4 & $21.1 \%$ \\
\hline Provided enjoyable work & 4 & $21.1 \%$ \\
\hline Gave me opportunities to make a difference & 3 & $15.8 \%$ \\
\hline $\begin{array}{l}\text { Designed work programs and benefits as } \\
\text { incentive to stay }\end{array}$ & 6 & $31.6 \%$ \\
\hline Offered work programs to meet my needs & 3 & $15.8 \%$ \\
\hline Designed benefit programs with incentive to & 3 & $15.8 \%$ \\
\hline Demonstrated that I am valued & 4 & $21,1 \%$ \\
\hline Not taking action to encourage me to stay & 7 & $36.8 \%$ \\
\hline Haven't done anything & 6 & $31.6 \%$ \\
\hline There have been no discussions with me & 2 & $10.5 \%$ \\
\hline
\end{tabular}

\subsubsection{Actions An Employer Can Take}

Participants were asked "What could your employer do to get you to stay beyond your current planned retirement date?" Table 9 below provides a summary of participant responses to this question. The majority $(84 \%)$ of participants suggested that there was something their employer could do to get them to consider staying beyond their current planned retirement date, while about $16 \%$ indicated that very little could be done. Just over $20 \%$ of participants suggested that nothing could be done to get them to change their current plans. Note that one participant who suggested that nothing could be done to get them to stay subsequently suggested that an overseas assignment could possibly change their plans. 
Table 9. Can Employer Actions Influence Retirement Plans? - Key Themes

\begin{tabular}{|l|c|c|}
\hline $\begin{array}{l}\text { Can Employer Actions Influence } \\
\text { Retirement Plans? }\end{array}$ & $\begin{array}{l}\text { Number of } \\
\text { Responses }\end{array}$ & $\begin{array}{c}\text { Percentage } \\
\text { of Cases } \\
\text { ( } \mathbf{n = 1 9 )}\end{array}$ \\
\hline $\begin{array}{l}\text { There is something my employer can do } \\
\text { Very little can be done }\end{array}$ & 16 & $84.2 \%$ \\
\hline Nothing can be done & 3 & $\mathbf{1 5 . 8 \%}$ \\
\hline
\end{tabular}

\section{Employer Actions to Influence Retirement Plans}

Participants identified a wide range of actions that their employer could take which could potentially influence their retirement plans, as summarized in Table 10 below.

Table 10. Actions an Employer Can Take to Influence Retirement Plans - Key Themes

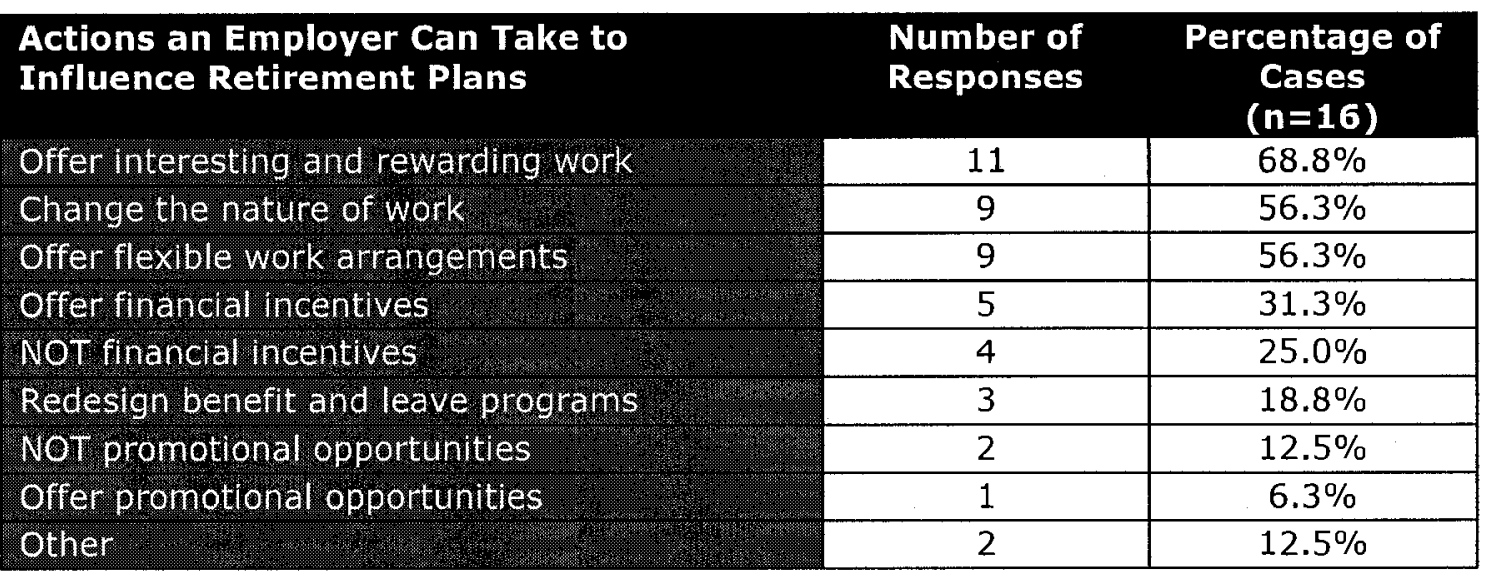

The three most frequently mentioned employer actions cited by the 16 participants who were open to changing their retirement plans were offering interesting and rewarding work $(68 \%)$; changing the nature of work (56\%); and offering flexible work arrangements $(56 \%)$. Given the high number of responses in these categories, these topics will be further explored later in this section.

Participants also mentioned financial incentives and promotions as well, however, the view on these two potential incentives was mixed. Within the group of participants that were 
open to adjusting their retirement plans, $31 \%$ were interested in financial incentives, while $25 \%$ explicitly stated that they were not interested in financial incentives. The view of promotions as an incentive to stay was also split, with only one individual suggesting that this action could potentially adjust their retirement plans and two individuals indicating that they were not interested in promotions.

Approximately $18 \%$ of participants suggested changes to benefit and leave programs as an incentive to influence their retirement plans, including more vacation or more flexible leaves for an extended period of time.

"I really think that its important that executives be offered time off without affecting their ability to hold the job or to take sort of a sabbatical.... it seems to be no way to get off the treadmill, once you are in a busy, difficult job, there seems to be no way to get off the treadmill and take a break, because people are counting on you being there to guide staff and to bring your corporate memory and to provide leadership on difficult issues."

- Female who plans to leave at age 54 with 30 years of service

In the other category, individuals suggested that waiver of language testing requirements for near-retirees and having opportunities to work with "people I enjoy" could possibly influence their retirement plans.

\section{Offer Interesting and Rewarding Work}

As noted earlier, the majority of participants $(68 \%)$ would reconsider their current retirement plans if they were offered interesting and rewarding work. Further examination of this data (see Table 11) gives more details on what respondents who gave this response mean. 
Table 11. Potential Action an Employer Can Take to Influence Retirement Plans: Offer Interesting and Rewarding Work - Key Themes

\begin{tabular}{|c|c|c|}
\hline $\begin{array}{l}\text { Potential Action an Employer Can Take to } \\
\text { Influence Retirement Plans }\end{array}$ & $\begin{array}{c}\text { Number of } \\
\text { Responses }\end{array}$ & $\begin{array}{c}\text { Percentage of } \\
\text { Cases } \\
(\mathbf{n = 1 6 )}\end{array}$ \\
\hline Offer interesting and rewarding work & 11 & $68.8 \%$ \\
\hline Offer work that is of interest & 6 & $37.5 \%$ \\
\hline Offer overseas assignment & 4 & $25.0 \%$ \\
\hline Offer exceptional assignment & 4 & $25.0 \%$ \\
\hline Offer work that makes a difference & 3 & $18.8 \%$ \\
\hline
\end{tabular}

Almost $40 \%$ of the individuals who gave this response expressed a need to have work that matches their interest and makes a difference. About one-quarter of individuals who were willing to adjust their retirement plans were seeking exceptional assignments.

"For me, though, when you talk about the big question of what would keep me 2 or more years, it's got to be a very heavy hitting project, something really big. It's too big to turn down. It's not about the money, we have enough money. Lifestyle money is not an issue."

- Female who plans to retire at age 53

One-quarter of individuals are specifically seeking overseas assignments. One in five want to be given work to do that makes a contribution.

\section{Change the Nature of Work}

As noted previously, just over half of the individuals who were willing to adjust their retirement plans would do so if the nature of work changed. Details on how respondents felt this could be done are outlined below (Table 12). 
Table 12. Potential Action an Employer Can Take to Influence Retirement Plans: Change the Nature of Work - Key Themes

\begin{tabular}{|c|c|c|}
\hline $\begin{array}{l}\text { Potential Action an Employer Can Take to } \\
\text { Influence Retirement Plans }\end{array}$ & $\begin{array}{l}\text { Number of } \\
\text { Responses }\end{array}$ & $\begin{array}{c}\text { Percentage of } \\
\text { Cases } \\
(n=16)\end{array}$ \\
\hline Change the nature of work & 9 & $56.3 \%$ \\
\hline Change how work is managed & 4 & $25.0 \%$ \\
\hline Allow a fundamental shift in duties & 4 & $25.0 \%$ \\
\hline Reduce the stress & 3 & $18.8 \%$ \\
\hline Offer a coaching and mentoring role & 2 & $12.5 \%$ \\
\hline
\end{tabular}

The type of change that they sought varied with some envisioning a change within the realm of their current role with respect to how work was managed $(25 \%)$ to reducing associated stress $(18 \%)$. Others were seeking a fundamental shift in duties $(25 \%)$ away from their current role to another role where they could apply their corporate knowledge and still be contributing to the organization. About $12 \%$ of participants proposed the idea of moving into a coaching and mentoring role as a way to entice them to stay beyond their current planned retirement date.

\section{Offer Flexible Work Arrangements}

As noted at the beginning of this section, flexible work arrangements was reported as an incentive that would potentially adjust the retirement plans of just over half the individuals who expressed an interest in entertaining offers from their employer to stay. Table 13 provides details on the type of flexible work arrangements identified by respondents. 
Table 13. Potential Action an Employer Can Take to Influence Retirement Plans: Offer Flexible Work Arrangements - Key Themes

\begin{tabular}{|l|c|c|}
\hline $\begin{array}{l}\text { Potential Action an Employer Can Take to } \\
\text { Influence Retirement Plans }\end{array}$ & $\begin{array}{c}\text { Number of } \\
\text { Responses }\end{array}$ & $\begin{array}{c}\text { Percentage of } \\
\text { Cases } \\
(\mathbf{n = 1 6 )}\end{array}$ \\
\hline Offer flexible work arrangements & 9 & $56.3 \%$ \\
\hline Work reduced hours & 7 & $43.8 \%$ \\
\hline Work only part of the year & 2 & $12.5 \%$ \\
\hline Work from home & 2 & $12.5 \%$ \\
\hline NOT flexible work arrangements & 1 & $6.3 \%$ \\
\hline
\end{tabular}

Many are looking to reduce the total number of hours worked in a year, either reduced

hours each week (44\%) or by working full-time for part of the year (13\%).

"Us human beings need to consider to grow, need to continue to grow and we need to feel worthwhile. So for me some of the key factors is how can I have work that is meaningful to me but that I can choose to work only 3-4 days a week and where I can apply my knowledge and continue to grow. And the other thing that I want to eliminate in my work is the part that nobody really likes, the red tape and you don't want to deal with the bureaucratic aspects of work, you just want to have work that you love and just focus your energy on that. In other words, you want to create the healthiest possible environment for your self."

- Female who plans to retire early with 28 years of service

It seems to me that management has to be flexible, I know what works for me and I know it's not going to be the same for everybody else...the key has to be flexibility and trying to find something that speaks to individual employees. Because as a fulltime employee you are locked in. You get your however many weeks of holidays you earned and certain hours you work every week. I think it is very liberating for people to do something that speaks to their own circumstances better. If you are a golfer, you don't want to work in the summer but you are happy to work 10 months of the year, or the reverse. It's an opportunity for an employer to offer a work package that is more tailored to the employee.

- Female who plans to retire at age 60 with over 35 years of service

Two individuals were seeking opportunities to work from home. While flexible work

arrangements were an incentive for many individuals, one participant reported that this

would not be an incentive in their case. 


\subsubsection{Categories of Employees Whose Retirement Decisions Were Affected by Employer Actions}

Summary results were presented to identify action (or inaction) that employers have taken which has caused study participants to consider retirement. This section presents a further analysis of participant responses to these questions along two different lines. The first line of inquiry and analysis segments the study participants into four different categories depending upon what types of employer actions have impacted their retirement plans. The four categories of employer actions are direct employer actions; employer inaction; both direct employer action and inaction; and no employer action (or inaction) has affected my retirement plans. This segmentation provides a better understanding of how different types of actions by employers are causing employees to consider retirement and what, if anything, employers can do to persuade employees to stay beyond their current planned retirement date.

The second line of inquiry and analysis separates the study participants in three different categories depending upon when they intend to leave or retire from the public service. The first category is individuals who plan to retire before reaching the point of retirement eligibility as defined by the Public Service Superannuation Act ("early exiters"). The second category includes individuals who plan to retire at or after the point of retirement eligibility ("early retirees"). The final category includes individuals that plan to retire with a full pension at or beyond 35 years of service ("full pensioners"). This line of inquiry also examines what might be driving these employees to consider retirement and what can be done to encourage them to stay. 


\subsubsection{Analysis of Results by Type of Employer Action that Has Caused Consideration of Retirement}

The following analysis segments the study participants into four different categories based on what type of employer action has caused them to consider retirement, as presented in Figure 6 in section 4.3.1.1.

As depicted in Figure 6, nearly $80 \%$ of participants reported that either action or inaction or both on the part of their employer has encouraged them to consider retirement. This is much higher proportion of individuals than reported work-related factors had influenced their retirement plans. This pattern of response suggests that while work-related factors are not as important as financial or life considerations in setting a retirement plan, employer actions can cause an employee to think differently about their retirement plan.

Table 14 below provides a summary of employer action and inaction that has caused nearly $80 \%$ of study participants to think about retirement. 
Table 14. Employer Action and Inaction Leading to Consideration of Retirement - Key Themes by Category

\begin{tabular}{|c|c|c|c|c|}
\hline Category & $\begin{array}{l}\text { Both action and } \\
\text { inaction by } \\
\text { employer } \\
(n=7)\end{array}$ & $\begin{array}{l}\text { Direct actions } \\
\text { by employer } \\
(n=5)\end{array}$ & $\begin{array}{l}\text { Inaction on the } \\
\text { part of the } \\
\text { employer } \\
(n=3)\end{array}$ & $\begin{array}{l}\text { My employer } \\
\text { has not } \\
\text { affected my } \\
\text { retirement } \\
\text { consideration } \\
(n=4)\end{array}$ \\
\hline $\begin{array}{l}\text { An employer action has caused } \\
\text { me to consider retirement }\end{array}$ & $100 \%$ & $100 \%$ & & \\
\hline $\begin{array}{l}\text { Wany work demands, not } \\
\text { enough results or rewards }\end{array}$ & $42.9 \%$ & $60.0 \%$ & - & - \\
\hline $\begin{array}{l}\text { Benefft program design } \\
\text { provides incentive to retire }\end{array}$ & $42.9 \%$ & $40.0 \%$ & - & - \\
\hline $\begin{array}{l}\text { Dissatisfaction with policies } \\
\text { and practices }\end{array}$ & $71.4 \%$ & $0 \%$ & - & - \\
\hline $\begin{array}{l}\text { Inaction on the part of my } \\
\text { employer has caused me to } \\
\text { consider retirement }\end{array}$ & $100 \%$ & - & $100 \%$ & - \\
\hline $\begin{array}{l}\text { Not proactuely engaging } \\
\text { expertenced workers }\end{array}$ & $71.4 \%$ & - & $100.0 \%$ & - \\
\hline $\begin{array}{l}\text { Not using a strategic } \\
\text { approach to plan for pending } \\
\text { retirements } \\
\text { Not appreciating and }\end{array}$ & $42.9 \%$ & - & $33.3 \%$ & - \\
\hline $\begin{array}{l}\text { woy appreciajng and } \\
\text { respecting experienced } \\
\text { workers }\end{array}$ & $14.3 \%$ & - & $33.3 \%$ & - \\
\hline
\end{tabular}

A comparison of study participants reporting that direct employer action caused retirement considerations versus those that reported both direct and indirect resulted in several observations.

First, study participants who were encouraged to consider retirement because of direct action by their employer did not identify dissatisfaction with employer policies and practices as an issue. This is in contrast to those participants who identified both employer action and inaction had caused them to consider retirement - the only category of participants in this analysis to report that they were dissatisfied with employer policies and practices, the most frequently mentioned employer action. Also, study participants whose retirement considerations were affected only by direct employer actions were more likely (60\%) to identify the issue of "many work demands, not enough results or rewards" than those 
individuals whose retirement considerations were influenced by both employer action and inaction (43\%).

A comparison of study participants who reported both employer action and inaction influencing retirement considerations with those that reported only employer inaction suggests a similar pattern, with only one exception. While all individuals reporting that only employer inaction caused them to consider retirement suggested that they were concerned about lack of proactive engagement of experienced workers by their employer, only $71 \%$ of individuals who were affected by both action and inaction on the part of their employer had this concern.

Further analysis of the three distinct groups of participants who identified employer action or inaction as a consideration in their retirement plan, as well as those that indicated that employer action has not affected their retirement deliberations, is provided in the profiles below. The profiles that follow have pulled the notable findings from detailed data tables summarizing the themes across each of the major lines of inquiry. These data tables are provided in Appendix C.

The threshold for determining which results to include in the profiles that follow was arbitrarily set at $40 \%$ for the broad theme or category level. This number was high enough to eliminate spurious sample-specific findings but low enough to capture areas of consensus within the sample. In a few cases, data results with frequency counts representing less than $40 \%$ were included if there was a diversity of perspectives reported and no single category garnered $40 \%$ of the responses. The sample size for several of the profiles that follow are in the range of three to five study participants, and therefore the $40 \%$ threshold for reporting theme or category level findings will be triggered by responses by as few as two individuals. 
Care is taken in interpreting the themes emerging from these smaller sample sizes.

Supporting detail of responses at the concept or topic level is provided when three or more study participants referenced this topic. Caveats with respect to small sample size are noted where appropriate throughout the discussion of the findings.

\subsubsection{Category: Both employer action and inaction leading to consideration of retirement}

Table 15 below provides a profile of study participants whose retirement plans were influenced by both employer action and inaction. This profile was developed by summarizing key data from Appendix C. Approximately 37\% of participants, or seven individuals, reported that they were encouraged to consider retirement based on both action and inaction of their employer. Males were overrepresented in this category. While only $37 \%$ of the total study participants were male, $57 \%$ of this group was men. Those with plans to retire with 35 years of service or more were more likely to fall in this category than other categories. Of the seven individuals within this category, three are already eligible for retirement and have been eligible, on average, for just over four years. The other four individuals are, on average, three and a half years from being eligible for retirement. Individuals within this category range from 0 to 4.5 years from retirement eligibility (i.e. average of just under two years to retirement eligibility). On average, individuals in this category plan to retire within the next two years. Key considerations in their retirement planning include financial considerations (100\%), life considerations $(71 \%)$, as well as work-related factors (71\%).

The most frequently referenced direct actions that encouraged them to retire mentioned by this group were the use of policies and practices that caused dissatisfaction (71.4\%). Examples of policies or practices that are dissatisfiers for individuals include emphasis on 
rules rather than intent; use of outside resources which lessens sense of achievement and community; and lack of consultation and communication related to significant change that impacts people. Note that only this category of individuals reported dissatisfaction with policies and practices as a consideration for retirement.

"The government as an employer has followed the trend of the public sector and moved away from taking any responsibility for loyal employees. Major decisions, which can drastically affect employees are taken and announced without warning, or even polite notification. If the government as an employer wants to retain staff it must demonstrate that it genuinely appreciates them, and not just by giving out token long service awards, etc."

- Male with 34 years of service who plans to retire in one more year with a full pension.

Other reasons for retirement considerations identified by this group include the design of benefit programs (42.9\%); and the existence of many work demands and not enough results or rewards $(42.9 \%)$.

Inaction on the part of the organization identified by many individuals within this category as encouraging retirement considerations included the fact that their employer was not proactively engaging experienced workers $(71.4 \%)$ or not using a strategic approach to plan for pending retirements $(42.9 \%)$.

"I am dealt with as an executive like all executives. There's been no sense that those executives that are approaching retirement age may have interests in special projects or in terms of phases of our career, we are at a stage where a meaningful contribution is the most important thing. We are started to think about our legacy is to an organization. What did I achieve? What have I brought about in an organization?... I don't think that there is a systematic planning for all the talk about talent management, there is not any particular systematic planning in terms of those executives who are looking at a potential date of retirement. You are asked when do you think you will retire and that's it."

- Male who plans to leave at age 60 with 28 years of service

There are things that the employer can do to get individuals in this category to stay. Over half of the individuals in this category indicated that if they were offered interesting and 
rewarding work they might consider staying. Changing the nature of work was also mentioned by $50 \%$ of individuals within this category, with a fundamental shift in duties noted by over $40 \%$ of individuals.

Two of the seven individuals reported that there was nothing that their employer could do to get them to stay. These individuals both had retirement plans for the next year and would have 35 years or more of service upon retirement. Six of the seven individuals in this category are interested in working after their retirement from the public service. 
Table 15. Profile - Participants Whose Retirement Plans Were Influenced by Both Employer Action and Inaction

\begin{tabular}{|c|c|}
\hline Category & $\begin{array}{l}\text { Participants whose retirement plans were influenced by both } \\
\text { employer action and inaction }\end{array}$ \\
\hline $\begin{array}{l}\text { Proportion of } \\
\text { total } \\
\text { interviewees }\end{array}$ & $36.8 \%$ or 7 individuals \\
\hline Who are they? & $\begin{array}{l}\text { Gender: Male }-57 \% \text {; Female }-43 \% \\
\text { Retirement plan: Early exit }-14 \% \\
\quad \text { Early retirement }-43 \% \\
\quad \text { Full years of service }-43 \% \\
\text { Average Years to Planned Retirement: } 2.1 \\
\text { Average Years to (Early) Retirement Eligibility: } 1.9\end{array}$ \\
\hline $\begin{array}{l}\text { Most frequently } \\
\text { identifed } \\
\text { retirement } \\
\text { factors }\end{array}$ & $\begin{array}{l}\text { Financial }(100.0 \%) \\
\text { - Being financially ready }(85.7 \%) \\
\text { - Need to earn an acceptable level of pension }(42.9 \%) \\
\text { Life Considerations }(71.4 \%) \\
\text { Work Related }(71.4 \%) \\
\text { - Work environment - satisfied }(42.9 \%)\end{array}$ \\
\hline $\begin{array}{l}\text { Direct employer } \\
\text { actions that } \\
\text { caused } \\
\text { individuals to } \\
\text { consider } \\
\text { retirement }\end{array}$ & $\begin{array}{l}\text { Dissatisfaction with policies and practices }(71.4 \%) \\
\text { - Unhappy with style of management or management } \\
\text { practices }(57.1 \%) \\
\text { Benefit programs }(42.9 \%) \\
\text { - Provide benefit package }(42.9 \%) \\
\text { Many work demands, not enough results or rewards }(42.9 \%) \\
\text { - No sense of progress or accomplishments }(42.9 \%)\end{array}$ \\
\hline $\begin{array}{l}\text { Inaction on the } \\
\text { part of the } \\
\text { employer that } \\
\text { caused } \\
\text { individuals to } \\
\text { consider } \\
\text { retirement }\end{array}$ & $\begin{array}{l}\text { Not proactively engaging experienced workers }(71.4 \%) \\
\text { - Not engaging me in a discussion }(42.9 \%) \\
\text { Not using a strategic approach to plan for pending retirements } \\
(42.9 \%) \\
\text { - Not proactively managing to retain corporate knowledge } \\
\quad(42.9 \%)\end{array}$ \\
\hline $\begin{array}{l}\text { Actions } \\
\text { employers could } \\
\text { take to get them } \\
\text { to stay }\end{array}$ & $\begin{array}{l}\text { Offer interesting and rewarding work }(57.1 \%) \\
\text { - Offer work that is of interest }(42.9 \%) \\
\text { Offer work that makes a difference }(42.9 \%) \\
\text { Change the nature of work }(57.1 \%) \\
\text { - Provide a fundamental shift in duties }(42.9 \%)\end{array}$ \\
\hline $\begin{array}{l}\text { Are they } \\
\text { interested in pos } \\
\text { retirement work? }\end{array}$ & Interest in post-retirement work ( $86 \%)$ \\
\hline
\end{tabular}




\subsubsection{Category: Direct employer actions encourage consideration of retirement}

The second category of participants is individuals whose retirement plans were influenced only by direct actions on the part of their employer, as summarized in Table 16 below. This category includes five individuals representing approximately $26.3 \%$ of all study participants. The individuals in this category were more likely to be female ( $80 \%)$ than male $(20 \%)$. Females accounted for nearly two-thirds of all study participants, making this gender slightly overrepresented in this category. The majority of individuals (60\%) in this category are planning for early retirement, with $20 \%$ of individuals also planning for an early exit and another $20 \%$ planning to stay until they receive a full pension. Of the five individuals in this category, only one individual is currently eligible for early retirement. The other four will be eligible, on average, within the next three and a half years. The average years to early retirement pension eligibility are 2.7 years and the average number of years to planned retirement is 3.2 years. Key considerations for this group of study participants in setting retirement plans include financial considerations (80\%) and life considerations $(80 \%)$ and to a lesser extent health and work-related factors.

Three of the five individuals in this group expressed concern about the level of work demands and the lack of corresponding results or accomplishments.

"The employer in this case would be the government of Canada and not this department, but the government has undergone so much change and dictated so much change that I do believe that really does encourage people to leave. Lack of performance, starting things over and over, an initiative that starts at the beginning of the year, doesn't come to fruition, and another one very similar replacing it. And the communications coming out of central agencies in terms of what we need to do and what you are facing in terms of challenges, it is bit of a broken record. I am becoming cynical and tired of the whole process. That has encouraged me to consider retirement a little more quickly."

- Female planning to retire at age 58 , two years before reaching eligibility for full pension 
$40 \%$ of individuals in this category reported that the benefit program offering which includes a pre-retirement training course has caused them to start thinking about retirement.

Employers can get the majority $(80 \%)$ of the individuals in this category to stay by offering interesting and rewarding work including overseas assignments, exceptional assignments and work that is of interest. Other influencing actions include changing the nature of work including how the work is managed, reducing associated stress and creating coaching and mentoring roles.

I think the decision (about retirement) will be more what is the work like at the time. The volume, most of that is just a humane amount of work and pace of work. A sense of accomplishment, instead of going from one deadline to the next to the next. To breathe just a bit. We've got to get to the point where we prioritize and stop doing things we can't do well and focus on things that count. Those are the three things.

- Female who plans to retire at age 55 with 32 years of service

Only $40 \%$ of individuals in this category mentioned the organization could get them to stay by changing the nature of work. This was a smaller group giving this response than seen in the other categories of individuals in this analysis, $67 \%$ to $100 \%$ of whom made this suggestion. This category of individuals is also interested in flexible work arrangements including reduced hours and working from home. Three of the five individuals in this category are considering working following their retirement from the public service. 
Table 16. Profile - Participants Whose Retirement Plans Were Influenced by Direct Employer Action

\begin{tabular}{|c|c|}
\hline Category & $\begin{array}{l}\text { Participants whose retirement plans were } \\
\text { influenced by direct actions on the part of their } \\
\text { employer }\end{array}$ \\
\hline $\begin{array}{l}\text { Proportion of total } \\
\text { interviewees }\end{array}$ & $26.3 \%$ or 5 individuals \\
\hline Who are they? & $\begin{aligned} & \text { Gender: Male }-20 \% ; \text { Female }-80 \% \\
& \text { Retirement plan: } \text { Early exit }-20 \% \\
& \text { Early retirement }-60 \% \\
& \text { Full years of service }-20 \%\end{aligned}$ \\
\hline $\begin{array}{l}\text { Retirement Eligibility } \\
\text { and Plans }\end{array}$ & $\begin{array}{l}\text { Average Years to Planned Retirement: } 3.2 \\
\text { Average Years to (Early) Retirement Eligibility: } 2.7\end{array}$ \\
\hline $\begin{array}{l}\text { Most frequently } \\
\text { identiffed retirement } \\
\text { factors }\end{array}$ & $\begin{array}{l}\text { Financial }(80.0 \%) \\
\text { - Being financially ready }(80.0 \%) \\
\text { Life Considerations }(80.0 \%) \\
\text { - Coordinating with partner's retirement plans } \\
\quad(60.0 \%) \\
\text { Health }(40.0 \%) \\
\text { Work Related }(40.0 \%)\end{array}$ \\
\hline $\begin{array}{l}\text { Direct employer } \\
\text { actions that caused } \\
\text { individuals to consider } \\
\text { retirement }\end{array}$ & $\begin{array}{l}\text { Many work demands, not enough results or rewards } \\
(60.0 \%) \\
\text { Benefit programs }(40.0 \%)\end{array}$ \\
\hline $\begin{array}{l}\text { Thaction on the part of } \\
\text { the employer that } \\
\text { caused individuals to } \\
\text { consider retirement }\end{array}$ & None reported \\
\hline $\begin{array}{l}\text { Actions employers } \\
\text { could take to get them } \\
\text { to stay }\end{array}$ & $\begin{array}{l}\text { Offer interesting and rewarding work }(80.0 \%) \\
\text { Change the nature of work }(40.0 \%) \\
\text { Flexible work arrangements }(40.0 \%)\end{array}$ \\
\hline $\begin{array}{l}\text { Are they interested in } \\
\text { post-retirement work? }\end{array}$ & Interest in post-retirement work $(60 \%)$ \\
\hline
\end{tabular}

\subsubsection{Category: Employer inaction encourages consideration of retirement}

The third category of individuals are those that reported that their retirement plans were influenced by inaction on the part of their employer (no direct actions on the part of their employer were reported). Table 17 below provides a summary of the profile of these individuals. Three individuals or approximately $16 \%$ of the total study participants fit in this category. The small sample size for this profile suggests that care be taken in interpreting these findings. Two-thirds of the individuals in this category were male and one-third were 
female. While the sample size is small, it should be noted that men are over represented in this category given that they constitute just under $40 \%$ of the total study participants. Onethird of individuals in this category are planning an early exit from the public service, while two-thirds have early retirement plans. No individuals in this category plan to stay with the public service to receive a full pension. On average, the individuals are just over four years from retirement (low of 1.5 years to a high of 8 years). Their retirement plans coincide, on average, with their eligibility, with two individuals planning on staying slightly beyond their eligibility and one individual planning to leave two years before. The most important factors influencing their retirement plans are life considerations, specifically coordinating with their partner's retirement plans, as well as work-related factors.

All three individuals in this group reported that their employer is not proactively engaging experienced workers. They suggested that there is a need to better understand and respond to the needs of older workers, to engage them in a discussion about what they are interested in doing and to start taking action to get people to stay longer in the workplace. Individuals in this group appeared to be frustrated that their employer was not taking a more strategic approach to planning for pending retirements, specifically taking action to ensure that corporate knowledge is retained when long-service employees retire.

"I would suggest that there is a problem in the department, perhaps in government as a whole that people know that there is a lot of us getting ready to retire. They are doing a good job of hiring bright young minds to come in and take our place. I am so impressed with the people we are bringing in here. However, they haven't figured out first of all, what to do with people like me, they haven't given it any real thought. One looks at all the plans that are in place to deal with the coming retirement to fill all these positions and have well trained people in them. There's nothing out there on how do you maintain a little bit of corporate memory, how do you deal with those people who are in positions and are getting tired and they're valued, I know I am valued here but they haven't thought about what do you do with people in that position."

- Male who is eligible to retire in 16 months; retirement plans depend on what he is doing at that time 
The majority of individuals in this category (67\%) would consider staying beyond their current planned retirement date if the nature of the work was changed. They are looking for a fundamental change in duties or in one case, a change in how work is managed. Flexible work arrangements might also entice this group to stay on longer, as $67 \%$ indicated they are seeking opportunities to work reduced hours or part of the year. Two of the three individuals are considered working after retirement.

Table 17. Profile - Participants Whose Retirement Plans Were Influenced by Employer Inaction

\begin{tabular}{|c|c|}
\hline Category & $\begin{array}{l}\text { Participants whose retirement plans were } \\
\text { influenced by employer inaction }\end{array}$ \\
\hline $\begin{array}{l}\text { Proportion of total } \\
\text { interviewees }\end{array}$ & $15.8 \%$ or three individuals \\
\hline Who are they? & $\begin{aligned} & \text { Gender: Male }-67 \% ; \text { Female }-33 \% \\
& \text { Retirement plan: } \text { Early exit }-33 \% \\
& \text { Early retirement }-67 \% \\
& \text { Full years of service }-0 \%\end{aligned}$ \\
\hline $\begin{array}{l}\text { Retirement Eligibility } \\
\text { and plans }\end{array}$ & $\begin{array}{l}\text { Average Years to Planned Retirement: } 4.3 \\
\text { Average Years to (Early) Retirement Eligibility: } 4.2\end{array}$ \\
\hline $\begin{array}{l}\text { Most frequently } \\
\text { identified retirement } \\
\text { factors }\end{array}$ & $\begin{array}{l}\text { Life Considerations }(100.0 \%) \\
\text { Coordinating with partner's retirement plans } \\
\quad(100.0 \%) \\
\text { Work Related }(66.7 \%)\end{array}$ \\
\hline $\begin{array}{l}\text { Direct employer } \\
\text { actions that caused } \\
\text { individuals to consider } \\
\text { retrement }\end{array}$ & None reported \\
\hline $\begin{array}{l}\text { Inaction on the part of } \\
\text { the employer that } \\
\text { caused indfyiduals to } \\
\text { consider retirement }\end{array}$ & Not proactively engaging experienced workers $(100.0 \%)$ \\
\hline $\begin{array}{l}\text { Actions employers } \\
\text { could take to get them } \\
\text { to stay }\end{array}$ & $\begin{array}{l}\text { Change the nature of work }(66.7 \%) \\
\text { Flexible work arrangements }(66.7 \%)\end{array}$ \\
\hline $\begin{array}{l}\text { Are they interested in } \\
\text { post-retirement work? }\end{array}$ & Interest in post-retirement work (67\%) \\
\hline
\end{tabular}

\subsubsection{Category: Employer action has not affected retirement considerations}

The final category of individuals is those that reported that their plans were not affected by the actions of their employer (see Table 18 for a profile). Four individuals, or approximately 
$20 \%$ of all study participants, are included in this category. The small sample size for this profile suggests that care be taken in interpreting these findings. The majority of participants are planning to retire at or shortly thereafter their retirement eligibility. One individual will leave in advance of being eligible with their pension slightly reduced. On average, the group is eligible to retire within a year, but their plans suggest they will stay a little longer. Two of the most important factors in setting retirement plans for individuals within this group are work-related factors, including the recognition that they have served and made their contribution. Note that one individual suggested that their dissatisfaction with work is a consideration in setting their retirement plan, however, they did not identify any action or inaction on the part of their employer that was causing them to consider retirement.

One of the four individuals in this category reported that there was nothing that their employer could do to get them to stay. For the remaining three individuals, all suggested that a change in the nature of work would be a motivator for them to stay. Specifically two mentioned a coaching and mentoring role and one individual identified the need to reduce stress in their job. Half of the individuals in this category are interested in flexible work arrangements, including reduced hours, working part of the year, or working from home. When asked what the employer could do to get her to stay beyond her planned retirement date, a female with plans to retire at age 60 had the following response:

"Well, I guess it will depend, I suppose it is possible, a really wonderful assignment that I couldn't turn down. And I don't know what that would be. It would also depend on a lot of other things, my health was still good, my interest is still there, level of energy and so forth. At some point, no matter how interesting the assignment, I am going to want to put in fewer hours. I put in minimum of 50 hours a week and usually between 50 and 60 hours a week. At some point, I want to do less. I am not sure, it may be that they would offer me something to do three days a week, halfday or merely 37.5 hours per week." 
Note that this category of individuals would not be enticed by the redesign of benefit

programs or by the offer of interesting and rewarding work, unlike the other three

categories of individuals examined in this analysis.

Table 18. Profile - Participants Whose Retirement Plans Were Not Influenced by Actions of Their Employer

\begin{tabular}{|c|c|}
\hline Category & $\begin{array}{l}\text { Participants whose retirement plans were not } \\
\text { affected by actions of their employer }\end{array}$ \\
\hline $\begin{array}{l}\text { Proportion of total } \\
\text { interviewees }\end{array}$ & $21.1 \%$ or 4 individuals \\
\hline Who are they? & $\begin{aligned} & \text { Gender: Male }-0 \% ; \text { Female }-100 \% \\
& \text { Retirement plan: } \text { Early retirement }-67 \% \\
& \text { Early exit }-33 \% \\
& \text { Full years of service }-0 \%\end{aligned}$ \\
\hline $\begin{array}{l}\text { Retirement Eligibility } \\
\text { and Plans }\end{array}$ & $\begin{array}{l}\text { Average Years to Planned Retirement: } 2.6 \\
\text { Average Years to Retirement Eligibility: } 0.9\end{array}$ \\
\hline $\begin{array}{l}\text { Most frequently } \\
\text { identified retirement: } \\
\text { factors }\end{array}$ & $\begin{array}{l}\text { Work Related (100.0\%) } \\
\text { Life Considerations }(50.0 \%)\end{array}$ \\
\hline $\begin{array}{l}\text { Direct employer } \\
\text { actions that caused } \\
\text { individuals to consider } \\
\text { retirement. }\end{array}$ & None reported \\
\hline $\begin{array}{l}\text { Inaction on the part of } \\
\text { the employer that } \\
\text { caused individuals to } \\
\text { consider retrement }\end{array}$ & None reported \\
\hline $\begin{array}{l}\text { Actions employers } \\
\text { could take to get them } \\
\text { to stay }\end{array}$ & $\begin{array}{l}\text { Change the nature of work }(75.0 \%) \\
\text { Flexible work arrangements }(50.0 \%)\end{array}$ \\
\hline $\begin{array}{l}\text { Are they interested in } \\
\text { post-retirement work? }\end{array}$ & Interest in post-retirement work $(100 \%)$ \\
\hline
\end{tabular}

In summary, the vast majority of participants $(81 \%)$ report that either action or inaction on

the part of their employer has caused them to consider retirement. Both direct actions and inaction appear to nearly equally important. As noted in Table 14, direct employer actions were mentioned by 12 study participants and indirect actions were identified by 10 study participants. The profile summaries (Tables $15,16,17$ and 18) also suggest that the type of employer action which is affecting retirement decisions may differ by gender. Male participants were more likely to identify either both employer action and inaction or simply 
employer inaction as having caused them to consider retirement. Female participants were more likely to mention that direct action by their employer had caused them to consider retirement or to indicate that their retirement considerations have not been affected by employer action.

While action or inaction on the part of their employer has caused study participants to consider retirement, many of them are open to extending their time in the public service beyond their current retirement plans. Only three of the 16 individuals who reported that employer action or inaction had caused them to consider retirement indicated that there was nothing that the employer could do to get them to stay. These individuals all planned to retire with 35 years of service.

Those that reported both employer action and inaction had caused them to consider retirement were, on average, closer to both their (early) retirement eligibility and planned retirement dates than those that reported a single type of employer action (either direct or inaction).

The results would suggest that there may be distinct groups of employees who have concerns about the public service that can possibly be addressed to encourage them to stay beyond their current retirement plans.

While the concerns of those individuals reporting that both action and inaction on the part of their employer has caused them to consider retirement are far-reaching, the actions that will retain them are not necessarily as broad. For this group of individuals, many of which are currently eligible or within a few years of being eligible to retire, the work is very important. Some could possibly stay longer if they were offered the right work, which in 
general is of interest to the individual and makes a difference. This group of individuals is also open to doing assignments or making a fundamental shift in their duties during the last few years of their career.

For those individuals who identified that direct actions on the part of their employer had affected their retirement considerations, their concerns are generally focused on the work demands and the inability to achieve a sense of progress or accomplishments. This group of individuals is also looking for interesting and rewarding work, but they are also looking to their employer to create a situation where the pressures and strains of work can be relieved. This might mean changing how work is managed, or creating coaching and mentoring roles to allow these employees to apply their corporate knowledge to groom younger employees for management and executive positions. Some individuals are also seeking flexible work arrangements, potentially as a way to relieve the stress associated with their work or to smooth the transition to retirement.

Those individuals that were influenced by inaction on the part of their employer were concerned that experienced workers, such as themselves, are not being engaged by their employer. This group of individuals is, on average, further away from retirement eligibility and planned retirement than either of the previously discussed groups. They feel that their employer does not understand or respond to the needs of older workers and are looking for their employer to start this engagement process to put their talents to best use. They are seeking a change in the nature of work and flexible work arrangements.

Study participants that reported that employer actions have not affected their retirement considerations are still open to the idea of changing their retirement plans. Employers can 
change the nature of work by providing opportunities for coaching and mentoring roles or providing jobs with less stress and pressure. Employers can also get individuals in this group to stay by introducing flexible work arrangements.

\subsubsection{Analysis by Retirement Plans of Early Exiters, Early Retirees and Full Pensioners}

Another lens through which to view responses from study participants is their retirement plans, more specifically, whether their retirement plans fall within one of the three following categories:

- Early exiters - individuals who plan to retire before reaching the point of retirement eligibility as defined by the Public Service Superannuation Act, which is age 55 with 30 years of service or age 60 with at least two years of service.

- Early retirees - those individuals who plan to retire at or after the point of retirement eligibility.

- Full pensioners - those individuals who plan to retire with 35 or more years of service, thereby qualifying them for the maximum pension benefits allowed by the Public Service Superannuation Act.

The proportion of study participants that fall within these three categories is summarized in Table 19 below. 
Table 19. Retirement Plans of Study Participants

\begin{tabular}{|c|c|c|}
\hline Category & Number of Responses & $\begin{array}{l}\text { Percentage of Cases } \\
(n=19)\end{array}$ \\
\hline Early Exiters & 3 & $15.8 \%$ \\
\hline Early Retirees & 10 & $52.6 \%$ \\
\hline Full Pensioners & 6 & $31.6 \%$ \\
\hline
\end{tabular}

Table 20 below classifies respondents using two constructs of interest: retirement intentions versus whether employer action and/or inaction has caused them to consider retirement.

Table 20. Retirement Plans of Study Participants

\begin{tabular}{|c|c|c|c|}
\hline Category & $\begin{array}{l}\text { Early Exiters } \\
\qquad(n=3)\end{array}$ & $\begin{array}{l}\text { Early Retirees } \\
\qquad(n=10)\end{array}$ & $\begin{array}{l}\text { Full Pensioners } \\
\qquad(n=6)\end{array}$ \\
\hline $\begin{array}{l}\text { An employer action has caused me to } \\
\text { consider retirement }\end{array}$ & $66.7 \%$ & $60 \%$ & $66.7 \%$ \\
\hline $\begin{array}{l}\text { Many work demands, not enough } \\
\text { results or rewards }\end{array}$ & $66.7 \%$ & $30 \%$ & $16.7 \%$ \\
\hline $\begin{array}{l}\text { Benefit program design provides } \\
\text { ineentive to retire }\end{array}$ & $33.3 \%$ & $20 \%$ & $33.3 \%$ \\
\hline $\begin{array}{l}\text { Dissatisfaction with policies and } \\
\text { practices }\end{array}$ & $0 \%$ & $20 \%$ & $50 \%$ \\
\hline $\begin{array}{l}\text { Inaction on the part of my employer } \\
\text { has caused me to consider retirement }\end{array}$ & $66.7 \%$ & $50 \%$ & $33.3 \%$ \\
\hline $\begin{array}{l}\text { Not proactively engaging } \\
\text { experienced workers }\end{array}$ & $66.7 \%$ & $40 \%$ & $33.3 \%$ \\
\hline $\begin{array}{l}\text { Not using a strategle approach to } \\
\text { plan for pending retirements }\end{array}$ & $0 \%$ & $30 \%$ & $16.7 \%$ \\
\hline $\begin{array}{l}\text { Not appreciating and respecting } \\
\text { experienced workers }\end{array}$ & $0 \%$ & $10 \%$ & $16.7 \%$ \\
\hline
\end{tabular}

For early exiters and early retirees, both employer action and inaction appear to be affecting retirement considerations. For those that plan to stay with the public service for 35 years of service or more, direct employer actions were more frequently noted than employer inaction as having caused considerations of retirement. 
For early exiters, the driving factors for consideration of retirement are having many work demands, but not seeing enough results or rewards. In addition, those with plans to exit the public service before meeting the definition of eligibility are also demonstrating concern that their employer is not proactively engaging experienced workers. Note that those in the early exiters category were much more likely to identify these issues than either the early retirees or full pensioners. In addition, early exiters noted no other concerns with their employer actions ${ }^{9}$.

Early retirees referenced both employer action and inaction as affecting their retirement considerations, although there were no significant areas of consensus in the responses from this group. The top three employer actions or inaction causing them to consider retirement are: not proactively engaging experienced workers (40\%); not using a strategic approach to plan for pending retirements (30\%); and many work demands, not enough results or rewards $(30 \%)$.

Full pensioners were more likely to reference employer action as a cause of consideration of retirement than employer inaction. The most frequently referenced employer action was use of policies and practices that caused dissatisfaction. Also considered in deliberations about retirement were benefit program design and that experienced workers are not being proactively engaged.

More detailed profiles of these three categories of retirement plans follow. The profiles have pulled the notable findings from detailed data tables summarizing the themes across each of the major lines of inquiry. These data tables are provided in Appendix D. An in-depth

\footnotetext{
${ }^{9}$ The fact that benefit programs are designed with an incentive to retire is under the control of the broader government of Canada and not their primary employer (the department).
} 
discussion of what makes the profile of each of the categories unique is included in Section 5, along with a comparison of these findings with the literature.

The threshold for determining which results to include in the profiles that follow was arbitrarily set at $40 \%$ for the broad theme or category level. This number was high enough to eliminate spurious sample-specific findings but low enough to capture areas of consensus within the sample. In a few cases, data results with frequency counts representing less than $40 \%$ were included if there was a diversity of perspectives reported and no single category garnered $40 \%$ of the responses. The sample size for several of the profiles that follow are in the range of three to five study participants, and therefore the $40 \%$ threshold for reporting theme or category level findings will be triggered by responses by as few as two individuals. Care is taken in interpreting the themes emerging from these smaller sample sizes. Supporting detail of responses at the concept or topic level is provided when three or more study participants referenced this topic. Caveats with respect to small sample size are noted where appropriate throughout the discussion of the findings.

\subsubsection{Category: Early Exiters}

Table 21 below provides a profile of early exiters, representing approximately $17 \%$ of all study participants. Note that all three individuals within this category are female; while male participants represented $37 \%$ of all participants in the study, none identified plans to exit the public service before meeting retirement eligibility requirements. Early exiters are within three to six years from early retirement and plan to retire, on average, within the next four years. Given the small sample size for this category of individuals, care should be exercised in interpreting these findings. 
The most frequently identified retirement factors noted by all individuals planning an early exit from the public service are life considerations and work-related factors. Two-thirds of these individuals mentioned financial considerations. The retirement factors referenced by this group suggest there are many things that are pulling them away before reaching retirement eligibility including life considerations related to coordinating with their partner's retirement plans and other family considerations. Some factors that are pushing these individuals to make an "early exit" from the public service are their dissatisfaction with the work environment and a need to mitigate the impact of work on their personal health. Two of the three individuals reported that at the point of their planned retirement, they felt they would have served and made their contribution to the public service.

"Well my husband who is already retired and has been retired for 3 years. It was a key driver. The other thing was for me, I wanted a change in lifestyle, I didn't want to be driven by this machine of work, I wanted to create some lifestyle changes and have some time to regenerate myself. Health issues, having my time, that was a factor too."

- Female who plans to retire at age 53

These individuals are encouraged to stay because they have been provided enjoyable work, but they have also stayed because benefits, particularly pensions, are designed to give them an incentive to stay. They are encouraged to consider retirement because there are many work demands, but not enough results or rewards and they do not feel that their employer is proactively engaging experienced workers.

"A difficulty of working in the government of Canada, it's difficult in every organization. The complexity, the fact that you may be working issues that are rather negative because those are the problem areas of the department that need resolution. And sometimes you don't see much progress in a project over a number of years because the projects are long-term and one erson may work for several years and not really make that much of a difference, they might move forward, but they don't actually resolve it."

- Female who plans to leave the public service at age 54 with 30 years of service 
This group of individuals can possibly be persuaded to stay longer in the public service if they are offered interesting and rewarding work; in addition, two-thirds suggested an overseas assignment could be a sufficient enticement for them. While two-thirds of individuals reported that they are interested in financial incentives to stay longer in the public service, one individual explicitly suggested that financial rewards would not be an incentive to stay.

Finally, although these individuals are looking to exit the public service, they are not looking to stop working completely. Two of the three individuals expressed an interest in working post-retirement.

Table 21. Profile - Participants Planning to Exit the Public Service Prior to Meeting Retirement Eligibility

\begin{tabular}{|c|c|}
\hline Category & Early Exiters $(n=3)$ \\
\hline Who are they? & Gender: Female $-100 \%$ \\
\hline $\begin{array}{l}\text { Retirement Eligibility } \\
\text { and Plans }\end{array}$ & $\begin{array}{l}\text { Average Years to Planned Retirement: } 4.0 \\
\text { Average Years to Early Retirement Eligibility: } 5.7\end{array}$ \\
\hline $\begin{array}{l}\text { Most frequently identified } \\
\text { retirement factors }\end{array}$ & $\begin{array}{l}\text { Life considerations }(100 \%) \\
\quad \text { Coordinating with partner's retirement plans }(100 \%) \\
\text { Work-related }(100 \%) \\
\text { Financial }(66.7 \%)\end{array}$ \\
\hline $\begin{array}{l}\text { What has the employer } \\
\text { done that has encouraged } \\
\text { them to stay? }\end{array}$ & $\begin{array}{l}\text { Provide interesting and rewarding work }(66.7 \%) \\
\text { Design benefits and work programs to meet my needs } \\
(66.7 \%)\end{array}$ \\
\hline $\begin{array}{l}\text { What has the employer } \\
\text { done that has encouraged } \\
\text { them to consider retiring? }\end{array}$ & $\begin{array}{l}\text { Many work demands, not enough results or rewards }(66.7 \%) \\
\text { Not proactively engaging experienced workers }(66.7 \%)\end{array}$ \\
\hline $\begin{array}{l}\text { What actions can the } \\
\text { employer take to } \\
\text { encourage them to stay } \\
\text { beyond their planned } \\
\text { retirement date? }\end{array}$ & $\begin{array}{l}\text { Offer interesting and rewarding work }(66.7 \%) \\
\text { Financial incentives }(66.7 \%)\end{array}$ \\
\hline $\begin{array}{l}\text { Are they interested in } \\
\text { post-retirement work? }\end{array}$ & Interest in post-retirement work $(66.7 \%)$ \\
\hline
\end{tabular}




\subsubsection{Category: Early Retirees}

Table 22 below provides a summary profile of study participants planning to retire early

from the public service. Just over half of the study participants, or 10 individuals, fell into the category of early retirees. The gender split of study participants that fall into this category is $40 \%$ male and $60 \%$ female, closely mirroring the gender split of all study participants. On average, individuals within this category will be eligible for early retirement in just over three years, but intend to retire in about three and a half years.

The most important retirement factor identified by individuals with early retirement plans was financial (80\%), followed by life considerations (70\%) and work-related factors (60\%). Being financially ready (70\%) and coordinating with partner's retirement plans (60\%) were most frequently identified as retirement considerations by the individuals within this category.

Four of the ten individuals within this category suggest that their employer is not doing things to encourage them to stay.

Those with early retirement plans are encouraged to consider retirement for a wide range of reasons. The most frequently referenced reasons identified by individuals within this category include that their employer is not proactively engaging experienced workers $(40 \%)$, as evidenced by lack of discussion with those who are nearing retirement or lack of action to get people to stay.

Three out of the ten individuals noted that while employer actions may be causing them to consider retirement, they are not being influenced or pushed to retire by their employer. 
As a group of employees, these individuals are looking for a wide range of enticements or incentives to stay at work, with a change in the nature of work being mentioned by 8 of the 10 individuals. The meaning of a change in the nature of work is quite diverse and could mean a fundamental shift in duties, a new coaching and mentoring role or a change in how work is managed. Some examples of changes that individuals would like to see in how work is managed include operating under "reasonable rules", better pace and prioritization of work, or more self-managed and flexible work.

Flexible work arrangements were also identified by half of the individuals in this group and for many, the flexibility they are seeking is reduced hours. $40 \%$ of individuals in this category also referenced interesting and rewarding work as an incentive to stay with the public service. While some mentioned work that is of interest and work that makes a difference, others identified assignments as potential incentives.

Eight of ten individuals within this category indicated that they would potentially be interested in post-retirement work. 
Table 22. Profile - Participants Planning an Early Retirement

\begin{tabular}{|c|c|}
\hline Category & Early retirees $(n=10)$ \\
\hline Who are they? & $\begin{array}{l}\text { Gender: } \\
\text { Male }-40 \% \text {; Female }-60 \%\end{array}$ \\
\hline $\begin{array}{l}\text { Retirement } \\
\text { Eligibility and } \\
\text { Plans }\end{array}$ & $\begin{array}{l}\text { Average Years to Planned Retirement: } 3.2 \\
\text { Average Years to Early Retirement Eligibility: } 3.5\end{array}$ \\
\hline $\begin{array}{l}\text { Most frequently } \\
\text { identified } \\
\text { retirement factors }\end{array}$ & $\begin{array}{l}\text { Financial }(80 \%) \\
\cdot \quad \text { Being financially ready }(70 \%) \\
\text { Life considerations }(70 \%) \\
\bullet \quad \text { Coordinating with partner's retirement plans }(60 \%) \\
\text { Work-related }(60 \%)\end{array}$ \\
\hline $\begin{array}{l}\text { What has the } \\
\text { employer done } \\
\text { that has } \\
\text { encouraged them } \\
\text { to stay? }\end{array}$ & Not doing things to encourage me to stay $(40 \%)$ \\
\hline $\begin{array}{l}\text { What has the } \\
\text { employer done }\end{array}$ & Not influencing me or pushing me to retire $(30 \%)$ \\
\hline $\begin{array}{l}\text { that has } \\
\text { encouraged them } \\
\text { to consider } \\
\text { reting? }\end{array}$ & Not proactively engaging experienced workers (40\%) \\
\hline $\begin{array}{l}\text { What actions can } \\
\text { the employer take } \\
\text { to encourage } \\
\text { them to stay } \\
\text { beyond their } \\
\text { planned } \\
\text { retirement date? }\end{array}$ & $\begin{array}{l}\text { Change the nature of work (80\%) } \\
\text { - Fundamental shift in duties ( } 40 \%) \\
\text { Offer coaching and mentoring role (30\%) } \\
\text { Flexible work arrangements }(50 \%) \\
\text { - Reduced hours }(40 \%) \\
\text { Offer interesting and rewarding work }(40 \%)\end{array}$ \\
\hline $\begin{array}{l}\text { Are they } \\
\text { interested in post- } \\
\text { retirement work? }\end{array}$ & Interest in post-retirement work $(80 \%)$ \\
\hline
\end{tabular}

\subsubsection{Category: Full Pensioners}

Table 23 provides a profile of study participants that intend to retire with a full pension from the federal government. Six individuals, or $32 \%$ of study participants, plan to retire with 35 years of service or more. There were equal numbers of male and female participants in this category, with the proportion of male participants slightly higher than that of the overall study. On average, these individuals have been eligible for early retirement for three and a half years, but plan to continue to work for at least another year. 
Financial factors were the most frequently mentioned factors in setting retirement plans ( $83 \%)$, followed by life considerations $(67 \%)$, work-related $(67 \%)$ and health $(50 \%)$. Being financially ready is the number one consideration in setting retirement plans. Coordinating with partner's retirement plans (50\%) and personal health (50\%) were also noted. With respect to work-related factors, half of the individuals noted that they have been satisfied with the work environment, likely a factor that has kept them in the workplace for nearly 35 years.

Half of the individuals within this category noted that their employer is not doing things to get them to stay. $50 \%$ indicated that they feel valued by their employer which has encouraged them to stay. Half indicated that their employer is not "pushing them to retire". The most significant action on the part of their employer which has encouraged some individuals within this group to consider retirement is put in place policies and practices that cause dissatisfaction. Examples of these policies and practices include bilingual requirements (sending those very near to retirement on French training) or the style of management practices.

"There's a clear generational change in the department. I feel that the new generation does not have anybody's interest at heart but their own. And so there's no interest in providing jobs or assignments or talking or communicating with those people at the end of their career whether they are interested in working or not. In other words you end up being effectively isolated and treated, and becoming irrelevant."

- Male who intends to retire at age 60 with over 35 years of service

One half of individuals indicated that there is nothing that can be done to get them to stay. Other individuals within this category suggested a range of approaches which might encourage them to stay beyond their current retirement plans including interesting and rewarding work, flexible work arrangements, and financial incentives. Two-thirds of individuals indicated that they would potentially be interested in post-retirement work. 
Table 23. Profile - Participants Planning to Retire with 35 Years of Service or More

\begin{tabular}{|c|c|}
\hline Category & Full Pensioners $(n=6)$ \\
\hline Who are they? & $\begin{array}{l}\text { Gender: } \\
\text { Male - 50\% } \\
\text { Female - } 50 \%\end{array}$ \\
\hline \multirow{2}{*}{$\begin{array}{l}\text { Retirement Eligibility } \\
\text { and Plans } \\
\text { Most frequently identified } \\
\text { retirement factors }\end{array}$} & $\begin{array}{l}\text { Average Years to Planned Retirement: } 1.3 \\
\text { Were eligible, on average, } 3.4 \text { years ago for retirement }\end{array}$ \\
\hline & $\begin{array}{l}\text { Financial ( } 83.3 \%) \\
\text { - Being financially ready }(83.3 \%) \\
\text { Life considerations }(66.7 \%) \\
\text { - Coordinating with partner's retirement plans } \\
\quad(50 \%) \\
\text { Work-related }(66.7 \%) \\
\text { - Work environment - satisfied (50\%) } \\
\text { Health (in good health and could work, retire while } \\
\text { have health, health) }(50 \%)\end{array}$ \\
\hline $\begin{array}{l}\text { What has the employer } \\
\text { done that has encouraged } \\
\text { them to stay? }\end{array}$ & $\begin{array}{l}\text { Not doing things to encourage me to stay } \\
\text { - Haven't done anything (50\%) } \\
\text { Demonstrated that I am valued (50\%) }\end{array}$ \\
\hline \multirow{2}{*}{$\begin{array}{l}\text { What has the employer } \\
\text { done that has encouraged } \\
\text { them to consider retiring? } \\
\text { What actions can the } \\
\text { employer take to } \\
\text { encourage them to stay } \\
\text { beyond their planned } \\
\text { retirement date? }\end{array}$} & $\begin{array}{l}\text { Not influencing me or pushing me to retire }(50 \%) \\
\text { Dissatisfaction with policies and practices }(50 \%)\end{array}$ \\
\hline & $\begin{array}{l}\text { Nothing can be done to get me to stay }(50 \%) \\
\text { Offer interesting and rewarding work }(33.3 \%) \\
\text { Flexible work arrangements }(33.3 \%) \\
\text { Financial incentives }(33.3 \%)\end{array}$ \\
\hline $\begin{array}{l}\text { Are they interested in } \\
\text { post-retirement work? }\end{array}$ & Inte \\
\hline
\end{tabular}




\section{Discussion}

Section 4 presented a summary of the results from interviews with study participants crossing a broad range of topics including the meaning of retirement and perspectives on the role of employers in influencing retirement considerations. This section includes a discussion of the results with a focus on the role of employers in influencing retirement plans. The goal is to understand how organizations can increase the proportion of engaged older workers who choose to remain with the organization until or after retirement eligibility. The section concludes with a discussion on how these findings relate to the factors identified to date in the literature that either encourage individuals to remain in the workplace or to exit through retirement.

\subsection{Retirement Plans of Early Exiters, Early Retirees and Full Pensioners}

Section 4.3.3 presented findings related to the role of the employer in influencing the retirement plans of three groups of individuals - those planning an early exit from the public service, those planning to take (early) retirement and those that plan to leave with a full pension after 35 years of service. The results identified a wide range of push and pull factors that cause individuals to move out of the public service, potentially making the approaches used to retain early exiters, early retirees and full pensioners slightly different. The discussion that follows looks at the commonalties and differentiators between these three groups in an attempt to understand how the organizations might convince workers approaching retirement to change their retirement plans and remain in the workforce. The discussion section is divided into three parts. The first part identified common perspectives on retirement and the role of the employer in affecting retirement considerations, followed by the second part which summarizes diverging perspectives on this issue. The third and 
final part of the discussion summarizes the factors identified in this study that impact retirement considerations.

\subsubsection{Common Perspectives on Retirement and the Role of Employer in Affecting Retirement Considerations}

There are some views of retirement which are commonly held by employees in this sample regardless of when they plan to retire. In general, retirement is seen as a time of gaining personal control, and is focused on activities related to leisure, work and family. A small proportion of individuals in each of the three categories of employees examined are apprehensive about this new stage of their life.

Further examination of the results would suggest that early retirees and full pensioners share many common perspectives on their plans for retirement activities. Most frequently mentioned retirement activities for early retirees and full pensioners include leisure and work, and to a much lesser extent, community, learning and family. Retirement factors considered when deciding whether to retire are also similar for these two groups, with the most important being financial, followed by life considerations, work-related considerations and health.

With respect to perspectives on the role of employer in affecting retirement considerations and plans, there are very few common perspectives that hold across all three categories of participants. That being said, the results suggest that providing flexible work arrangements is an approach that employers can take to influence the retirement plans for a substantial percent of their workforce (i.e. one third of both early exiters and full pensioners and half of early retirees suggesting that this might induce them to change their current retirement plans). In addition to the above suggestions, the data reveals a number of things that an 
employer can do to influence the decision making process of early retirees and full pensioners.

Specifically this study found that both early retirees and full pensioners are more likely to postpone their retirement if they are offered interesting and rewarding work and financial incentives. It should be noted that for the individuals in this sample the work is more important than the money.

\subsubsection{Diverging Perspectives on Retirement and the Role of Employer in Affecting Retirement Considerations}

Early exiters, early retirees and full pensioners often have diverging views on retirement

and the role of employers in affecting retirement considerations. Following is a discussion of the unique factors influencing retirement considerations for each of the three categories of study participants. The threshold used to identify unique factors in this section was at least a $30 \%$ difference in the response rate between one category and the rest. In addition, a factor was deemed to be unique if the group was the only one that gave the response.

\subsubsection{Early Exiters}

This group of individuals was much more likely to view retirement as a time when activities would be under their personal control than early retirees or full pensioners.

Leisure is referenced by all study participants as a retirement activity; however, the characterization of leisure activities does differ for early exiters who placed significant emphasis on vacation and rest. This type of leisure activity was infrequently mentioned by early retirees and full pensioners who see leisure time being focused on outdoor activities and hobbies. 
Similarly, while all groups talked about working after retirement, early retirees were more likely to emphasize that if they worked, it would be part-time. In addition, while some early retirees and full pensioners suggested they would definitely work after retirement, none of the early exiters indicated they had definite plans to work.

All study participants planning to exit early from the public service plan to volunteer after they finish work - a higher percentage planning this activity than was observed in the early retiree or full pensioner groups. With respect to learning as a retirement activity, no early exiters expressed intent to continue learning.

With respect to the factors that employees consider when deciding when to retire, the views of early exiters and other study participants sometimes diverge. For early exiters, workrelated factors and life considerations are equally important, followed by financial and health considerations. For early retirees and full pensioners, the factors considered (listed in order of importance) are financial, life considerations, work-related and health. The most important considerations for early exiters in setting retirement plans were coordinating with partner's retirement plans and other family considerations. With respect to work-related factors, early exiters were much more likely than those in other groups to indicate they felt they had served and made their contribution, were dissatisfied with the work environment and needed to exit the workforce to mitigate the impact of work on personal health.

Early exiters were more likely than other study participants to identify that inaction on the part of their employer had encouraged them to consider retirement. A specific concern of early exiters that does not appear to be an issue for either early retirees or full pensioners is that their employer does not understand or respond to the needs of older workers. In fact, 
while early retirees and full pensioners identified a wide range of employer inaction that has encouraged them to consider retirement, early exiters are very focused on the gap between how they expect to be engaged as productive and contributing workers and the current approach used by their employer.

Early exiters are much more likely to identify "many work demands, not enough results or rewards" as a factor that is influencing their retirement considerations. While this is a concern for the majority $(67 \%)$ of early exiters, it was mentioned by one in three early retirees and one in six full pensioners. On the other hand, unlike their colleagues in the full pension group, early exiters did not mention that their employer's use of specific policies and practices causes dissatisfaction.

On a positive note, all early exiters reported that their employer has taken some action which has encouraged them to stay - a higher percent than was observed in the other two groups. Early exiters were also more likely to point to interesting and rewarding work and benefit programs with built-in retention incentives as having contributed to their consideration to stay longer in the public service.

Finally, views on what action their employer can take to get them to stay set the early exiter apart from early retirees and full pensioners. Early exiters are much more likely to want interesting and rewarding work, such as overseas assignments. They also noted that they would be induced to stay by financial incentives, which was infrequently mentioned by both early retirees and full pensioners.

These observations about the early exiters would suggest that they are a group of employees whose views on retirement are different than other employees. They view 
retirement as an opportunity to be in control and to have time for vacation and rest. Their decision to retire is heavily influenced by life considerations, primarily coordinating with partner's retirement plans. In addition to this family-related "pull" from the workforce, early exiters are clearly dissatisfied with the work environment and are concerned that their employer does not understand and respond to the needs of older workers. Interesting and rewarding work is a key tactic that can be used to get early exiters to extend their time in the workplace.

\subsubsection{Early Retirees}

Early retirees assign slightly different meaning to retirement than other study participants. While all early exiters and full pensioners see retirement as a way to gain personal control over choices and activities, only $70 \%$ of early retirees assign this meaning to retirement. Similarly, very few early retirees referenced retirement as a time for personal interests as part of their own meaning of retirement, in contrast with the majority of early exiters and full pensioners. That being said, early retirees are more likely than either early exiters or full pensioners to see retirement as a time of significant change and mention awaiting this stage of their life with positive anticipation.

As previously discussed, the results for early retirees and full pensioners are quite similar; however, there are some points of divergence between these two groups that are worth noting.

Early retirees report a wider range of employer actions, which have caused them to consider retirement than either early exiters or full pensioners whose concerns are much more narrowly focused. Specifically, early retirees mentioned an imbalance of work demands and 
results or rewards, incentives in benefit programs, as well as policies and practices that cause dissatisfaction. Early exiters placed more emphasis on an imbalance of work demands and full pensioners identified dissatisfaction with policies and practices more often than early retirees. Similarly, their perspectives with respect to inaction on the part of their employer are also more diverse, with a focus on the lack of proactive engagement of experienced workers and absence of a strategic approach to plan for pending retirements. The other groups were more narrowly focused, with a common concern that their employer is not engaging experienced workers.

Early retirees are substantially less likely to report that their employer has already taken some action that encouraged them to stay longer in the workforce. In fact, no one in this group mentioned that their employer takes action to demonstrate they are valued.

With respect to suggested incentives to keep them in the workplace, early retirees have some views that are common with early exiters and others that are more consistent with full pensioners. Potential incentives to stay that are common with early exiters are changing the nature of work and redesigning benefit and leave programs. On the other hand, early retirees share a common interest with full pensioners in interesting and rewarding work.

These observations suggest that early retirees are different from other groups of employees for several reasons. First, retirement is viewed as a time of significant change and opportunity. A wider range of work-related factors is pushing them to consider retirement and no single employer action stands out as a major influence. Early retirees do not see much action on the part of their employer to suggest that they are valued or wanted in the workplace. Finally, their views on potential offers to get them to stay are also wide-ranging 
and revolve around the nature and content of the work as well as benefit and leave programs.

\subsubsection{Full Pensioners}

Full pensioners plan to dedicate their retirement time to a somewhat different set of activities than other study participants. In particular, they are more likely to want to dedicate time to learning in their retirement and less likely to want to take up community work.

While early retirees and full pensioners share very similar views on retirement factors, one significant difference was noted - full pensioners were satisfied with their work environment while early retirees are not.

While both early retirees and full pensioners were more likely to reference direct employer action than inaction when identifying things that their employer had done which has encouraged them to consider retirement, specific actions or inaction reported by members of these two groups is slightly different. Specifically, full pensioners were more likely than other employees to note that their employer is using specific policies and practices that cause them to be dissatisfied, and more likely to suggest that their employer does not appreciate and respect older workers. Their retirement considerations are not, however, influenced by the lack of engagement of older workers and the imbalance of work demands and rewards/results, factors of importance to those in the early exiter group.

Full pensioners' experience of what their employer has done to get them to consider staying is mixed. Half suggest that their employer is not taking any action to get them to stay, while 
another $50 \%$ suggest that their employer demonstrates that they are valued. This experience is in direct contrast with early exiters who reported a wide range of actions that their employer has taken to get them to stay.

Finally, one in two full pensioners suggest that there is no action an employer can take to get them to stay as their retirement plans are firmly set. This is contrast with the vast majority of study individuals who are open to considering changing their retirement plans. Finally, those full pensioners who are open to staying beyond their current retirement plans are less interested in changing the nature of work than other employees.

Full pensioners are different than other groups of employees for several reasons. Many have set firm retirement plans and are not open to changing these plans regardless of the actions that their employer might take. A key factor in setting their retirement plan is that they have been satisfied with their work environment. That being said, this group emphasizes that they are encouraged to consider retirement because of dissatisfaction with employer policies and practices and a lack of appreciation and respect for older workers.

\subsection{Summary of Factors Which Impact Retirement Considerations}

The analysis of common and diverging perspectives of early exiters, early retirees and full pensioners resulted in the identification of factors which either encourage individuals to consider retiring or to consider staying beyond their retirement eligibility date. These factors are summarized in the table below along with a summary of the findings from this research that support the identification of these factors as impacting retirement considerations of those individuals approaching retirement. The factor is noted in the table only when at least half of the group identified it as potentially impacting their retirement deliberations. Further discussion follows on how the factors identified in this research compare with those already 
identified in the literature. The factors which are consistent with the literature are presented first, followed by those that have emerged in this research. The discussion concludes with those factors which were previously identified in the literature but were not identified in this study.

Table 24. Summary of Factors Which Affect Retirement Considerations Identified in this Research

\begin{tabular}{|c|c|c|c|c|}
\hline \multicolumn{5}{|c|}{ Factors Under the Control of Employer } \\
\hline & \multirow{2}{*}{$\begin{array}{l}\text { Consistent } \\
\text { with the } \\
\text { Literature? }\end{array}$} & \multicolumn{3}{|c|}{ Potential Target Workforce Segment } \\
\hline & & $\begin{array}{c}\text { Individuals } \\
\text { Considering an } \\
\text { Early Exit }\end{array}$ & $\begin{array}{c}\text { Individuals } \\
\text { Considering Early } \\
\text { Retirement }\end{array}$ & $\begin{array}{c}\text { Individuals } \\
\text { Considering } \\
\text { Completing } 35 \text { Years } \\
\text { of Service or More }\end{array}$ \\
\hline \multicolumn{5}{|l|}{$\begin{array}{l}\text { Factors That } \\
\text { Encourage } \\
\text { Individuals to } \\
\text { Consider Staying }\end{array}$} \\
\hline $\begin{array}{l}\text { Flexible Work } \\
\text { Arrangements }\end{array}$ & Yes & & $\sqrt{ }$ & \\
\hline Financial Incentives & Yes & $\sqrt{ }$ & & \\
\hline $\begin{array}{l}\text { Interesting and } \\
\text { rewarding work }\end{array}$ & New & $\sqrt{ }$ & & \\
\hline $\begin{array}{l}\text { Development: } \\
\text { Practices }\end{array}$ & New & $\sqrt{ }$ & $\sqrt{ }$ & \\
\hline $\begin{array}{l}\text { Benefit and } \\
\text { Work/Leave } \\
\text { Programs }\end{array}$ & New & $\sqrt{ }$ & & \\
\hline $\begin{array}{l}\text { Recognition and } \\
\text { Reward Practices }\end{array}$ & New & & & $\sqrt{ }$ \\
\hline \multicolumn{5}{|l|}{$\begin{array}{l}\text { Factors That } \\
\text { Encourage } \\
\text { Individuals to } \\
\text { Consider Retirement }\end{array}$} \\
\hline Work Ehvironment & New & $\sqrt{ }$ & & $\sqrt{ }$ \\
\hline $\begin{array}{l}\text { Early Retirement } \\
\text { Schemes. }\end{array}$ & Yes & & $\sqrt{ }$ & \\
\hline
\end{tabular}




\subsubsection{Factors Consistent with the Literature}

\section{Flexible Work Arrangements}

The results suggest that existing programs that allow for flexible work arrangements are already encouraging individuals approaching retirement to stay in the workplace. About $15 \%$ of study participants suggested that work programs such as the pre-retirement transition program, income averaging program and alternative work arrangements encourage them to stay in the workplace. Flexible work arrangements were also mentioned as an incentive that could be offered to get them to stay in the workplace by nearly half of the individuals in this study. One half of early retirees and one in three early exiters and full pensioners are interested in an offer of flexible work arrangements. Working reduced hours was the most frequently mentioned flexible work arrangement, and there was also interest in working from home or working for part of the year. In some cases, flexible work arrangements are seen as an opportunity to transition to retirement, or to reduce the pressures and workload of a full-time position. Flexible work arrangements are seen as an incentive by all study participants, regardless of their retirement plans.

The literature review suggests that greater work flexibility can lead to changes in retirement decisions, either preventing individuals from retiring or retaining them on a reduced work schedule following retirement (Werkerle and Shultz, 1999; Christensen and Pitt-Catsouphes, 2005; and Morissette, Schellenberg, and Silver, 2004).

This research showed support for the idea that increasing flexibility will influence the retirement decisions of older workers. One in six study participants indicated that they are encouraged to consider staying with their employer because they have been offered work programs that met their needs, such as pre-retirement transition programs, income 
averaging, and flexible work arrangements. One in two participants who were interested in entertaining offers from their employer to stay suggested that an offer of flexible work arrangements could potentially influence their retirement plans. For study participants, attractive work arrangements include reduced hours, working part of the year and working from home.

This research also found that workers approaching retirement are interested in flexible work arrangements as a way to transition to retirement and also to continue to work and contribute productively following retirement. As an example, the pre-retirement transition program offered by the public service provides the opportunity for public servants approaching retirement to work on a part-time schedule with no effect on their pensionable earnings once a retirement date has been set. The finding that over $80 \%$ of study participants are interested in work as a retirement activity points to a good opportunity to continue to use their talents under a bridge employment arrangement, potentially through contract work.

\section{Financial Incentives}

Financial incentives were identified as a factor under the control of employers that could possibly influence retirement plans. The views on this topic were not, however, unanimous. Approximately one-third of study participants viewed financial payments as incentives while one in four study participants specifically stated they were not interested in financial incentives. Financial incentives were most frequently identified by those planning an early exit from the workforce (67\%). One-third of those planning to complete 35 years of service before retiring and only $10 \%$ of individuals planning an early retirement noted this as an action their employer could take to get them to stay. One-third of those planning an early exit from the public service and $30 \%$ of those planning an early retirement noted that 
financial incentives would not motivate them to reconsider their current retirement plans.

Two of the four individuals that indicated they are not motivated to stay by financial incentives noted that there was little that could be done to get them to stay.

The literature review suggested that there is a group of older workers whose motivation to remain in the workforce is that their employment provides them with a necessary stream of income support (Schellenberg, Turcotte and Ram, 2005; Jepsen, 2002). The literature also suggests that while increased salary may contribute to retention of older workers, this incentive may have to be combined with other offers, such as flexible work arrangements, to keep these older workers in the workplace (Morissette, Schellenberg and Ram, 2004).

Financial considerations, particularly being financially ready to retire, emerged in this study as being one of the most important factors in setting retirement plans. Individuals approaching retirement consider the value of their future pension and consider whether it is sufficient to sustain their desired retirement lifestyle. A small proportion of individuals suggested that they are encouraged to stay beyond their eligibility date because benefit programs, particularly pensions, are designed with an incentive to stay. This study also found that some workers approaching retirement would consider changing their retirement plans if financial incentives were offered by their employer; however, views on this incentive were mixed with about one quarter of respondents stating that they would not stay even if offered financial incentives. In summary, this research shows continued support for financial rewards as an incentive to retain individuals approaching retirement; however, it suggests that financial rewards are not a universal incentive and will appeal to only some older workers, primarily those planning an early exit from the public service. 


\section{Early Retirement Schemes}

The literature review suggested that strong financial incentives to retire early are presented in the design of many Registered Pension Plans, particularly defined-benefit plans, offered by Canadian employers (Policy Research Initiative, 2005). As a result, workers are often eligible for a pension before 60 , an age at which many workers are still healthy and able to continue working.

The results of this research suggest that the public service pension plan, as a definedbenefit plan, does offer incentives for public servants to "retire early." Over half of the study participants intend to retire at or within a short time period after the first point of eligibility for an unreduced pension. Many workers will meet the eligibility criteria of 30 years of service when they are at or around the age of 55 . Only $30 \%$ of study participants intended to work 35 years to increase their pension to the maximum benefits allowed under the public service pension plan.

\subsubsection{New Factors Identified in this Research}

Several factors were identified in this research which have not received attention in the literature including interesting and rewarding work, development practices, work and leave/benefit programs, recognition and reward practices and work environment. The key findings related to each of these factors are discussed below.

\section{Interesting and Rewarding Work}

The research suggests that interesting and rewarding work provides an incentive for individuals approaching retirement to consider staying beyond their retirement eligibility date. Over $40 \%$ of study participants suggested that they have considered staying longer because they have been provided interesting and rewarding work, and nearly $70 \%$ of individuals indicated that an offer of interesting and rewarding work would entice them to 
stay beyond their current planned retirement date. Individuals who are considering an early exit from the public service appear to be motivated by interesting and rewarding work. The research results suggest that early exiters were most likely to report they had stayed because of interesting and rewarding work (67\%). In addition, an offer of interesting and rewarding work was also the most commonly mentioned action (100\%) that their employer could take to get them to stay beyond their current retirement plans.

Those that are planning an early retirement and those planning to complete 35 years of service or more are also interested in an offer of interesting and rewarding work as an incentive to stay, but not to the same extent as those planning an early exit from the public service. This incentive was mentioned by only $40 \%$ of early retirees and one-third of those planning to retire with a full pension.

\section{Development Practices}

Development practices for older workers are also a factor under the control of employers that can be used to extend the time older workers are willing to stay in the workplace. The results from this research would suggest that for many of the individuals participating in this study, current development practices may be encouraging them to consider retirement. For example, over $40 \%$ of study participants suggested that their employer is not proactively engaging experienced workers. Also, $37 \%$ of individuals felt that their employer is not taking an action to encourage them to stay.

For many individuals, development does not necessarily mean promotional opportunities; in fact, only $6 \%$ of study participants see a promotion as an incentive to remain in the workplace. Two study participants reported that promotion would not be an incentive for 
them, indicating that they were not were not interested in assuming stress levels associated with higher levels.

Many study participants, particularly those planning an early exit from the public service $(67 \%)$ expressed a concern that they are not being proactively engaged to put their talents to best use. $40 \%$ of those planning early retirement and one-third of those planning to retire with 35 years of service or more also expressed this concern. Therefore, employers need to proactively engage all employees to understand what, if anything, can be done to retain the knowledge and experience of older workers in the workplace. The following two quotes from two separate individuals, one at the manager level and the other at the executive level illustrate the potential opportunities that might exist for workers approaching retirement to meet their own personal and development needs:

Although I am not interested in going into the EX group on a permanent basis, I am interested in growing.... I know that there are a lot of EXs that have to go on extended leave, and personally someone like me, I would enjoy have an EX experience for 3 or 6 month period but I am not sure who to turn and tell that and to make that known, so if there is a need that I can be considered for such a position.... The idea behind this is not a financial one. It is one where you can expand your horizons and where you can contribute to the organization. I do believe I have the qualifications to be an EX and I have certainly chosen not to be because I am trying to reduce my work week. I understand that if I took an assignment like this for 3-6 months it would require extra effort and I would be willing to invest in that for that period. So I think that this is the kind of incentive could be very valuable at CIC where there are so many people and so much movement.

- Female manager who intends to take early retirement in about four years

I really think that it's important that executives be offered time off without affecting their ability to hold the job or to take sort of a sabbatical. I know that we have a new executive policy and you can take leave for executive learning but it seemed quite restricted... Instead of tying the leave to something specific, it should be more like a sabbatical concept. For personal renewal, maybe go to the south of France for three months, if you are at that stage of your life that you can afford that or you have the opportunity to do that. It seems to be no way to get off the treadmill, once your in a busy, difficult job, there seems to be no way to get off the treadmill and take a break, because people are counting on you being there to guide staff and to bring your corporate memory and to provide leadership on difficult issues.

- Female executive who plans to leave the public service before meeting the requirements for early retirement 
Within these two discussions, one individual nearing retirement expressed a desire to take an extended leave for personal renewal but identified a practical challenge of "getting off the treadmill", while the other indicated an interest in taking on a new and invigorating short-term challenge, stepping into an executive role. There is an opportunity for employers to develop programs to facilitate these types of personal development and needs, with the results being workers who are energized and willing to stay on longer in the workplace.

Development of older workers may also include a significant change in duties, one that makes use of their expertise but adds a new challenge to their remaining years in the workplace. The results suggest that one in four individuals is looking for a fundamental change in duties and approximately $13 \%$ of individuals are interested in a coaching and mentoring role. These types of opportunities were most frequently identified by individuals planning to leave the public service before reaching eligibility for early retirement or by those with early retirement plans.

\section{Work and Leave/Benefit Programs}

Work and leave/benefit programs are another factor that employers control and can use to potentially influence retirement plans. One-quarter of study participants indicated that they are encouraged to consider retirement because the design of benefit programs provides an incentive to retire. In fact, those that are planning an early exit from the public service are encouraged to stay by the design of these benefit plans, with the goal of minimizing the penalties associated with leaving before meeting minimum pension eligibility requirements.

Work programs and benefits, such as pre-retirement transition programs, income averaging programs, and leave programs, can also incent those that are approaching retirement to 
stay longer. Finally, nearly $20 \%$ suggested that redesigning or expanding benefit and leave programs was an action an employer could take to encourage them to change their retirement plans.

Individuals planning an early retirement or those considering an early exit from the public service are more likely to view work and benefit programs as an incentive to stay longer in the public service.

\section{Recognition and Reward Practices}

Recognition and reward practices were identified as a factor which impacts considerations related to retirement. One in five individuals have been encouraged to stay beyond their retirement eligibility date because their employer demonstrates that they are valued. Over half of full pensioners and one third of early exiters reported that they feel valued, while no early retirees suggested this was the case. Full pensioners were more likely to suggest that they were encouraged to consider retirement because their employer was not demonstrating that long-serving employees are valued.

\section{Work Environment}

The research identified a number of practices which relate to the general work environment which are causing individuals to consider retirement - use of policies and practices which cause dissatisfaction and the fact that there is an imbalance between the work demands and the achieved results.

Nearly one third of study participants suggested that there are many work demands, but not enough results or accomplishments. This imbalance of demands and rewards in the work environment has caused them to consider retirement. This issue was mentioned by 
two-thirds of study participants planning an early exit from the public service, $30 \%$ of those planning early retirement and $17 \%$ of those planning to retire with a full pension. Actions employers can take to address this concern, particularly to give employees an opportunity to see progress and accomplishments in their work may help encourage employees to consider extending their time in the public service.

Another element of the work environment are the policies and practices adopted by the management of the organization. One-quarter of study participants suggested that they were encouraged to consider retirement because of policies and practices that cause dissatisfaction. Dissatisfaction with management policies and practices were most frequently noted by those planning to retire with 35 years of service or more $(50 \%)$.

\subsubsection{Factors Not Evident in this Research}

The literature review identified several factors which did not emerge as factors impacting the retirement deliberations of the individuals participating in this study. This section provides a summary of the literature in relation to these factors and a commentary in relation to any evidence from this study with respect to those factors.

\section{Early Retirement Counseling Programs}

The views of early retirement counseling programs and their effect on retirement decisions was not conclusive in the literature review. While Feldman (1994) hypothesized that employees who receive preretirement counseling are more likely to retire early, others including Werkerle and Shultz (1999) did not find support for this as a factor to encourage early retirement.

In this research study, a small proportion of study participants $(10 \%)$ did identify that they were encouraged to consider retirement because their employer offered pre-retirement 
training programs. This factor, however, did not emerge as a major influence in their decision but helped them through the preparatory steps of planning for retirement. Given the exploratory nature of this research, the lack of support for this factor suggests that this topic continued to be explored.

\section{Discrimination}

The literature review suggested that stereotypes of older workers can be a barrier for many older workers who wish to continue in the workplace (Schetagne, 2001; Jepsen, 2002; The Urban Institute, 2007). One of the critiques of literature in this area is that much of the research to date in this field characterizes the employer's view on older workers. The existing literature does not focus on the perceptions of older workers as the key decisionmakers of their own retirement plans and whether discrimination in the workplace affects these decisions.

The results of this research thesis did not identify discrimination as a factor which impacts the retirement considerations of older workers. Two in five individuals did however suggest that their employer did not proactively engaging experienced workers. While we cannot say with certainty why the employer is not engaging older workers, a negative view of older workers could potentially be one reason among many.

\section{Absence of Training or Learning}

The literature review suggested that employability levels of older workers are affected by levels of investment in training and learning, and there is evidence to suggest that this investment decreases as workers age (Jepsen, 2002; Statistics Canada, 2004). There are a number of authors who note that both increased training investments and shifts in attitudes and perceptions regarding training for older workers will be required to build and maintain 
employability levels of older workers in Canada in the future (Morissette, Schellenberg and Silver, 2004; OECD, 2005; Policy Research Initiative, 2005).

An absence of training or learning was not identified in this research as a factor that influences the retirement decisions of older workers. While study participants expressed concern that their employer was not proactively engaging older workers and noted that this inaction was causing them to consider retirement, the results do not suggest that lack of investment in training for older workers is an issue faced by those individuals participating in this research study. 


\section{Conclusions}

This research thesis set out to explore the role of employers in retirement decisions, and specifically what employers can do to increase the proportion of engaged older workers who choose to remain with the organization until or after retirement age. This research focus was selected to help fill the gap in existing knowledge about the role of the employer in influencing individual retirement decisions. Existing theories and empirical research related to retirement decisions tend to focus on the impact of broad macroeconomic variables and individual variables and little attention has been given to variables under the control of organizations. Within the literature on organizational variables, there are differing perspectives on whether employers can really influence retirement decisions and to date, a limited number of incentives have been identified.

This research makes a theoretical contribution by demonstrating that employers do have an impact on retirement plan deliberations. Individuals consider work-related factors in setting their retirement plans and note that employer action and inaction has caused them to consider retiring or staying beyond their current retirement plans. While financial and life considerations are the leading factors in setting retirement plans, it is clear that employer policies, programs and actions are weighed by individuals during their retirement plan deliberations.

Another key contribution to the theory related to the impact of organizations on retirement decisions is the finding that potential incentives go beyond those already identified in the literature to date and are likely more complex to implement in organizations. Two of the most commonly identified incentives in the literature are flexible work arrangements and 
financial incentives. In addition to confirming financial incentives and flexible work arrangements as organizational factors impacting retirement decisions, several new factors were identified in this research and include interesting and rewarding work, development practices, recognition and reward practices, work and benefit/leave programs and work environment. A wider range of factors to influence retirement decisions makes the design of policies and programs to achieve retention of workers approaching retirement much more complex.

A key line of inquiry in this research was whether the views of potential incentives differs based on the worker's intended retirement plan. Using the results of this analysis, the research contributes to expands the current theory by identifying that some incentives may be more attractive depending upon the individual's retirement plans (early exit, early retirement, maximum pensionable years of service). Figure 7 below summarizes the differentiating work-related factors in retirement decisions for each of these three groups. 


\section{Figure 7: Differentiating Work-Related Factors in Retirement Decisions}

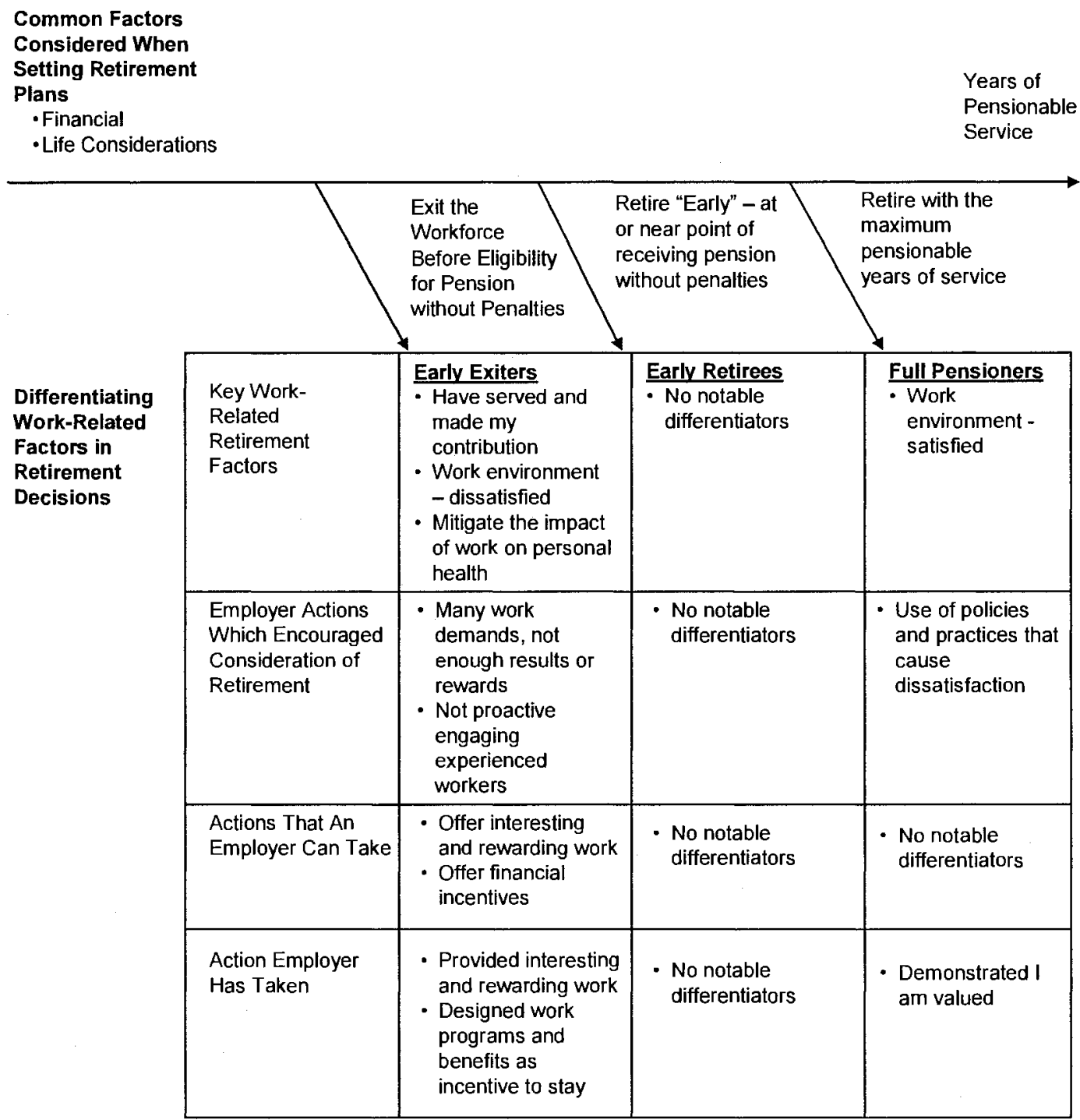

This research suggests that early exiters are most distinct, and the perspectives of individuals planning to retire at or shortly thereafter reaching the earliest point of retirement eligibility are very similar to those who plan to remain in the workplace until they have served the maximum number of years of pensionable service. For early exiters, workrelated factors play a significant role in the retirement plan deliberations of early exiters. 
They are strongly influenced by an imbalance of work demands and results/rewards, and feel that they are not being proactively engaged. Interesting and rewarding work, financial incentives and work programs/benefits are important incentives for this group. There were a few notable differentiators for full pensioners, including a more positive view of their satisfaction with work which has kept them in the workplace, particularly a feeling of being valued. This group is concerned, however, about some employer policies and practices.

This research was designed to understand how organizations can increase the proportion of engaged older workers who choose to remain with the organization until or after retirement age. The research resulted in the identification of factors which influence retirement decisions, including some already noted in the literature and some new factors. A limitation of this research is that while it identifies a wide range of potential factors that influence retirement decisions, it does not assess the relative importance of these factors in retirement decisions. Further research is required to better understand the specific impact these factors have on keeping older workers in the workplace, for example, which policies or practices are most effective in influencing retirement decisions.

This research attempted to investigate whether individuals who have set different retirement plans (early exit before retirement eligibility, retirement at point of eligibility, or retirement with maximum pensionable years of service) may be influenced by different factors when setting those plans. The results would suggest that employers can influence the retirement decisions of these categories of study participants using slightly different approaches. Given the small sample size for some of these segments, further research targeted at each of these groups is required to better understand their unique preferences and motivators. One potential area of focus is to understand the motivations behind the 
retirement plans of those intending to leave the public service before meeting pension eligibility requirements. While this group of individuals is small, it represents a talent base of employees that are relatively young and who are willing to stay longer if the right work environment exists. Another potential area for future research is to further investigate the early retiree population to confirm the most effective incentives for this group and to understand how much longer they are willing to remain in the workplace. This research can serve as a starting point in this regard.

Another limitation of this research is that the research participants self-identified and therefore profile of individual retirement plans (early exiters, early retirees, full pensioners) may not reflect the broader population. For example, while early exiters represented $15 \%$ of the sample for this study, there is a possibility that this group and other groups were overor under-represented relative to the broader population. Given limited resources and the need to focus on efforts that will have the most impact, it is important for employers to understand the relative size of each of these groups and to develop policies and programs which will result in greater retention of older workers. 


\section{References}

Adams, G. \& Rau, B. Job seeking among retirees seeking bridge employment. Personnel Psychology, 57 (3), 719-744.

Bowlby, G. (2007). Defining retirement. Perspectives on Labour and Income, February 2007, 15-19. Ottawa: Statistics Canada.

Bryman, A. \& Bell, E. (2003). Business research methods. New York: Oxford University Press Inc.

Christensen, K. \& Pitt-Catsouphes, M. (2005). Accommodating older workers' needs for flexible work options. Ivey Business Journal Online, 69 (6). Retrieved January 15, 2008 from http://www.iveybusinessjournal.com/archives/issue.asp?intIssue ID $=68$.

Conroy, N., Lamontagne, M., Stone, L., \& Moloney, P. (2006). Additional topics for future research. In L. Stone (Ed), New frontiers of research on retirement (429-444). Ottawa: Statistics Canada.

Duchesne, D. (2002). Seniors at work. Perspectives on Labour and Income, Summer 2002, 33-44. Ottawa: Statistics Canada.

Eisenhardt, K.M. (1989). Building theories from case study research. Academy of Management Review, 14 (4), 532-550.

Feldman, D.C. (1994). The decision to retire early: A review and conceptualization. Academy of Management Review, 19 (2), 285-311. 
Gauthier, H. \& Asselin, S. (2006). Growing diversity? Typical transitions towards retirement from active workforce participation. In L. Stone (Ed), New frontiers of research on retirement (291-320). Ottawa: Statistics Canada.

Glaser, B.G. \& Strauss, A.L. (1967). The discovery of grounded theory; strategies for qualitative research. Chicago: Aldine Publishing Co.

Human Resources Development Canada. (2002). Collective Agreement and Older Workers in Canada. Retrieved December 27, 2007 from HRSDC website: http://www.hrsdc.gc.ca/en/lp/spila/wlb/caowc/10chapter 5.shtml.

Institute for Research on Public Policy (2007). Expert round table on older workers, May 27, 2007: Rapporteur's report. Montreal, QC: Institute for Research on Public Policy

Jepsen, M. (2002). The scientific debate on older workers. In M. Jepsen, D. Foden \& M. Hutsebaut (Eds.), Active strategies for older workers (25-50). Brussels: European Trade Union Institute.

Kerr, D., Ibbott, P. \& Beaujot, R. (2004). Probing the future of mandatory retirement. Discussion paper no. 04-05. Population Studies Centre, University of Western Ontario. Accessed January 23, 2008 from http://www.ssc.uwo.ca/sociology/popstudies/dp/dp0405.pdf

Kieren, P. (2001). Early retirement trends. Perspectives on Labour and Income, Winter 2001, 7-13. Ottawa: Statistics Canada.

Lazear, E.P. (1979). Why is there mandatory retirement?. Journal of Political Economy, 87 (6), 1261-1284. 
Morissette, R., Schellenberg, G. and Silver, C. (2004). Retaining older workers. Perspectives on Labour and Income, October 2004, 15-20. Ottawa: Statistics Canada.

Marshall, K. \& Ferrao, V. (2007). Participation of older workers. Perspectives on Labour and Income, August 2007, 5-11. Ottawa: Statistics Canada.

Organisation for Economic Co-operation and Development. (2005). Ageing and Employment Policies: Canada. Paris: Organisation for Economic Co-operation and Development.

Patton, M.Q. (2002). Qualitative research \& evaluation methods. Thousand Oaks: Sage Publications.

Peters, V. (2004). Working and training: First results of the 2003 Adult Education and Training Survey (Catalogue No. 81-595-MIE2004015). Ottawa: Statistics Canada.

Policy Research Initiative. (2005). Encouraging choice in work and retirement: Project Report. Ottawa: Policy Research Initiative.

Pyper, W. \& Giles, P. (2002). Approaching retirement. Perspectives on Labour and Income, Winter 2002, 9-15. Ottawa: Statistics Canada.

Reday-Mulvey, G. (2005). Working beyond 60: Key policies and practices in Europe. New York: Palgrave Macmillan.

Schellenberg, G. (2004). The retirement plans and expectations of non-retired Canadians aged 45 to 59. (Catalogue no. 11F0019MIE - No. 223). Ottawa: Statistics Canada.

Schellenberg, G., Turcotte, M. \& Ram, B. (2005). Post-retirement employment. Perspectives on Labour and Income, September 2005, 14-17. Ottawa: Statistics Canada. 
Statistics Canada (2001). Table 102-0121. Health-adjusted life expectancy, at birth and at age 65, by sex and income group, Canada and provinces. Retrieved March 14, 2008 from http://cansim2.statcan.ca/cgibin/cnsmcgi.exe?Lang $=E \&$ RootDir $=\mathrm{CII} /$ \&ResultTemplate $=\mathrm{CII} / \mathrm{CII} \quad$ \&Array Pick $=1 \&$ Arr ayId $=1020121$.

Statistics Canada (2004). The near-retirement rate. Perspectives on Labour and Income, February 2004, 18-22. Ottawa: Statistics Canada.

Statistics Canada. (2005). Population projections for Canada, provinces and territories (Catalogue no. 91-520-XIE). Ottawa: Statistics Canada.

Statistics Canada (2006). Low income cutoffs for 2005 and low income measures for 2004. (Catalogue no: 75F000MIE, Vol. 4). Ottawa: Statistics Canada.

Statistics Canada. (2007a) Employment Trends in the Federal Public Service. (Catalogue no. 11-621-MIE - No. 053). Ottawa: Statistics Canada.

Statistics Canada. (2007b). Portrait of the canadian population in 2006, by age and sex, 2006 Census. (Catalogue no. 97-551-XIE). Ottawa: Statistics Canada.

Statistics Canada. (2007c). Pension Plans in Canada Survey. Retrieved January 29, 2008 from Statistics Canada website: http://www.statcan.ca/cgibin $/ \mathrm{imdb} / \mathrm{p} 2 \mathrm{SV} . \mathrm{pl}$ ?Function $=$ getSurvey\&SDDS $=2609 \& \mathrm{ang}=\mathrm{en} \& \mathrm{db}=\mathrm{IMDB} \& \mathrm{dbg}=\mathrm{f} \& \mathrm{adm}=$ 8\&dis $=2$. 
Stone, L.O., \& Nouroz, H. (2006). Patterns of work-to-retirement transition among Canadian public-sector employees. In L. Stone (Ed), New frontiers of research on retirement (291320). Ottawa: Statistics Canada.

Watson Wyatt (2008). Watson Wyatt Special Memorandum 08-02. Retrieved February 26, 2008 from Watson Wyatt website http://ebnc,benefitnews.com/attachmentcache/BenefitsNetwork/2008/02/11/111340876WWphasedretirement.pdf.

Weckerle, J.R. \& Shultz, K.S. (1999). Influences on the bridge employment decision among older USA workers. Journal of Occupational and Organizational Psychology, 72, 317-329.

Yin, R.K. (2003). Case study research: Design and methods (3rd ed.). Thousand Oaks, CA: Sage Publications, Inc. 
Appendix A - Email to Solicit Study Participants 
From: Primeau. Heather [mailto:Heather.Primeau@cic.gc.ca]

Sent: Thu 29/05/2008 4:10 PM

To: CIC-EX-AND-EX-Equivalent; CIC-Middle-Managers-NHQ

Cc: akeough@connect.carleton.ca; Armit.Lara; Poirier.Anita

Subject: Sprott School of Business Study on Retirement/école de commerce Sprott étude sur la retraite

(Le français suit)

What can employers do to keep employees engaged in the workplace until or beyond the point of pension eligibility? This question is being posed by many employers as they plan for the impact of retirement of large proportions of their workforce in next five to ten years.

Do you have any thoughts or perspectives to share on this topic?

Annette Keough, a Masters student at Sprott School of Business at Carleton University, is currently conducting a study to understand what policies or programs under the control of employers can be used to delay the retirement of older workers. This student thesis is being supervised by Dr. Linda Duxbury.

Volunteers are required to participate in short 20-30 minute interviews either in person or by phone. Interview topics include retirement plans; factors considered in setting retirement plans; and the impact of their employer in encouraging them to stay in the workplace or to retire.

Target Profile for Participants

The profile of individuals being targeted for this research includes:

- A member of a knowledge-based occupational category - scientific and professional; computer systems; program and administrative; executive; and administrative and foreign service;

- Within five years of eligibility for retirement and actively contemplating their retirement plans;

- Willing to discuss their retirement plans and the impact of their employer on these plans in a confidential interview;

- Working within CIC NHQ (the scope of the study has been limited to this group recognizing regional differences)

Information shared in these interviews will be kept in confidence as will the names of those individuals who were interviewed. In return for helping identify volunteers for the study, CIC will receive a report based on themes and aggregate results. Comments will not be attributed to specific individuals.

Approximately 25 volunteers are required and due to the scope of the study not all volunteers will be selected.

If you are interested in volunteering for this study, please contact the researcher indicating the number of years to your retirement eligibility and your language preference for the interview. The student can conduct interviews in English and can bring another student to help translate for those volunteers who prefer to conduct the interview in French.

Contact Details

Annette Keough 
Researcher

(613) 271-7364

akeough@connect.carleton.ca

Thanks,

Heather

Heather Primeau

Director, Learning and Development Division / Directrice, Division de l'apprentissage et perfectionnement

613-952-5242 | facsimile / télécopieur 613-952-9064 Heather.Primeau@cic.gc.ca

Citizenship and Immigration Canada | 219 Laurier Avenue West Ottawa ON K1A 1L1

Citoyenneté et Immigration Canada | 219 avenue Laurier Ouest Ottawa ON K1A 1L1

Government of Canada | Gouvernement du Canada

Que peuvent faire les employeurs pour maintenir l'engagement des employés envers leur milieu de travail jusqu'à ce qu'ils deviennent admissibles à la retraite ou même audelà? Ceci est la question que se posent beaucoup d'employeurs qui se préparent à voir partir à la retraite, une grande partie de leurs effectifs dans les cinq à dix prochaines années.

Avezvous des idées ou des points de vue à faire valoir sur le sujet?

Annette Keough, étudiante à la maîtrise à l'école de commerce Sprott de l'Université Carleton, effectue présentement une étude visant à mieux comprendre quels sont les programmes ou les politiques à la disposition des employeurs pour tenter de retarder le départ à la retraite des travailleurs les plus âgés. La thèse de Mme Keough est supervisée par Dr. Linda Duxbury.

Nous recherchons des bénévoles qui accepteraient de participer à de courtes entrevues de 20 à 30 minutes en personne ou par téléphone. Les sujets abordés incluront les projets de retraite, les facteurs qui entrent en ligne de compte lors de la préparation de projets de retraite, et l'influence de l'employeur qui incite ses employés à rester au travail ou au contraire à prendre leur retraite.

Profil visé des participants:

La présente étude recherche des individus :

- qui appartiennent à une catégorie professionnelle fondée sur le savoir - scientifique et professionnelle, systèmes d'ordinateurs, services des programmes et de l'administration, direction, administration et service extérieur;

- admissibles à prendre leur retraite dans les cinq prochaines années et qui préparent activement leurs projets de retraite;

- prêts à discuter au cours d'une entrevue confidentielle de leurs projets de retraite et de l'influence de leur employeur sur ces projets;

- qui travaillent au sein de l'administration centrale (AC) de Citoyenneté et Immigration Canada (CIC) (la portée de l'étude se limite aux employés de l'AC, car on reconnaît l'existence de distinctions régionales).

Les renseignements fournis au cours des entrevues, ainsi que les noms des personnes interrogées, resteront confidentiels. En échange de l'aide fournie pour trouver des bénévoles pour l'étude, CIC recevra un rapport par thèmes faisant état de résultats globaux. Les commentaires cités ne seront pas attribués à des personnes précises. 
Nous avons besoin d'environ 25 bénévoles et, en raison de la portée de l'étude, tous les bénévoles ne seront pas retenus.

Si vous désirez participer bénévolement à l'étude, veuillez communiquer avec la chercheuse et lui indiquer le nombre d'années qu'il vous reste à travailler avant de devenir admissible à la retraite, ainsi que votre langue de choix pour l'entrevue. L'étudiante peut mener les entrevues en anglais et utiliser les services d'un(e) autre étudiant(e) pour tenir le rôle d'interprète pour ceux qui désirent avoir une entrevue en français.

Personneressource

Annette Keough

Chercheuse

6132717364

akeough@connect.carleton.ca

Merci,

Heather

Heather Primeau

Director, Learning and Development Division / Directrice, Division de l'apprentissage et perfectionnement

613-952-5242 | facsimile / télécopieur 613-952-9064

Heather.Primeau@cic.gc.ca

Citizenship and Immigration Canada | 219 Laurier Avenue West Ottawa ON K1A 1L1 Citoyenneté et Immigration Canada | 219 avenue Laurier Ouest Ottawa ON K1A 1L1

Government of Canada | Gouvernement du Canada 
Appendix B - Interview Script 


\title{
Carleton University Sprott School of Business
}

Master of Management Studies Research Study Interview Script

\author{
Influencing the Retirement Intentions of Older Workers - Approaches \\ to Retain Existing Employees Considering Retirement
}

\section{Introduction}

Thank you for agreeing to share your perspectives as part of a research study I am conducting as part of my studies at Sprott School of Business.

This research is being undertaken for several reasons.

- Many employers, including Citizenship and Immigration Canada, will have a large proportion of their workforce eligible to retire within the next ten years, taking with them vast knowledge and expertise.

- A suggested approach to reduce the effect of such a significant exodus from the workforce is to encourage individuals to stay in the workplace beyond the point at which they are eligible to retire.

- To date, little research focus has been placed on understanding the incentives required to keep individuals in the workforce.

The purpose of the research is to further explore and understand how policies and programs under the control of organizations impact retirement decisions of older workers. The information shared in this interview will be used to identify factors which can potentially influence the retirement intentions of older workers.

There is some additional information that I would like to share with you about this research study.

- Clearance by the Carleton University Research Ethics Committee

- This research project has been reviewed and received ethics clearance by the Carleton University Research Ethics Committee. I am providing you with a Letter of Information and will ask that you review the letter and give your consent to be included in this research study before we begin.

- Confidentiality

- Approximately 25 individuals will be interviewed as part of this study. These are individuals who self-identified as being willing to participate in the study.

- The discussions in these interviews will be kept confidential and will not be shared with anyone at CIC.

- CIC will receive a report which will include themes summarized from these interviews and representative quotes from the discussions. Quotes will not be attributed to any individual.

- Copy of Research Report Available to Participants

- Research participants may also receive a copy of the result, upon request. Are you interested in receiving the results?

- Permission to Record Interview

- To help support the collation and analysis of the information shared in this interview, I am asking your permission to record this conversation. If you 
would prefer that this interview not be recorded, I will take detailed notes.

What is your preference?

Do you have any questions for me before the interview begins?

\section{Interview Questions}

1. What does retirement mean to you?

- Probing/follow-up questions

- What concepts come to mind when you think about retirement?

- Does your idea of retirement include a transition period between work and retirement? If so, what does this transition look like?

2. When are you "eligible" to retire? When do you plan to retire?

- Probing/follow-up questions

- How long will it be before you are eligible to retire with a full pension (no penalty)?

- Do you plan to retire before, after or at the specific time of eligibility?

3. What activities do you plan to do when you retire?

- Probing/follow-up questions

- What will be the role of family? Leisure? Community?

- What will be the role of work?

- What will be the role of education and training?

4. What factors did you or will you consider when setting your retirement plan?

- Probing/follow-up questions

- What personal factors did you consider in setting your retirement plans?

- What work-related factors did you consider?

- Are there any other factors that you considered?

5. Employers sometimes do things that cause employees to consider leaving the workplace through retirement or to stay beyond the point at which they are eligible to retire. These actions might be related to you personally, to your position or work unit, or applicable across the entire organization.

- What has your employer done that has encouraged you to consider retirement? What has your employer not done that has encouraged you to consider retirement?

- What has your employer done that has encouraged you to stay beyond your retirement eligibility date?

6. What could your employer do to get you to stay beyond your current planned retirement date?

- Probing/follow-up questions 
- Consider the actions you noted above as having encouraged you to consider retirement. What could your employer do differently in the future to encourage you to think about staying in the workplace longer?

7. Is there anything else that you would like to share? 
Appendix C - Data Tables Summarizing Key Themes from Interviews - By Classification of Employees Whose Retirement

Decisions were Impacted by Employer Action/Inaction 
Table 25. Meaning of Retirement - Key Themes - By Classification of Employees Whose Retirement Decisions were Impacted by Employer Action/Inaction

\begin{tabular}{|c|c|c|c|c|}
\hline Meaning of Retirement & $\begin{array}{c}\text { Both action and } \\
\text { inaction by } \\
\text { employer } \\
(\mathbf{n}=7)\end{array}$ & $\begin{array}{l}\text { Direct actions } \\
\text { by employer } \\
\qquad(n=5)\end{array}$ & $\begin{array}{l}\text { Inaction on the } \\
\text { part of the } \\
\text { employer } \\
(\mathbf{n}=\mathbf{3})\end{array}$ & $\begin{array}{l}\text { My employer } \\
\text { has not } \\
\text { affected my } \\
\text { retirement } \\
\text { consideration } \\
(n=4)\end{array}$ \\
\hline Gaining personal control & $100 \%$ & $100 \%$ & $67 \%$ & $50 \%$ \\
\hline Expand activities beyond work & $43 \%$ & $0 \%$ & $0 \%$ & $0 \%$ \\
\hline Activities under personal control & $43 \%$ & $20 \%$ & $33 \%$ & $25 \%$ \\
\hline Freedom to make choices & $57 \%$ & $60 \%$ & $0 \%$ & $0 \%$ \\
\hline Time for personal interests & $57 \%$ & $60 \%$ & $33 \%$ & $50 \%$ \\
\hline Remaining busy & $0 \%$ & $20 \%$ & $33 \%$ & $0 \%$ \\
\hline Time of significant change & $57 \%$ & $60 \%$ & $100 \%$ & $100 \%$ \\
\hline Opportunity and potential & $29 \%$ & $0 \%$ & $0 \%$ & $50 \%$ \\
\hline Career change or shift & $29 \%$ & $0 \%$ & $0 \%$ & $25 \%$ \\
\hline New phase of life & $0 \%$ & $40 \%$ & $67 \%$ & $75 \%$ \\
\hline Achievement and reward & $0 \%$ & $0 \%$ & $33 \%$ & $0 \%$ \\
\hline Positive anticipation & $14 \%$ & $40 \%$ & $33 \%$ & $0 \%$ \\
\hline Apprehensive anticipation & $14 \%$ & $20 \%$ & $67 \%$ & $25 \%$ \\
\hline Closer to end of life & $14 \%$ & $0 \%$ & $33 \%$ & $25 \%$ \\
\hline Loss & $0 \%$ & $20 \%$ & $0 \%$ & $0 \%$ \\
\hline Apprehensive anticipation & $0 \%$ & $0 \%$ & $33 \%$ & $25 \%$ \\
\hline
\end{tabular}


Table 26. Retirement Activities - Key Themes - By Classification of Employees Whose Retirement Decisions were Impacted by Employer Action/Inaction

\begin{tabular}{|c|c|c|c|c|}
\hline Retirement Activities & $\begin{array}{c}\text { Both action and } \\
\text { inaction by } \\
\text { employer } \\
(\mathbf{n}=\mathbf{7})\end{array}$ & $\begin{array}{l}\text { Direct actions } \\
\text { by employer } \\
\qquad(n=5)\end{array}$ & $\begin{array}{l}\text { Inaction on the } \\
\text { part of the } \\
\text { employer } \\
(n=3)\end{array}$ & $\begin{array}{l}\text { My employer } \\
\text { has not } \\
\text { affected my } \\
\text { retirement } \\
\text { consideration } \\
(n=4)\end{array}$ \\
\hline Leisure & $100 \%$ & $100 \%$ & $100 \%$ & $100 \%$ \\
\hline Outdoor activities & $57 \%$ & $60 \%$ & $33 \%$ & $50 \%$ \\
\hline Travel and tourism & $57 \%$ & $60 \%$ & $100 \%$ & $100 \%$ \\
\hline Hobbies & $57 \%$ & $80 \%$ & $33 \%$ & $25 \%$ \\
\hline More time on current interests & $57 \%$ & $80 \%$ & $0 \%$ & $25 \%$ \\
\hline Time with friends & $0 \%$ & $60 \%$ & $0 \%$ & $0 \%$ \\
\hline Vacation and rest & $0 \%$ & $20 \%$ & $33 \%$ & $25 \%$ \\
\hline Other leisure & $43 \%$ & $0 \%$ & $0 \%$ & $25 \%$ \\
\hline Work & $86 \%$ & $60 \%$ & $67 \%$ & $100 \%$ \\
\hline Working & $86 \%$ & $60 \%$ & $67 \%$ & $100 \%$ \\
\hline Not to any extent & $14 \%$ & $0 \%$ & $0 \%$ & $0 \%$ \\
\hline Not for money & $43 \%$ & $0 \%$ & $0 \%$ & $0 \%$ \\
\hline Maybe & $14 \%$ & $60 \%$ & $33 \%$ & $25 \%$ \\
\hline Definitely & $14 \%$ & $0 \%$ & $0 \%$ & $75 \%$ \\
\hline Part-time & $29 \%$ & $40 \%$ & $0 \%$ & $50 \%$ \\
\hline Related to current work & $14 \%$ & $0 \%$ & $67 \%$ & $25 \%$ \\
\hline Not related to current work & $14 \%$ & $0 \%$ & $0 \%$ & $0 \%$ \\
\hline Community & $43 \%$ & $80 \% \%$ & $33 \%$ & $50 \%$ \\
\hline Volunteer & $43 \%$ & $40 \%$ & $33 \%$ & $25 \%$ \\
\hline $\begin{array}{l}\text { Volunteer - resume prior } \\
\text { activity }\end{array}$ & $0 \%$ & $40 \%$ & $0 \%$ & $25 \%$ \\
\hline Family & $43 \%$ & $43 \%$ & $0 \%$ & $25 \%$ \\
\hline Spending time & $14 \%$ & $14 \%$ & $0 \%$ & $0 \%$ \\
\hline Providing support & $29 \%$ & $29 \%$ & $0 \%$ & $25 \%$ \\
\hline Leaming & $43 \% \%$ & $40 \%$ & $0 \%$ & $25 \%$ \\
\hline
\end{tabular}


Table 27. Retirement Factors - Key Themes - By Classification of Employees Whose Retirement Decisions were Impacted by Employer Action/Inaction

\begin{tabular}{|c|c|c|c|c|}
\hline Retirement Factors & $\begin{array}{c}\text { Both action and } \\
\text { inaction by } \\
\text { employer } \\
(n=7)\end{array}$ & $\begin{array}{c}\text { Direct actions } \\
\text { by employer } \\
\qquad(n=5)\end{array}$ & $\begin{array}{l}\text { Inaction on the } \\
\text { part of the } \\
\text { employer } \\
(\mathbf{n}=\mathbf{3})\end{array}$ & $\begin{array}{l}\text { My employer } \\
\text { has not } \\
\text { affected my } \\
\text { retirement } \\
\text { consideration } \\
(n=4)\end{array}$ \\
\hline Financial & $100 \%$ & $80 \%$ & $33 \%$ & $75 \%$ \\
\hline Being financially ready & $86 \%$ & $80 \%$ & $33 \%$ & $75 \%$ \\
\hline $\begin{array}{l}\text { Need to earn an acceptable } \\
\text { level of pension }\end{array}$ & $43 \%$ & $0 \%$ & $0 \%$ & $25 \%$ \\
\hline Life Considerations & $71 \%$ & $80 \%$ & $100 \%$ & $50 \%$ \\
\hline $\begin{array}{l}\text { Coordinating with partner's } \\
\text { retirement plans }\end{array}$ & $71 \%$ & $60 \%$ & $100 \%$ & $25 \%$ \\
\hline Family considerations & $29 \%$ & $40 \%$ & $33 \%$ & $25 \%$ \\
\hline Other life decisions & $0 \%$ & $20 \%$ & $0 \%$ & $25 \%$ \\
\hline Health & $29 \%$ & $40 \%$ & $33 \%$ & $50 \%$ \\
\hline Health & $14 \%$ & $0 \%$ & $33 \%$ & $25 \%$ \\
\hline Retire while have health & $14 \%$ & $40 \%$ & $0 \%$ & $25 \%$ \\
\hline Work-Related & $71 \%$ & $40 \%$ & $67 \%$ & $100 \%$ \\
\hline $\begin{array}{l}\text { Have served and made my } \\
\text { contribution }\end{array}$ & $14 \%$ & $20 \%$ & $0 \%$ & $50 \%$ \\
\hline $\begin{array}{l}\text { Finding the right transition to } \\
\text { retirement }\end{array}$ & $29 \%$ & $20 \%$ & $0 \%$ & $25 \%$ \\
\hline Work environment - satisfied & $43 \%$ & $20 \%$ & $0 \%$ & $25 \%$ \\
\hline Work environment - dissatisfied & $29 \%$ & $20 \%$ & $0 \%$ & $25 \%$ \\
\hline $\begin{array}{l}\text { Mitigate the impact of work on } \\
\text { personal health }\end{array}$ & $14 \%$ & $0 \%$ & $67 \%$ & $0 \%$ \\
\hline Other work-related & $0 \%$ & $0 \%$ & $0 \%$ & $50 \%$ \\
\hline
\end{tabular}


Table 28. Employer Actions That Have Encouraged Consideration of Retirement - Key Themes - By Classification of Employees Whose Retirement Decisions were Impacted by Employer Action/Inaction

\begin{tabular}{|c|c|c|c|c|}
\hline $\begin{array}{l}\text { Employer Actions That Have } \\
\text { Encouraged Consideration of } \\
\text { Retirement }\end{array}$ & $\begin{array}{c}\text { Both action and } \\
\text { inaction by } \\
\text { employer } \\
(n=7)\end{array}$ & $\begin{array}{l}\text { Direct actions } \\
\text { by employer } \\
\qquad(n=5)\end{array}$ & $\begin{array}{l}\text { Inaction on the } \\
\text { part of the } \\
\text { employer } \\
(n=3)\end{array}$ & $\begin{array}{l}\text { My employer } \\
\text { has not } \\
\text { affected my } \\
\text { retirement } \\
\text { consideration } \\
(n=4)\end{array}$ \\
\hline $\begin{array}{l}\text { Not influencing or pushing me } \\
\text { to retire }\end{array}$ & $0 \%$ & $40 \%$ & $33 \%$ & $100 \%$ \\
\hline $\begin{array}{l}\text { Direct action that has } \\
\text { encouraged me to consider } \\
\text { retirement }\end{array}$ & $100 \%$ & $100 \%$ & $0 \%$ & $0 \%$ \\
\hline $\begin{array}{l}\text { Many work demands, not } \\
\text { enough results or rewards }\end{array}$ & $43 \%$ & $60 \%$ & $0 \%$ & $0 \%$ \\
\hline $\begin{array}{l}\text { Pressures external to the } \\
\text { department }\end{array}$ & $0 \%$ & $20 \%$ & $0 \%$ & $0 \%$ \\
\hline $\begin{array}{l}\text { Work is demanding and } \\
\text { stressful }\end{array}$ & $14 \%$ & $40 \%$ & $0 \%$ & $0 \%$ \\
\hline Need to adapt to change & $0 \%$ & $40 \%$ & $0 \%$ & $0 \%$ \\
\hline $\begin{array}{l}\text { No sense of progress or } \\
\text { accomplishment }\end{array}$ & $43 \%$ & $40 \%$ & $0 \%$ & $0 \%$ \\
\hline $\begin{array}{l}\text { Benefit program provides } \\
\text { incentive to retire. }\end{array}$ & $43 \%$ & $40 \% \mathrm{~s}$ & $0 \%$ & $0 \%$ \\
\hline Provide benefit package & $43 \%$ & $20 \%$ & $0 \%$ & $0 \%$ \\
\hline $\begin{array}{l}\text { Provide pre-retirement training } \\
\text { course }\end{array}$ & $0 \%$ & $40 \%$ & $0 \%$ & $0 \%$ \\
\hline $\begin{array}{l}\text { Use of policies and practices } \\
\text { that eause dissatisfaction }\end{array}$ & $71 \% 8$ & $00 \%$ & $0 \%$ & $0 \%$ \\
\hline $\begin{array}{l}\text { Unhappy with style of } \\
\text { management or management } \\
\text { practices }\end{array}$ & $57 \%$ & $0 \%$ & $0 \%$ & $0 \%$ \\
\hline Bilingual requirements & $29 \%$ & $0 \%$ & $0 \%$ & $0 \%$ \\
\hline
\end{tabular}


Table 29. Employer Inaction That Has Encouraged Consideration of Retirement - Key Themes - By Classification of Employees Whose Retirement Decisions were Impacted by Employer Action/Inaction

\begin{tabular}{|c|c|c|c|c|}
\hline $\begin{array}{l}\text { Employer Inaction That Has } \\
\text { Encouraged Consideration of } \\
\text { Retirement }\end{array}$ & $\begin{array}{c}\text { Both action and } \\
\text { inaction by } \\
\text { employer } \\
(\mathbf{n = 7})\end{array}$ & $\begin{array}{l}\text { Direct actions } \\
\text { by employer } \\
\qquad(n=5)\end{array}$ & $\begin{array}{l}\text { Inaction on the } \\
\text { part of the } \\
\text { employer } \\
(n=3)\end{array}$ & $\begin{array}{l}\text { My employer } \\
\text { has not } \\
\text { affected my } \\
\text { retirement } \\
\text { consideration } \\
(n=4)\end{array}$ \\
\hline $\begin{array}{l}\text { Inaction on the part of my } \\
\text { employer has encouraged me } \\
\text { to consider retirement }\end{array}$ & $100 \%$ & $0 \%$ & $100 \%$ & $0 \%$ \\
\hline $\begin{array}{l}\text { Not proactively engaging } \\
\text { experienced workers }\end{array}$ & $71 \%$ & $0 \%$ & $100 \%$ & $0 \%$ \\
\hline $\begin{array}{l}\text { Not engaging me in a } \\
\text { discussion }\end{array}$ & $43 \%$ & $0 \%$ & $33 \%$ & $0 \%$ \\
\hline $\begin{array}{l}\text { Not doing things to get people } \\
\text { to stay }\end{array}$ & $29 \%$ & $0 \%$ & $33 \%$ & $0 \%$ \\
\hline $\begin{array}{l}\text { Not understanding or } \\
\text { responding to the needs of } \\
\text { older workers }\end{array}$ & $29 \%$ & $0 \%$ & $67 \%$ & $0 \%$ \\
\hline $\begin{array}{l}\text { Not using a strategic } \\
\text { approach to plan for pending } \\
\text { retirements. }\end{array}$ & $43 \%$ & $0 \%$ & $33 \%$ & $0 \%$ \\
\hline $\begin{array}{l}\text { Not planning for or managing } \\
\text { pending retirements }\end{array}$ & $29 \%$ & $0 \%$ & $0 \%$ & $0 \%$ \\
\hline $\begin{array}{l}\text { Not proactively managing to } \\
\text { retain corporate knowledge }\end{array}$ & $43 \%$ & $0 \%$ & $33 \%$ & $0 \%$ \\
\hline $\begin{array}{l}\text { Wot appreciating and } \\
\text { respecting } \\
\text { experienced workers }\end{array}$ & $14 \%$ & $0 \%$ & $33 \%$ & $0 \%$ \\
\hline $\begin{array}{l}\text { Not considering the needs of } \\
\text { employees in job assignments }\end{array}$ & $14 \%$ & $0 \%$ & $0 \%$ & $0 \%$ \\
\hline $\begin{array}{l}\text { Not demonstrating that long- } \\
\text { serving employees are valued }\end{array}$ & $14 \%$ & $0 \%$ & $33 \%$ & $0 \%$ \\
\hline
\end{tabular}


Table 30. Employer Actions That Has Encouraged Consideration of Staying Beyond Retirement Eligibility Date - Key Themes - By Classification of Employees Whose Retirement Decisions were Impacted by Employer Action/Inaction

\begin{tabular}{|c|c|c|c|c|}
\hline $\begin{array}{l}\text { Employer Actions That Has } \\
\text { Encouraged Consideration of } \\
\text { Staying Beyond Retirement } \\
\text { Gligibility Date } \\
\text { Some action that has } \\
\text { encouraged me to consider } \\
\text { staying }\end{array}$ & $\begin{array}{c}\text { Both action and } \\
\text { inaction by } \\
\text { employer } \\
(\mathbf{n}=7) \\
57 \%\end{array}$ & $\begin{array}{l}\text { Direct actions } \\
\text { by employer } \\
\qquad \begin{array}{c}(\mathbf{n}=5) \\
\mathbf{8 0} \%\end{array}\end{array}$ & $\begin{array}{l}\text { Inaction on the } \\
\text { part of the } \\
\text { employer } \\
(n=3) \\
67 \%\end{array}$ & $\begin{array}{l}\text { My employer } \\
\text { has not } \\
\text { affected my } \\
\text { retirement } \\
\text { consideration } \\
(n=4) \\
50 \%\end{array}$ \\
\hline $\begin{array}{l}\text { Provided interesting and } \\
\text { rewarding work }\end{array}$ & $0 \%$ & $60 \%$ & $67 \%$ & $25 \%$ \\
\hline $\begin{array}{l}\text { Provided jobs/assignments } \\
\text { that met my needs }\end{array}$ & $0 \%$ & $40 \%$ & $33 \%$ & $25 \%$ \\
\hline Provided enjoyable work & $0 \%$ & $40 \%$ & $33 \%$ & $0 \%$ \\
\hline $\begin{array}{l}\text { Gave me opportunities to } \\
\text { make a difference. }\end{array}$ & $0 \%$ & $20 \%$ & $0 \%$ & $0 \%$ \\
\hline $\begin{array}{l}\text { Designed work programs } \\
\text { and benefits as an incentive } \\
\text { to stay }\end{array}$ & $43 \%$ & $20 \%$ & $33 \%$ & $25 \%$ \\
\hline $\begin{array}{l}\text { Offer work programs to meet } \\
\text { my needs }\end{array}$ & $14 \%$ & $20 \%$ & $0 \%$ & $25 \%$ \\
\hline $\begin{array}{l}\text { Designed benefit programs } \\
\text { with an incentive to stay }\end{array}$ & $29 \%$ & $0 \%$ & $33 \%$ & $0 \%$ \\
\hline $\begin{array}{l}\text { Demonstrated that } 1 \text { am } \\
\text { valued }\end{array}$ & $29 \%$ & $20 \%$ & $0 \%$ & $25 \%$ \\
\hline $\begin{array}{l}\text { Not taling action to } \\
\text { encourage me to stay }\end{array}$ & $57 \%$ & $00 \%$ & $33 \%$ & $50 \%$ \\
\hline Haven't done anything & $43 \%$ & $0 \%$ & $33 \%$ & $50 \%$ \\
\hline $\begin{array}{l}\text { There have been no } \\
\text { discussions with me }\end{array}$ & $29 \%$ & $0 \%$ & $0 \%$ & $0 \%$ \\
\hline
\end{tabular}


Table 31. Actions My Employer Can Take to Influence Retirement Plans - Key Themes - By Classification of Employees Whose Retirement Decisions were Impacted by Employer Action/Inaction

\begin{tabular}{|c|c|c|c|c|}
\hline $\begin{array}{l}\text { Actions My Employer Can Take } \\
\text { to Influence Retirement Plans }\end{array}$ & $\begin{array}{c}\text { Both action and } \\
\text { inaction by } \\
\text { employer } \\
(\mathbf{n}=7)\end{array}$ & $\begin{array}{l}\text { Direct actions } \\
\text { by employer } \\
\qquad(n=5)\end{array}$ & $\begin{array}{l}\text { Inaction on the } \\
\text { part of the } \\
\text { employer } \\
(n=3)\end{array}$ & $\begin{array}{l}\text { My employer } \\
\text { has not } \\
\text { affected my } \\
\text { retirement } \\
\text { consideration } \\
(n=4)\end{array}$ \\
\hline $\begin{array}{l}\text { There is some action my } \\
\text { employer can take }\end{array}$ & $71 \%$ & $100 \%$ & $100 \%$ & $75 \%$ \\
\hline $\begin{array}{l}\text { Offer interesting and } \\
\text { rewarding work }\end{array}$ & $57 \%$ & $80 \%$ & $33 \%$ & $0 \%$ \\
\hline Offer exceptional assignment & $14 \%$ & $20 \%$ & $33 \%$ & $0 \%$ \\
\hline Offer work that is of interest & $43 \%$ & $20 \%$ & $33 \%$ & $0 \%$ \\
\hline $\begin{array}{l}\text { Offer work that makes a } \\
\text { difference }\end{array}$ & $43 \%$ & $0 \%$ & $0 \%$ & $0 \%$ \\
\hline Offer overseas assignment & $14 \%$ & $40 \%$ & $33 \%$ & $0 \%$ \\
\hline Change the nature of work & $57 \%$ & $40 \%$ & $67 \%$ & $75 \%$ \\
\hline $\begin{array}{l}\text { Offer a coaching and } \\
\text { mentoring role }\end{array}$ & $0 \%$ & $20 \%$ & $0 \%$ & $50 \%$ \\
\hline $\begin{array}{l}\text { Allow a fundamental shift in } \\
\text { duties }\end{array}$ & $43 \%$ & $0 \%$ & $67 \%$ & $0 \%$ \\
\hline Reduce the stress & $14 \%$ & $20 \%$ & $0 \%$ & $25 \%$ \\
\hline Change how work is managed & $14 \%$ & $40 \%$ & $33 \%$ & $0 \%$ \\
\hline $\begin{array}{l}\text { Offer flexible work } \\
\text { arrangements }\end{array}$ & $29 \%$ & $40 \%$ & $67 \%$ & $50 \%$ \\
\hline Work reduced hours & $29 \%$ & $20 \%$ & $67 \%$ & $50 \%$ \\
\hline Work only part of the year & $0 \%$ & $0 \%$ & $33 \%$ & $25 \%$ \\
\hline Work from home & $0 \%$ & $20 \%$ & $0 \%$ & $25 \%$ \\
\hline $\begin{array}{l}\text { NOT flexible work } \\
\text { arrangements }\end{array}$ & $0 \%$ & $0 \%$ & $0 \%$ & $25 \%$ \\
\hline Offer inancial incentives. & $29 \%$ & $20 \%$ & $38 \%$ & $25 \%$ \\
\hline Offer financial incentives & $29 \%$ & $20 \%$ & $33 \%$ & $25 \%$ \\
\hline NOT financial incentives & $0 \%$ & $40 \%$ & $33 \%$ & $25 \%$ \\
\hline $\begin{array}{l}\text { Rergaigh beneft and leave } \\
\text { programs. }\end{array}$ & $20 \%$ & $20 \%$ & $0 \%$ & $0 \%$ \\
\hline $\begin{array}{l}\text { Offer promotional } \\
\text { opportunities }\end{array}$ & $0 \%$ & $0 \%$ & $33 \%$ & $0 \%$ \\
\hline $\begin{array}{l}\text { Offer promotional } \\
\text { opportunities }\end{array}$ & $0 \%$ & $0 \%$ & $33 \%$ & $0 \%$ \\
\hline $\begin{array}{l}\text { NOT promotional } \\
\text { opportunities }\end{array}$ & $14 \%$ & $20 \%$ & $0 \%$ & $0 \%$ \\
\hline Other & $0 \%$ & $20 \%$ & $18 \%$ & $0 \%$ \\
\hline
\end{tabular}


Appendix D - Data Tables Summarizing Key Themes from Interviews - By

Retirement Plans 
Table 32. Meaning of Retirement - Key Themes - By Retirement Plans

\begin{tabular}{|c|c|c|c|}
\hline Meaning of Retirement & $\begin{array}{l}\text { Early Exiter } \\
\qquad(n=3)\end{array}$ & $\begin{array}{l}\text { Early Retiree } \\
\qquad(n=10)\end{array}$ & $\begin{array}{l}\text { Full Pensioner } \\
\qquad(n=6)\end{array}$ \\
\hline Gaining personal control & $100 \%$ & $70 \%$ & $100 \%$ \\
\hline Expand activities beyond work & $0 \%$ & $10 \%$ & $33 \%$ \\
\hline Activities under personal control & $67 \%$ & $20 \%$ & $33 \%$ \\
\hline Freedom to make choices & $33 \%$ & $50 \%$ & $17 \%$ \\
\hline Time for personal interests & $100 \%$ & $20 \%$ & $84 \%$ \\
\hline Remaining busy & $0 \%$ & $20 \%$ & $0 \%$ \\
\hline Time of significant change & $33 \%$ & $90 \%$ & $67 \%$ \\
\hline Opportunity and potential & $0 \%$ & $20 \%$ & $33 \%$ \\
\hline Career change or shift & $0 \%$ & $20 \%$ & $17 \%$ \\
\hline New phase of life & $33 \%$ & $40 \%$ & $33 \%$ \\
\hline Achievement and reward & $0 \%$ & $10 \%$ & $0 \%$ \\
\hline Positive anticipation & $0 \%$ & $40 \%$ & $0 \%$ \\
\hline Apprehensive anticipation & $33 \%$ & $30 \%$ & $17 \%$ \\
\hline Closer to end of life & $33 \%$ & $10 \%$ & $17 \%$ \\
\hline Loss & $0 \%$ & $10 \%$ & $0 \%$ \\
\hline Apprehensive anticipation & $0 \%$ & $10 \%$ & $17 \%$ \\
\hline
\end{tabular}


Table 33. Retirement Activities - Key Themes - By Retirement Plans

\begin{tabular}{|c|c|c|c|}
\hline Retirement Activities & $\begin{array}{l}\text { Early Exiter } \\
\qquad(n=3)\end{array}$ & $\begin{array}{l}\text { Early Retiree } \\
\qquad(n=10)\end{array}$ & $\begin{array}{l}\text { Full Pensioner } \\
\qquad(\mathbf{n = 6})\end{array}$ \\
\hline Lelsure & $100 \%$ & $100 \%$ & $100 \%$ \\
\hline Outdoor activities & $33 \%$ & $50 \%$ & $67 \%$ \\
\hline Travel and tourism & $100 \%$ & $70 \%$ & $67 \%$ \\
\hline Hobbies & $33 \%$ & $50 \%$ & $67 \%$ \\
\hline More time on current interests & $33 \%$ & $40 \%$ & $67 \%$ \\
\hline Time with friends & $33 \%$ & $20 \%$ & $0 \%$ \\
\hline Vacation and rest & $67 \%$ & $10 \%$ & $0 \%$ \\
\hline Other leisure & $0 \%$ & $10 \%$ & $50 \%$ \\
\hline Work & $67 \%$ & $80 \%$ & $83 \%$ \\
\hline Working & $67 \%$ & $80 \%$ & $83 \%$ \\
\hline Not to any extent & $0 \%$ & $10 \%$ & $0 \%$ \\
\hline Not for money & $0 \%$ & $20 \%$ & $17 \%$ \\
\hline Maybe & $33 \%$ & $30 \%$ & $33 \%$ \\
\hline Definitely & $0 \%$ & $20 \%$ & $33 \%$ \\
\hline Part-time & $67 \%$ & $30 \%$ & $17 \%$ \\
\hline Related to current work & $0 \%$ & $20 \%$ & $33 \%$ \\
\hline Not related to current work & $0 \%$ & $10 \%$ & $0 \%$ \\
\hline community & $100 \%$ & $50 \%$ & $33 \%$ \\
\hline Volunteer & $67 \%$ & $30 \%$ & $33 \%$ \\
\hline $\begin{array}{l}\text { Volunteer - resume prior } \\
\text { activity }\end{array}$ & $33 \%$ & $20 \%$ & $0 \%$ \\
\hline Family & $33 \%$ & $30 \%$ & $33 \%$ \\
\hline Spending time & $0 \%$ & $30 \%$ & $0 \%$ \\
\hline Providing support & $33 \%$ & $0 \%$ & $33 \%$ \\
\hline Learning & $0 \%$ & $30 \%$ & $50 \%$ \\
\hline
\end{tabular}


Table 34. Retirement Factors - Key Themes - By Retirement Plans

\begin{tabular}{|c|c|c|c|}
\hline Retirement Factors & $\begin{array}{l}\text { Early Exiter } \\
\qquad(\mathbf{n}=\mathbf{3})\end{array}$ & $\begin{array}{l}\text { Early Retiree } \\
\qquad(\mathbf{n = 1 0})\end{array}$ & $\begin{array}{l}\text { Full Pensioner } \\
\qquad(n=6)\end{array}$ \\
\hline Financial & $67 \%$ & $80 \%$ & $83 \%$ \\
\hline Being financially ready & $67 \%$ & $70 \%$ & $83 \%$ \\
\hline $\begin{array}{l}\text { Need to earn an acceptable } \\
\text { level of pension }\end{array}$ & $0 \%$ & $20 \%$ & $33 \%$ \\
\hline Life considerations & $100 \%$ & $70 \%$ & $67 \%$ \\
\hline $\begin{array}{l}\text { Coordinating with partner's } \\
\text { retirement plans }\end{array}$ & $100 \%$ & $60 \%$ & $50 \%$ \\
\hline Family considerations & $67 \%$ & $30 \%$ & $17 \%$ \\
\hline Other life decisions & $0 \%$ & $10 \%$ & $17 \%$ \\
\hline Health & $33 \%$ & $30 \%$ & $50 \%$ \\
\hline Health & $0 \%$ & $10 \%$ & $33 \%$ \\
\hline Retire while have health & $33 \%$ & $20 \%$ & $17 \%$ \\
\hline Work-Related & $100 \%$ & $60 \%$ & $67 \%$ \\
\hline $\begin{array}{l}\text { Have served and made my } \\
\text { contribution }\end{array}$ & $67 \%$ & $20 \%$ & $0 \%$ \\
\hline $\begin{array}{l}\text { Finding the right transition to } \\
\text { retirement }\end{array}$ & $33 \%$ & $20 \%$ & $17 \%$ \\
\hline Work environment - satisfied & $0 \%$ & $10 \%$ & $67 \%$ \\
\hline Work environment - dissatisfied & $67 \%$ & $20 \%$ & $0 \%$ \\
\hline $\begin{array}{l}\text { Mitigate the impact of work on } \\
\text { personal health }\end{array}$ & $67 \%$ & $10 \%$ & $0 \%$ \\
\hline Other work-related & $0 \%$ & $20 \%$ & $0 \%$ \\
\hline
\end{tabular}


Table 35. Employer Actions That Have Encouraged Consideration of Retirement - Key Themes - By Retirement Plans

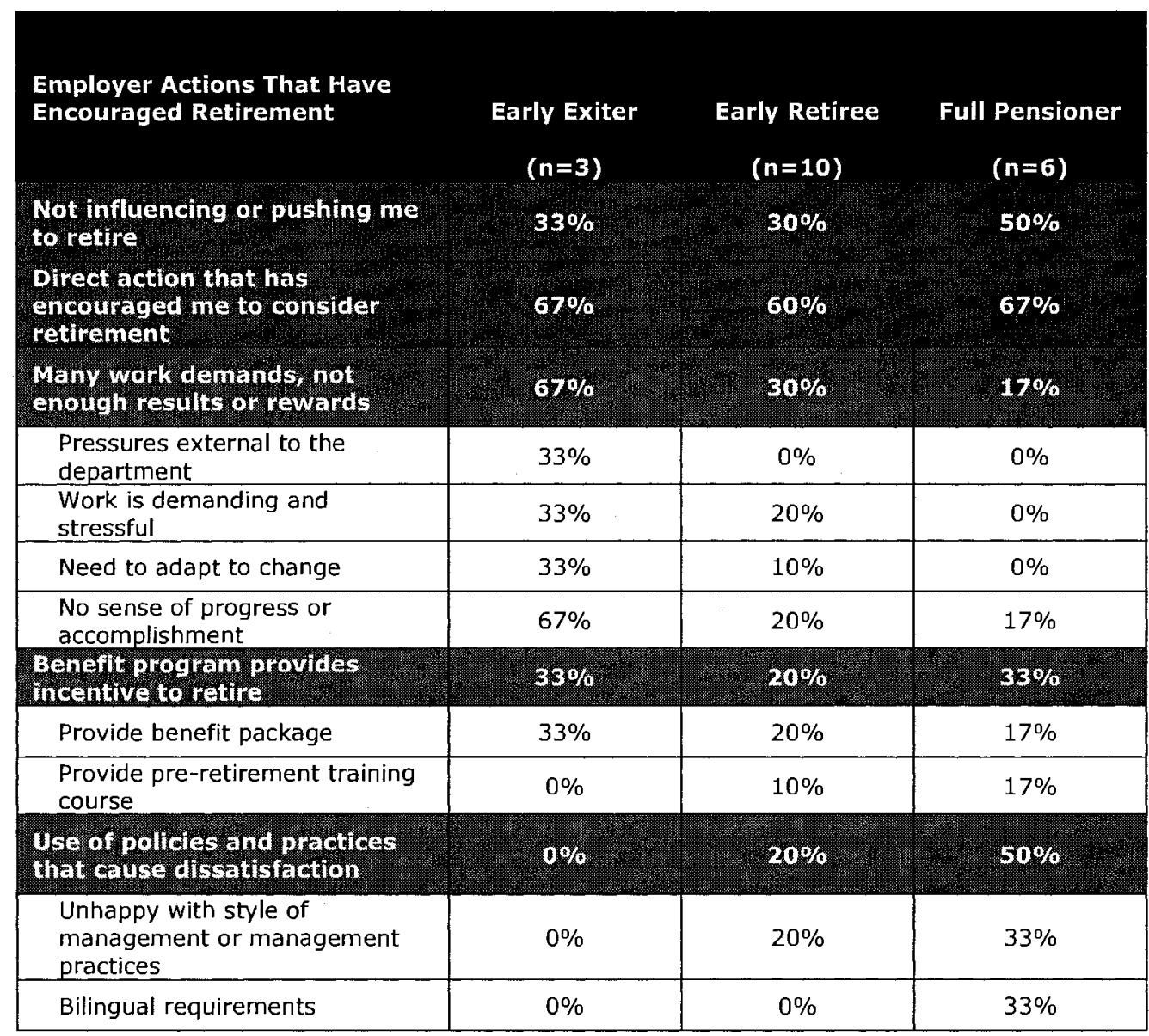


Table 36. Employer Inaction That Has Encouraged Consideration of Retirement - Key Themes - By Retirement Plans

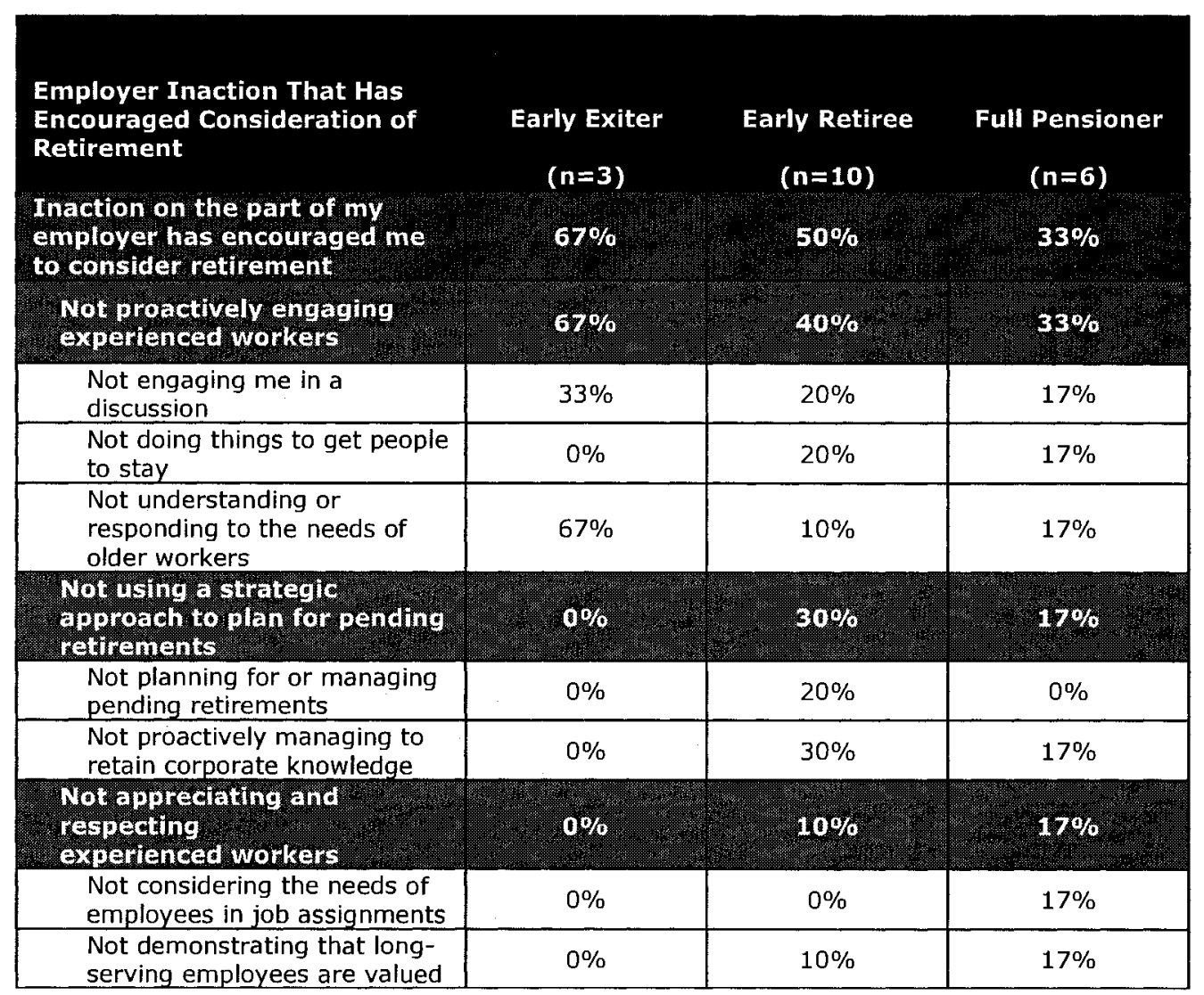


Table 37. Employer Actions That Has Encouraged Consideration of Staying Beyond Retirement Eligibility Date - Key Themes - By Retirement Plans

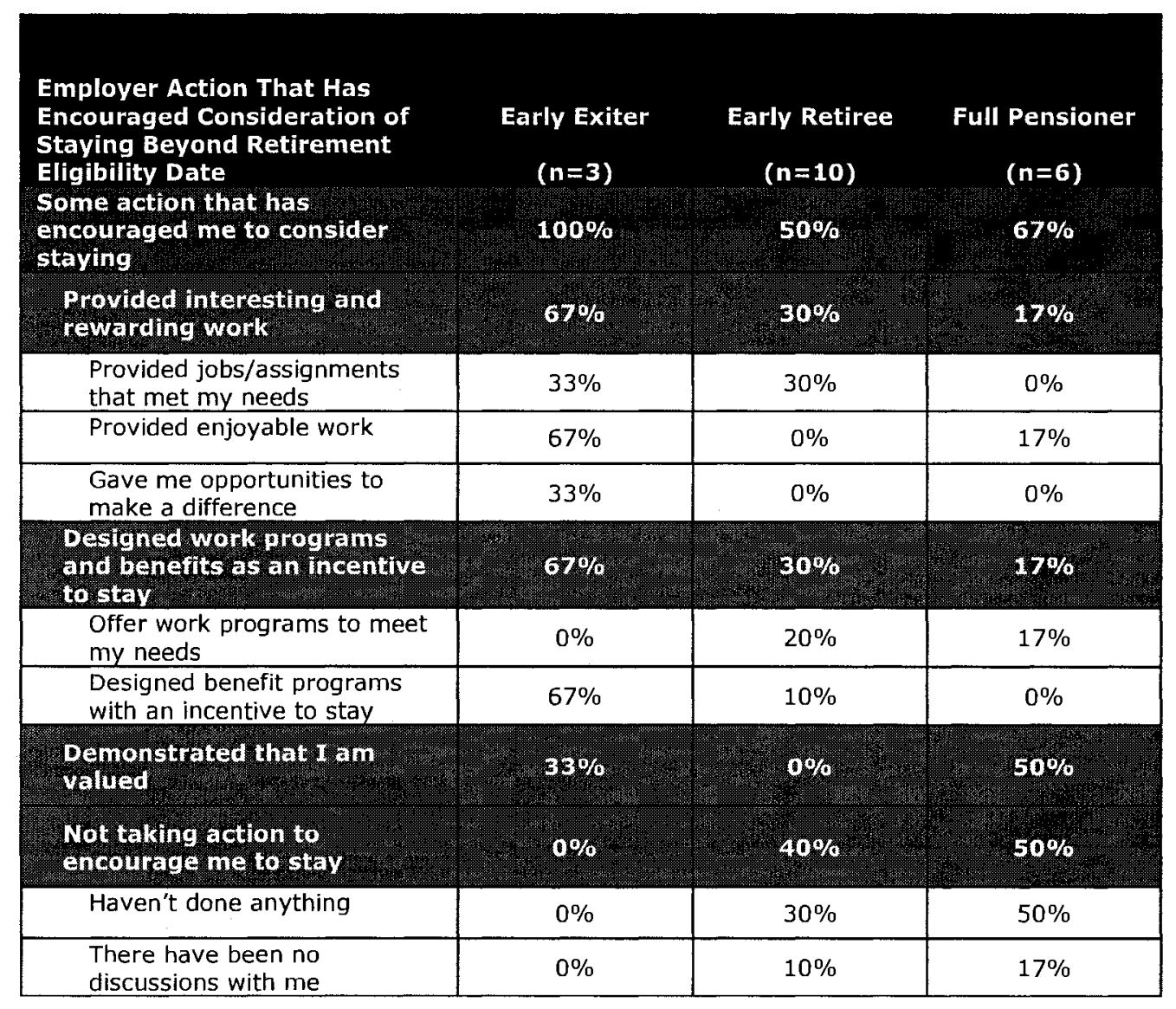


Table 38. Actions My Employer Can Take to Influence Retirement Plans - Key Themes - By Retirement Plans

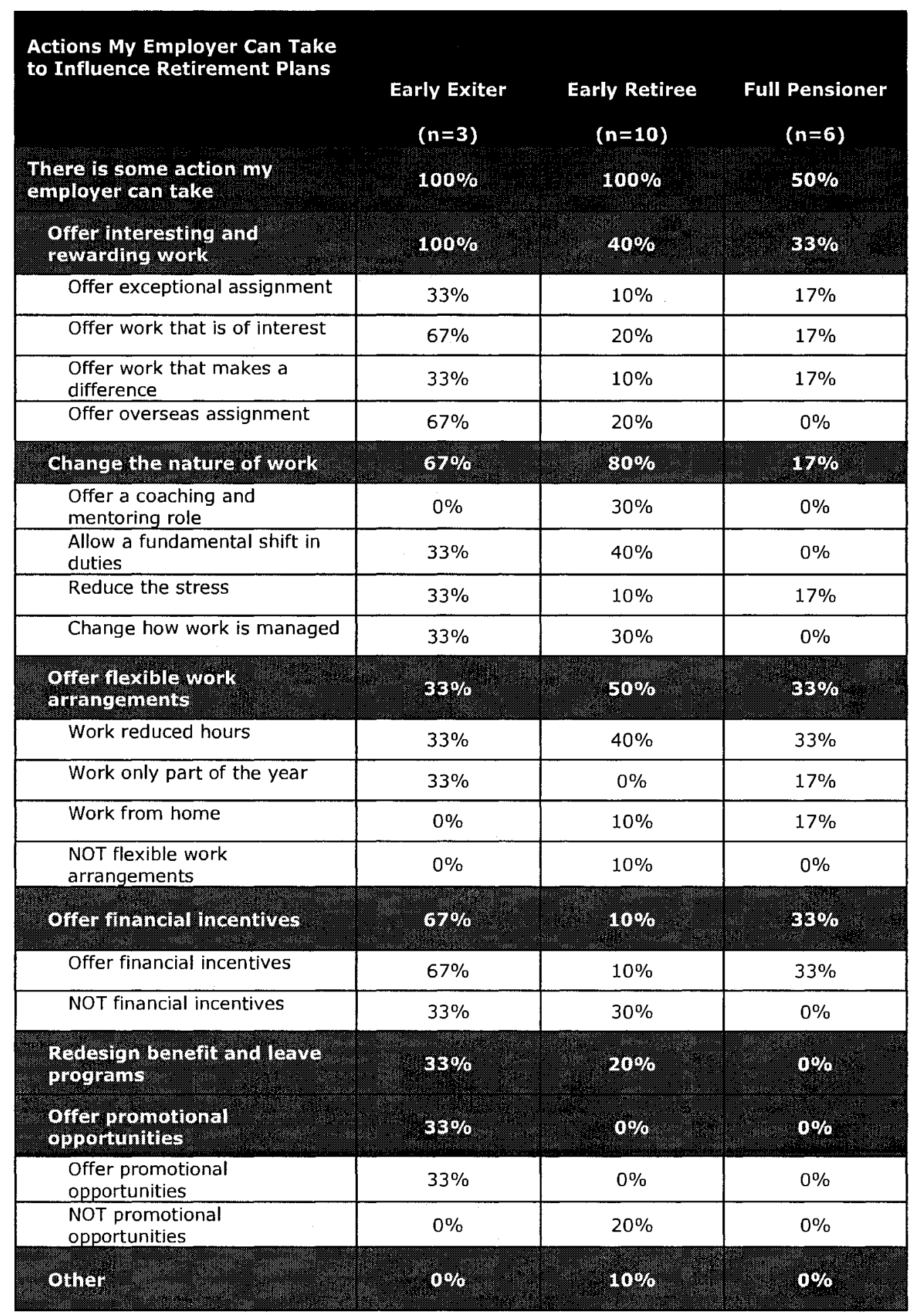

